\title{
A Comprehensive Review on a PV Based System to Harvest Maximum Power
}

\author{
Muhammad Yaqoob Javed ${ }^{1}$ (D), Adeel Feroz Mirza ${ }^{2}$, Ali Hasan ${ }^{1}$, Syed Tahir Hussain Rizvi ${ }^{3, *}$, \\ Qiang Ling ${ }^{2}$, Muhammad Majid Gulzar ${ }^{4}\left(\mathbb{D}\right.$, Muhammad Umair Safder ${ }^{1}$ (D) and Majad Mansoor ${ }^{2}$ \\ 1 Electrical and Computer Engineering Department, COMSATS University Islamabad, Lahore 54000, Pakistan; \\ Yaqoob.javed@cuilahore.edu.pk (M.Y.J.); alihasan710@gmail.com (A.H.); \\ umairsafder@cuilahore.edu.pk (M.U.S.) \\ 2 Department of Automation, University of Science and Technology of China, Hefei 230001, China; \\ adeelmirza@mail.ustc.edu.cn (A.F.M.); qling@ustc.edu.cn (Q.L.); majad@mail.ustc.edu.cn (M.M.) \\ 3 Department of Computer Engineering, University of Lahore, Lahore 54000, Pakistan \\ 4 Department of Electrical Engineering, University of Central Punjab, Lahore 54000, Pakistan; \\ majid.gulzar@ucp.edu.pk \\ * Correspondence: tahir.hussain@dce.uol.edu.pk
}

Received: 25 October 2019; Accepted: 27 November 2019; Published: 4 December 2019

check for updates

\begin{abstract}
In this paper, a comprehensive review of essential components of the PV (Photovoltaic) system is elaborated, and their comparative unique features are discussed. The paper describes hardware design (power converters topologies specifically) employed in PV based energy generation systems to harvest maximum power from the available energy source. In this study, thirty different Maximum Power Point Tracking (MPPT) techniques have been critically analyzed and their response with respect to partial shading condition has been discussed. It is very difficult to say which technique is best as one must consider various factors and parameters while selecting a technique such as application, convergence speed, accuracy, efficiency, system reliability, and cost and performance of available hardware. Aiming at the complexity, hardware implementation, tracking speed, steady-state accuracy, or global maximum detection of the algorithm, an MPPT algorithm based on a rule table is proposed. In addition, the MPPT of a PV system based on bio inspired techniques is considered. The bio inspired algorithms and its application in PV system are compared for the authenticity of the review, and six different MPPT techniques are implemented on PV systems. A comparative analysis is made based on the results of four different cases of irradiance.
\end{abstract}

Keywords: maximum power point tracking (MPPT); renewable energy (RE); photovoltaic (PV)

\section{Introduction}

Currently, the changing trends and recent advancements in power generation sector across the globe has changed the focus of the researchers to come up with a unique and reliable solution to meet the dramatically escalating energy demand at a domestic level as well as commercial or even more at an industrial scale of the ever-growing, never-ending population of the world, keeping the environment clean and suitable for the inhabitants. In addition, for economic development and prosperity, energy production is of vital importance to become a strong competitor amongst the leading nations of the world.

The depletion of conventional fossil fuel reserves used for energy generation and even more production and consumption of biofuel couldn't reduce greenhouse gases emission, thus still pose serious problems to the ecosystem. Renewable energy (RE) based power generation technologies (Solar, Wind, Flywheel, Fuel Cell, Small Hydro-turbines etc.) are the ultimate, unique and reliable, 
and the most feasible and robust solutions to minimize the hazardous environmental effects caused by conventional fossil fuel-based power generation systems in operation around the developed as well as the underdeveloped nations of the world.

In literature, numerous power converter topologies regarding operational standalone as well as grid integrated PV based energy generation systems have been elaborated. Their pros and cons depending upon the technology and application requirements have been discussed in this research article. The converters like boost, buck, buck-boost, cuk, Single Ended Primary Inductor Converter (SEPIC), and fly-back converters topologies are the most frequently used power converter configurations in PV based energy systems. Single Ended Primary Inductor Converter (SEPIC) converter topology has better efficiency compared to other designs. Interleaved converter topology in conjunction with a boost converter has been used for the PV system [1,2]. Multi-level inverter topologies have also been employed for PV systems [3]. Cascaded multi-level converter topology is a modified version of the multi-level converter used in the PV system with improved efficiency and better power conversion [4].

In this paper, the conventional, as well as their advanced modified versions of power converters for PV based energy technology, have been discussed comprehensively. In Section 2, the generic model and its modified versions of the PV module and cell design and its electrical characteristics have been elaborated. In Section 3, a brief overview of the power converter and their advanced versions in PV based systems with pros and cons are given to illustrate the inverter topologies used in the PV system. Section 4 presents the conventional Maximum Power Point Tracking techniques used for the Photovoltaic system. Furthermore, Section 5 describes the soft computing techniques used for Maximum Power Point Tracking to date, which are almost 26 in number. Moreover, Section 6 shows a comparative analysis of six commonly used techniques and illustrates their results under different environmental conditions. In the end, conclusions are drawn about these power converter designs.

\section{PV Cell}

A photovoltaic cell is a PN junction device (like photodiode); it produces electricity from sunlight and this conversion process is called the Photovoltaic effect. A single PV cell can't produce an enormous amount of power. Usually, it produces just a few millivolts of voltage. It generates few amperes of current at high irradiance. A PV panel consists of several PV cells connected in series or parallel combination, to attain the required power. However, the output of the PV panel fluctuates with the change in operating conditions, such as varying positions of the sun, solar irradiance, and surface temperature. Thus, the overall output of the PV system is nonlinear in nature. Furthermore, to produce high voltage, multiple PV panels are connected in series to form a PV string. Multiple PV strings are attached in parallel combination to form a photovoltaic array to meet the requirements of the power processing unit.

\subsection{PV Cell Models}

Multiple PV models are reported. However, the two most commonly used models are single and double diode models. Both have different levels of complexity. The mathematical formulas for these models are represented by the Shockley Diode Equation. The details of these models are shown below.

\subsubsection{Single Diode Model}

Ideally, a photovoltaic cell can be characterized as a current source connected in parallel with a diode. However, a practical model consists of series resistance (Rs) and parallel resistance (Rp). The Rs and Rp represent the practical losses in a PV cell, which is due to leakage current and internal resistance. Figure 1 depicts an ideal and practical representation of a single diode model of a PV cell. The simplicity and accuracy are two trade-offs of this model. The complete mathematical equation 
of both models is based on Shockley diode equations and are expressed in Equations (1) and (2). Equation (3) presents the expression of diode thermal voltage:

$$
\begin{gathered}
I=I_{p v}-I_{o} \exp \left(\left(\frac{V_{d}}{n V_{t}}\right)-1\right), \\
I=I_{p v}-I_{o} \exp \left(\left(\frac{V+I R_{s}}{n V_{t}}\right)-1\right)-\frac{V+I R_{s}}{R_{p}}, \\
V_{t}=\frac{n_{s} A k T}{q},
\end{gathered}
$$

where $I_{P V}$ and $V_{P V}$ represent the cell current and voltage, respectively. The reverse saturation current of the diode is represented as Io, the drop across the diode is represented by $V_{d}$, diode thermal voltage is represented by $V_{t}$, the ideality factor of the diode is denoted by $n$, and $R_{s}$ and $R_{p}$ represent the series and parallel resistance of the $P V$ cell, respectively. However, $R_{S}$ should be very small, almost equal to zero and $R_{p}$ should be very large, ideally equal to infinity. To simplify the analysis, these resistances may be neglected.

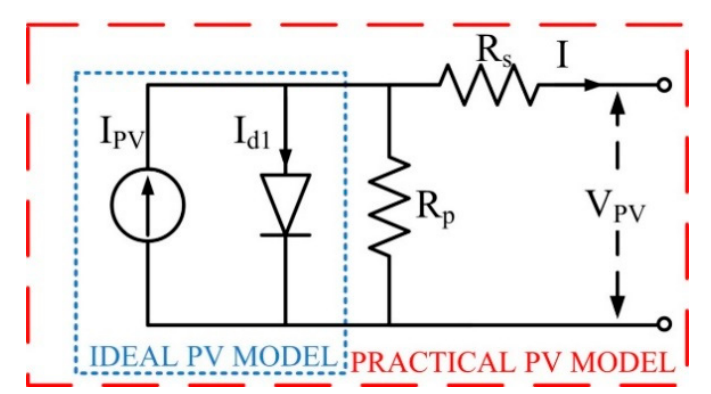

Figure 1. Ideal and practical representation of a single diode model.

\subsubsection{Double Diode Model}

Another technique to model a PV cell is the double diode model. It consists of an extra diode in the equivalent circuit representation to account for space charge losses within the PV cell. Figure 2 represents the double diode model of the PV cell. Theoretically, the first diode represents diffusion current element and the second diode represents space-charge recombination. Equations (4) and (5) show the mathematical formula for the double diode model:

$$
\begin{gathered}
I=I_{p v}-I_{o 1} \exp \left(\left(\frac{V+I R_{s}}{n V_{t}}\right)-1\right)-I_{o 2} \exp \left(\left(\frac{V+I R_{s}}{n V_{t}}\right)-1\right)-\frac{V+I R_{s}}{R_{p}}, \\
V_{t}=\frac{n_{s} k T}{q}
\end{gathered}
$$

where

$I_{01}=$ represents diffusion current element,

$I_{o 2}=$ represents the space charge region,

$n_{s}=$ Number of Photovoltaic cells connected in series,

$k=$ Boltzmann's Constant,

$q=$ Charge,

$R_{s}=$ Series Resistance,

$R p=$ shunt resistance,

$A=$ Diode identity time,

$T=$ Temperature $\left({ }^{\circ} \mathrm{K}\right)$, 
$I_{p v}=$ Photovoltaic cell current.

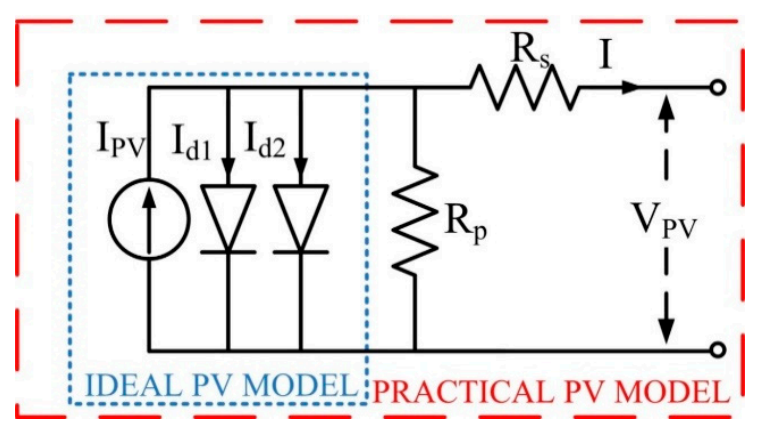

Figure 2. Ideal and practical representation of the double diode model.

\subsection{Electrical Characteristics of the PV Panel}

Figure 3 visualizes the electrical characteristics curves of the PV array at STC. The blue line indicates the current-voltage characteristics curve, and the green line indicates the power voltage characteristic curve of the PV panel. The characteristics of the PV module are evaluated by a Matlab/Simulink model proposed by [1].

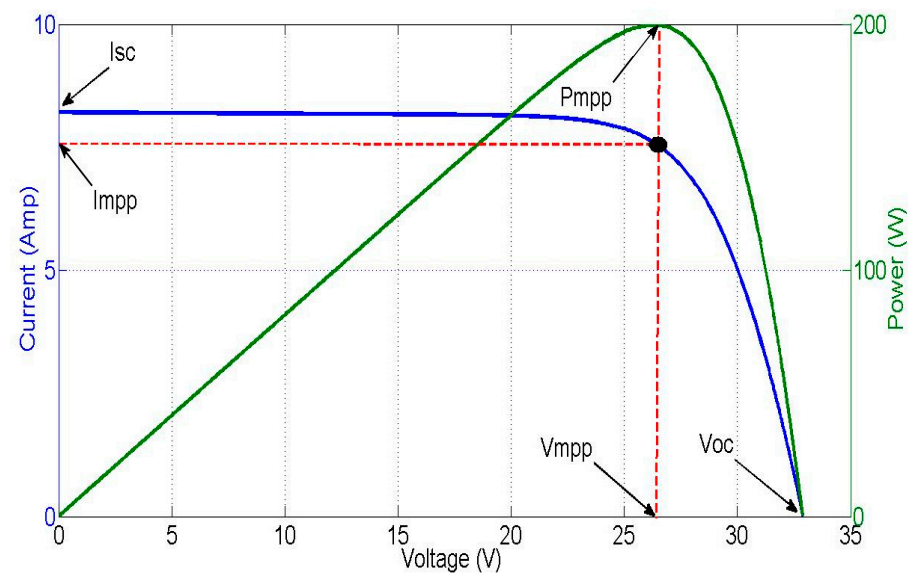

Figure 3. Electrical characteristics curves of Kyocera-KC200GT (City, Manufacturer, City, US State abbrev. if applicable, Country).

The PV panel used for this implementation is KC200GT by Kyocera and Table 1 reveals its basic specifications. Figure 3 illustrates that, under STC, the current to voltage (IV) curve has a unique knee point that is known as the maximum power point (MPP). This I-V curve is like the curve provided by the Kyocera-KC200GT manufacturer's shown in the datasheet [2].

Table 1. Kyocera-KC200GT parameters.

\begin{tabular}{cc}
\hline$I_{m p p}$ & $7.6 \mathrm{~A}$ \\
$V_{m p p}$ & $26.3 \mathrm{~V}$ \\
$P_{m p p}$ & $200 \mathrm{~W}$ \\
$I_{s c}$ & $8.21 \mathrm{~A}$ \\
$V_{o c}$ & $32.9 \mathrm{~V}$ \\
Number of Cells $\left(N_{S}\right)$ & 54 \\
$K_{v}$ & $-0.123 \mathrm{~V} / \mathrm{K}$ \\
$K_{i}$ & $0.0032 \mathrm{~A} / \mathrm{K}$ \\
\hline
\end{tabular}




\subsubsection{Uniform Irradiance Condition}

In the uniform irradiance condition (UIC), all the cells in the PV array are getting identical irradiance. In UIC, a unique maximum power point appears in the I-V and $\mathrm{P}-\mathrm{V}$ characteristics curve. Thus, the maximum power point tracking problem becomes simple. However, the I-V characteristics of the PV array are nonlinear in nature because of the varying weather conditions. Thus, the PV arrays do not show a fixed resistance mechanism. Hence, the MPP of the PV array varies with respect to the position of the sun. Equations (6)-(9) depict the mathematical relationship between MPP and weather conditions (Temperature and Irradiance):

$$
\begin{gathered}
I_{m p p}=K_{i} I_{s c}, \\
V_{m p p}=K_{v} V_{o c}, \\
I_{s c}=\left(I_{s c}+K_{1} \Delta T\right) \frac{G}{G m}, \\
V_{o c}=V_{o c, n}+K_{v} \Delta T
\end{gathered}
$$

$I_{m p p}=$ Current at MPP,

$V_{m p p}=$ Voltage at MPP,

$K i=$ Current proportional factor,

$K v=$ Voltage proportional Factor,

$I_{s c}=$ Short-circuit Current,

$V_{o c}=$ Open circuit Voltage.

Figures 4 and 5 illustrate the I-V and P-V characteristics curve at different irradiance values under UIC. It clearly shows that: the $I_{s c}$ varies with the change in irradiance and so does the MPP. However, all the curves have a unique MPP. Moreover, the MPP is directly proportional to $I_{s c}$ as shown in Equation (8), while Figures 6 and 7 show the response of the PV module due to the change in temperature. It can be observed that the MPP is inversely proportional to the temperature.

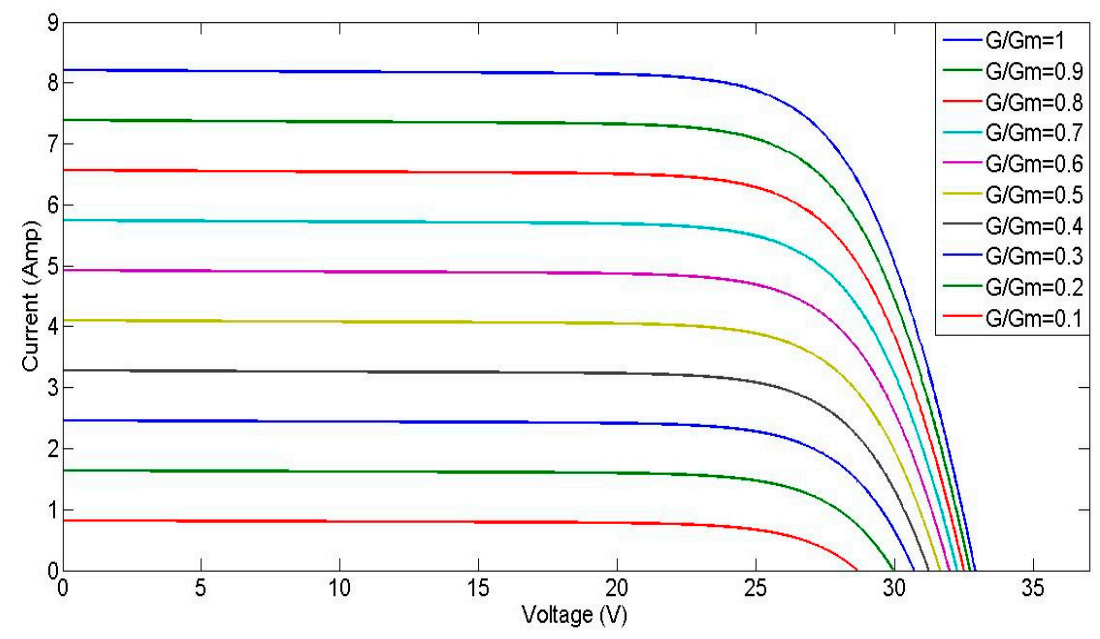

Figure 4. Current vs. Voltage characteristics at different irradiance. 


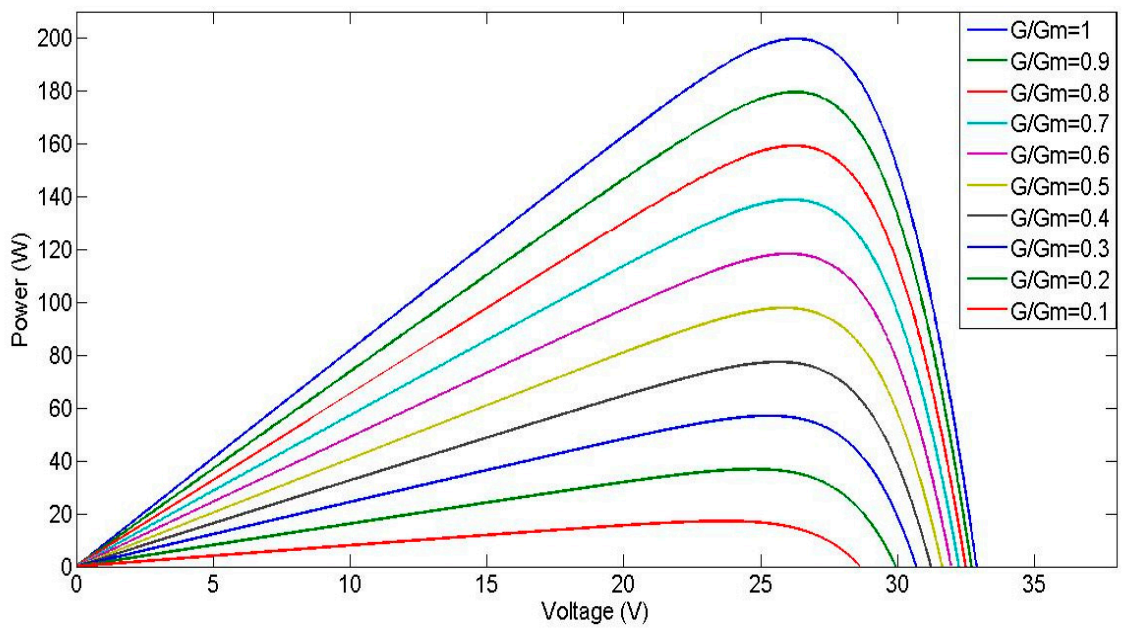

Figure 5. Power vs. Voltage characteristics at different irradiance.

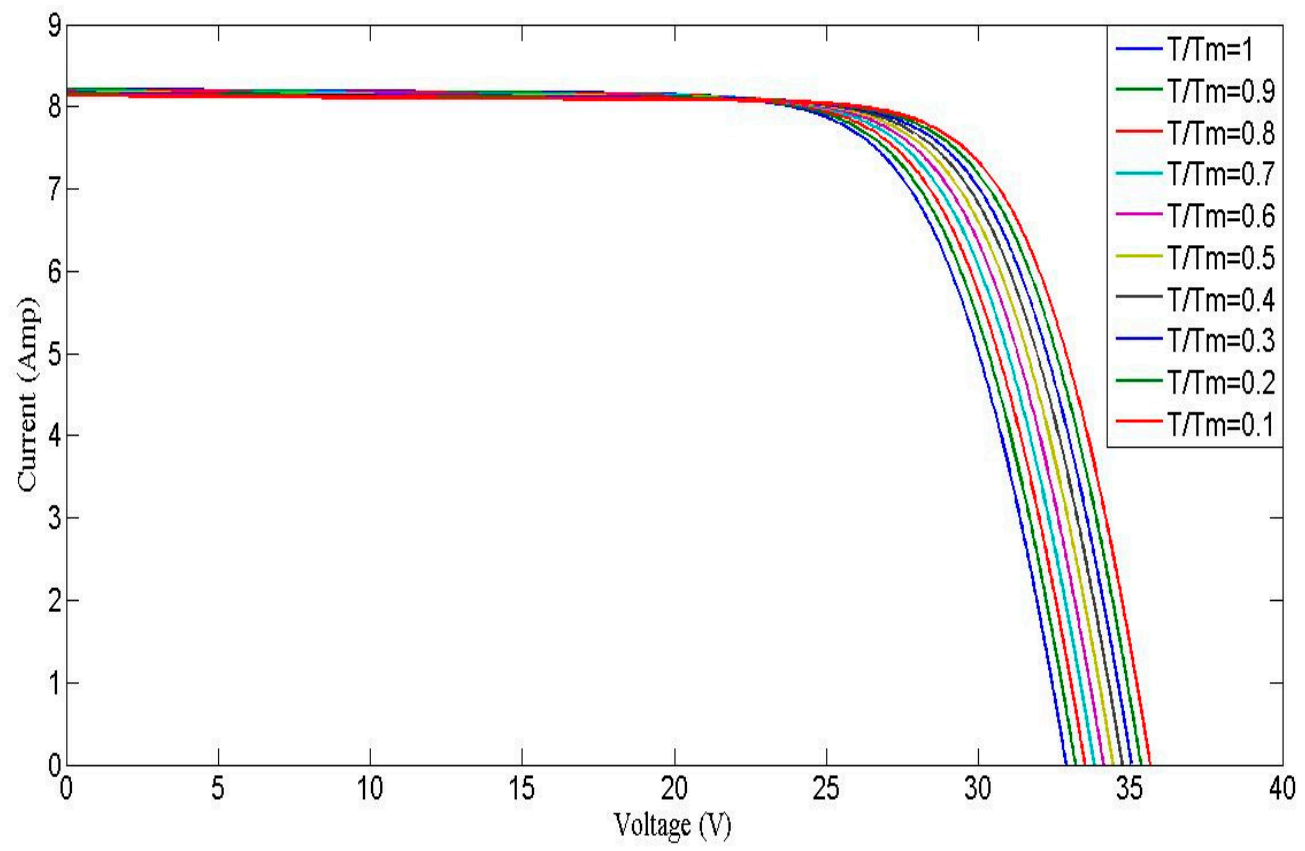

Figure 6. Power vs. Voltage characteristics at different temperatures.

\subsubsection{Partial Shading Condition (PSC)}

A single PV cell can produce a few watts of electricity. Thus, multiple PV cells are connected in series and parallel configurations to form a PV module. However, a PV string consists of multiple PV modules connected in series. While a PV array consists of multiple PV strings connected in a parallel configuration. PSC is a phenomenon at which some part of the PV module is receiving different irradiance level as compared to other parts. Thus, in a string, a shaded module will produce low current. However, in a series-connected PV system, current should remain constant, but, in this case, the shaded module will work in a reverse biased condition, and it will drop a huge amount of voltage across $R_{p}$. Thus, it produces a hotspot at that point and sometimes it will damage the PV module. Thus, to reduce the huge power loss due to PSC, a bypass diode is used to avoid the shaded module. The bypass diode is normally used to minimize the adverse effect of the shaded module, and the voltage drop across the bypass diode is just 0.7 V. Figure 8 depicts the PSC. The PV string shown in Figure 8 a represents a uniform irradiance condition (UIC). However, Figure $8 \mathrm{~b}-\mathrm{d}$ represent PV strings with different irradiance levels i.e., PSC. Under UIC, all the solar module works as a current source, 
and all diodes work in reverse biased conditions. However, under PSC, the shaded solar cells act as an open circuit. Thus, the total current flow throws the internal resistance $R_{p}$, which produces a huge voltage loss. In order to avoid this voltage-drop, the bypass diode works in a forward biased condition, and the solar cell is completely bypassed. Thus, the voltage drop would be just $0.7 \mathrm{~V}$.

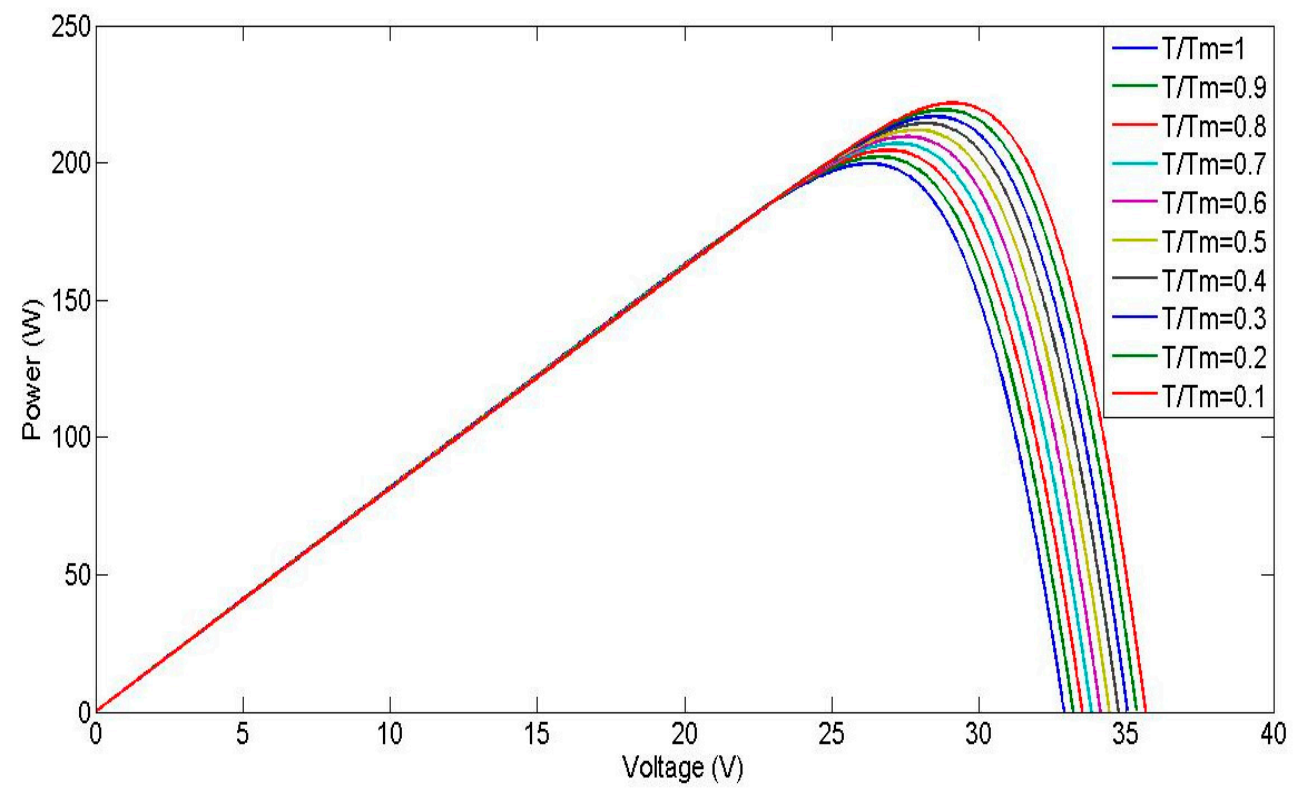

Figure 7. Current vs. Voltage characteristics at different temperatures.

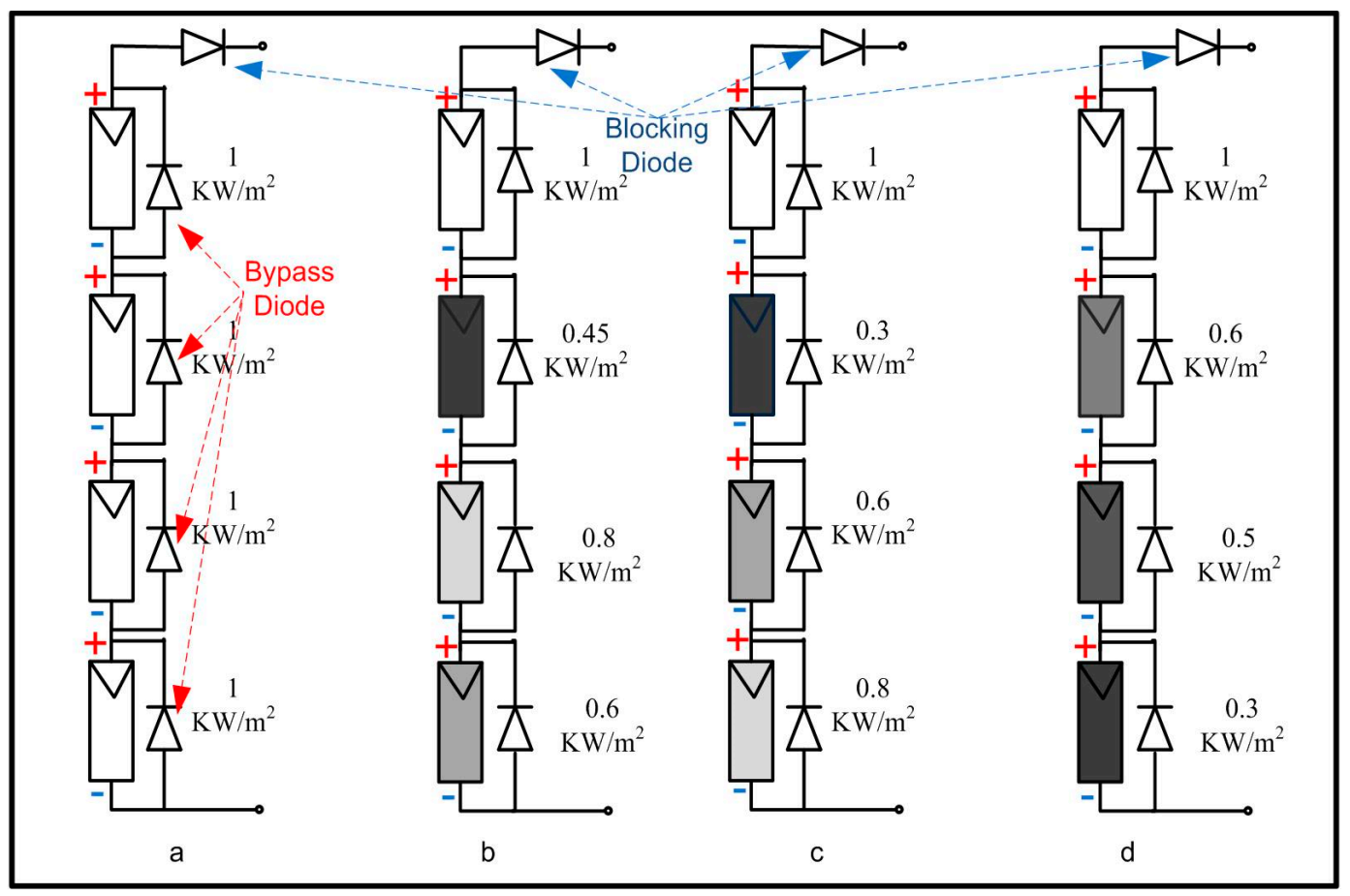

Figure 8. (a) PV string at uniform irradiance condition, (b-d) PV string under partial shading conditions.

The PV string with different irradiance condition is shown in Figure 8. The power vs. voltage $(\mathrm{P}-\mathrm{V})$ curve of the PV string subjected to multiple PSC is illustrated in Figure 9. The curve in blue with a single maximum peak at $800 \mathrm{~W}$ corresponds to a UIC. However, the remaining curve illustrates PSC. Thus, Figure 9 shows that multiple peaks appear in the P-V curves during partial shading conditions. However, there is a single MPP that appears in each curve, which is known as global peak (GP), 
and remaining peaks are known as local peak (LP). Furthermore, in UIC, there is just one GP and no LP. However, under PSC, there are many LPs but only a single GP. Thus, to detect the GP from all existing peaks, an accurate and robust tracking technique is required and that is known as Maximum Power Point Tracking (MPPT). The MPPT becomes more complex and challenging with the variation in temperature and irradiance. For example, in Figure 9, the light blue line indicates UIC, but, due to the PSC case, multiple peaks are produced in the remaining curves. The shading curves have GP at $800 \mathrm{~W}, 613 \mathrm{~W}, 528 \mathrm{~W}, 406 \mathrm{~W}, 397 \mathrm{~W}$, and $330 \mathrm{~W}$. Similarly, the voltage at GP is between $80 \mathrm{~V}$ to $120 \mathrm{~V}$.

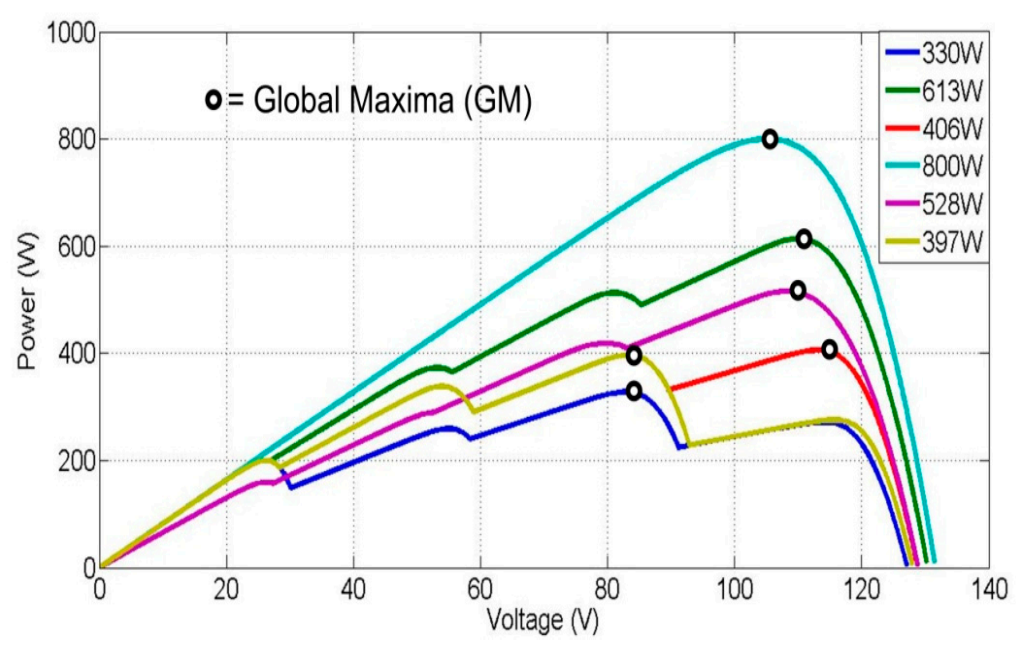

Figure 9. P-V characteristics curve for uniform and partial shading.

\section{A PV System}

Figure 10 shows the complete block diagram of a standalone PV system. The major components of a standalone PV system are PV panels, MPPT based DC/DC converter, charge controller, DC/AC inverter, batteries, filters, and a microcontroller to control the output of the PV panel and harvest maximum power from the PV system. As the position of the sun is not static, the output characteristics of the PV panel are nonlinear in nature. Furthermore, if the panel is partially shaded or the environment is rapidly changing, then multiple peaks generate in the PV characteristics curve [3]. Thus, the main issue in the PV system is to track maximum power and to force the PV system to work at maximum power efficiency. Thus, an optimum control strategy is required to resolve this issue.

\subsection{Converter Topologies}

The power converter topology is the most important part of the renewable energy-based power generation system. It primarily focuses on the type of application that is being employed. The electrical power converter is an integral component of the generation system which integrates the renewable energy source (Solar, Wind, Fuel Cell, Fly Wheel) to the distributed or centralized power grid (micro-grid, main power grid, or national grid). In PV-based energy systems, converters are employed to modify the output power to increase or decrease the voltage value in accordance with system compliance. Several power converter topologies have been defined and implemented in the literature for renewable energy systems. Some of these converter topologies that have been discussed below focus on PV-based energy generation systems. 


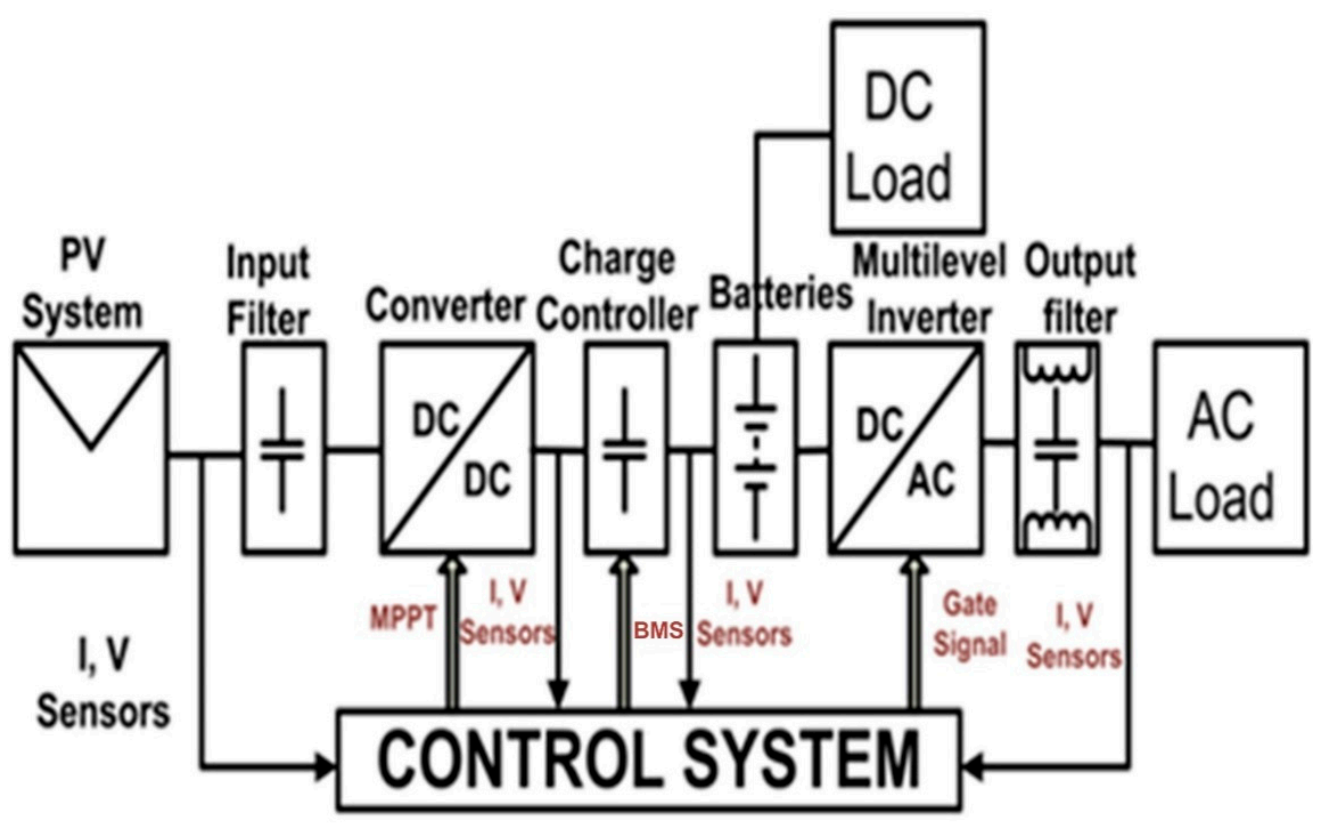

Figure 10. Basic block diagram of the PV system.

The most frequently or commonly employed converters for efficient power conversion in PV based power systems are classified as a boost, buck, and buck-boost converters. These converters find their applications in renewable energy systems, such as standalone system, grid-integrated system, micro-grid, smart-grid systems, or hybrid energy systems. In such power generation systems, efficient and robust MPPT algorithms are imposed to control the output of the converter in order to harvest maximum power from PV panels under different environmental conditions. The selection of any of these generic power converters depends upon the specific applications that are targeted.

\subsubsection{Buck Converter}

The buck converter topology is mostly used as a power converter for PV-based energy systems. It is used to reduce the input voltage, so, in buck converter, the output voltage is always less than the input voltage (Vin > Vout). The buck converter basically works in two operational modes, which are continuous conduction mode of operation and discontinuous mode of operation. Both of the conduction (operational) modes are responsible for power provision to both the critically as well as normally attached load.

The MATLAB/Simulink model published in $[4,5]$ is used to develop this buck converter. Figure 11 illustrates the buck converter connected with the PV panels. In the continuous operational mode, the switch (MOSFET switch) is ON thus conducting current, while the circuit diode is in OFF or reverse biased, whereas, in the discontinuous operational mode, the switch is in an OFF state while the circuit diode in this operation is $\mathrm{ON}$ or forward biased. The relation for the conversion ratio of the converter output current, output voltage, output resistor, and PV module electrical parameters in conjunction with and the duty cycle is given by Equation (10):

$$
\frac{V_{b k}}{V_{p v}}=\frac{I_{b k}}{I_{p v}}=\sqrt{\frac{R_{o}}{R_{i n}}}=D,
$$

where $V_{b k}$ is the output voltage of the buck converter, $V_{p v}$ refers to PV module voltage, $I_{b k}$ represents the output current of the buck converter, $I_{p v}$ is the PV module current thus input current to power converter, $R_{o}$ is the output or load resistor attached to the power converter, $R_{\text {in }}$ refers to the input resistor of the buck converter, and $D$ represents the duty ratio of the converter switch. 


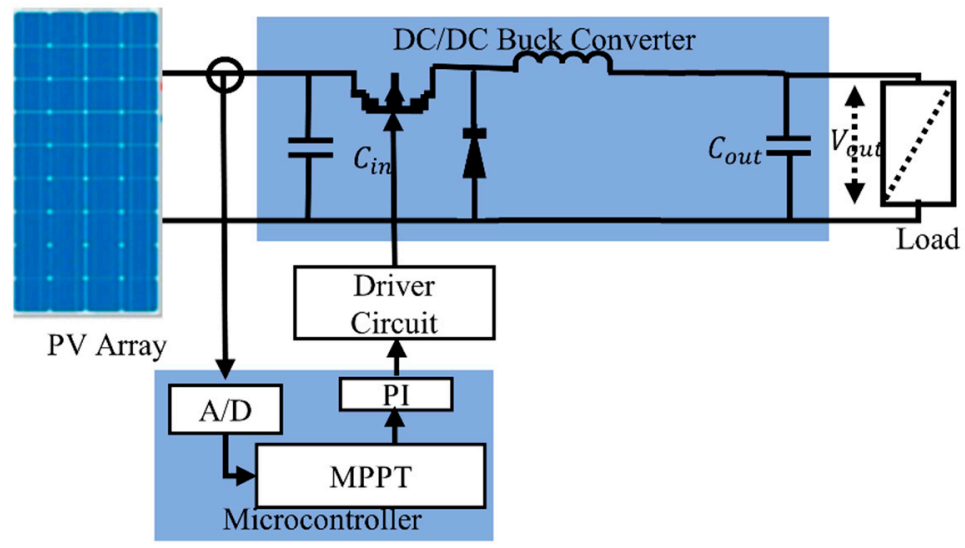

Figure 11. The buck converter with a PV module.

The buck converter model is the simplest, has higher power efficiency, and it is a perfect choice for the power design engineer to integrate it as a power converter for the application of PV based power generation systems. The unique behavior of the buck converter facilitates an efficient battery bank charging under uncertain conditions of power provision from PV array. Moreover, it also has the capability to regulate the solar panel's output voltage, current as well as power efficiency. When the mode of operation of the buck converter is frequently changed from continuous conduction to discontinuous conduction due to shading and non-shading conditions, the system's robustness is affected, and it requires a complex circuit design and superior control algorithm for stable and reliable operations of the PV-based energy generation system. The mode of operation of the buck converter primarily depends upon the environmental variations as well as climatic conditions, thus reducing the efficiency of the converter and challenging the reliable operation of the buck converter to provide continuous power to the connected load. To address these limitations of the buck converter, converter configuration is modified and proposed in the available literature [4,5]. The generic model of a buck converter with a PV module is shown in Figure 11.

One of the major drawbacks of reduced efficiency is improper damping of the LC filter, which produces unwanted harmonics at the output of the power converter, forcing the PV system to operate under specific conditions at a local minima power point and resulting in immense power reduction. To avoid undesired harmonics in the output waveform, an additional damping compensation circuit is required that increases system complexity further. Its practical implementation becomes challenging due to the variable impedance characteristic nature of the PV module [6]. Veerachary proposed the most feasible and practically viable solution to eliminate unwanted oscillations (harmonics) produced at the output side of the general buck converter by using a fourth-order buck converter that is far more stable, reliable, efficient, and cost-effective under any variation in weather or environmental conditions [7].

To maximize the output power and conversion efficiency of the buck converter, a switched capacitor circuit design with a buck converter comprising a reconfigurable switched capacitor in conjunction with PV systems is proposed in [8]. In this reconfiguration model, a dual predefined mode of operation-based strategy is employed, which works by using input current and voltage values of the power converter and thus minimizing power losses. The major drawback of this topology is its additional requirement of switching device circuits, hence increasing switching and conduction losses and rendering down the overall efficiency of the implemented PV system. The switching losses can be mitigated by employing multiple modulation schemes, such as the Space Vector Modulation (SVM) technique, the Pulse Width Modulation (PWM) technique, the Enhanced PWM (EPWM) technique, and the Hybrid Pulse Width Modulation (HPWM) technique [9].

Another topology of the multiphase interleaved buck converter is proposed which is mainly based on splitting the total output current of the power converter into a number of desired phases. 
It is a successful strategy to reduce the current stress on the overall PV system due to the connected load. This novel strategy of splitting current into phases facilitates reducing conduction losses, thus maximizing system efficiency [10]. To avoid conduction and switching losses due to additional incorporated devices, a buck converter is designed to keep the power converter operating in the continuous mode for the whole duty cycle [11]. Another converter design was proposed, namely a synchronous converter in which the MOSFET is used by replacing the diode to improve the power conversion efficiency by reducing conduction loss imposed by the switch [12]. For efficient and robust control, the bi-directional flow of power was introduced: the topology of the bidirectional power flow converter for the application of a PV based system specifically focusing on DC micro-grid power systems [13].

\subsubsection{Boost Converter}

The boost converter is commonly used for PV-based energy generation systems. A boost converter boosts the output voltage of the PV panel by changing the duty cycle. The PV output voltage must be synchronized with the connected load to perfectly adapt to the characteristics of the PV system. The boost converter has two operational modes, including the continuous (CCon) operational mode and the discontinuous (DCon) operational mode. The basic model of a boost converter is shown in Figure 12. The generic model of a boost converter consists of mainly an input side inductor $L_{i}$, a diode $D_{o}$, a switch (MOSFET/ IGBT), and an output side capacitor $C_{o}$. The mathematical formulation for representing the dynamic state of a boost converter with PV based power generation system is given by Equation (11):

$$
I_{p v}=C_{o} V_{p v}+I_{L_{i}} \text {, }
$$

where $C_{o}$ is the output side capacitor, $V_{p v}$ is the PV module voltage, $I_{p v}$ is PV module current, and $I_{L}$ is the inductor current. The voltage gain, current gain, and their mathematical relationship with duty cycle is represented by Equation (12):

$$
\frac{V_{b t}}{V_{p v}}=\frac{I_{b t}}{I_{p v}}=\sqrt{\frac{R_{o}}{R_{i n}}}=\frac{1}{1-D}
$$

where $V_{b t}$ is the battery voltage or the output voltage.

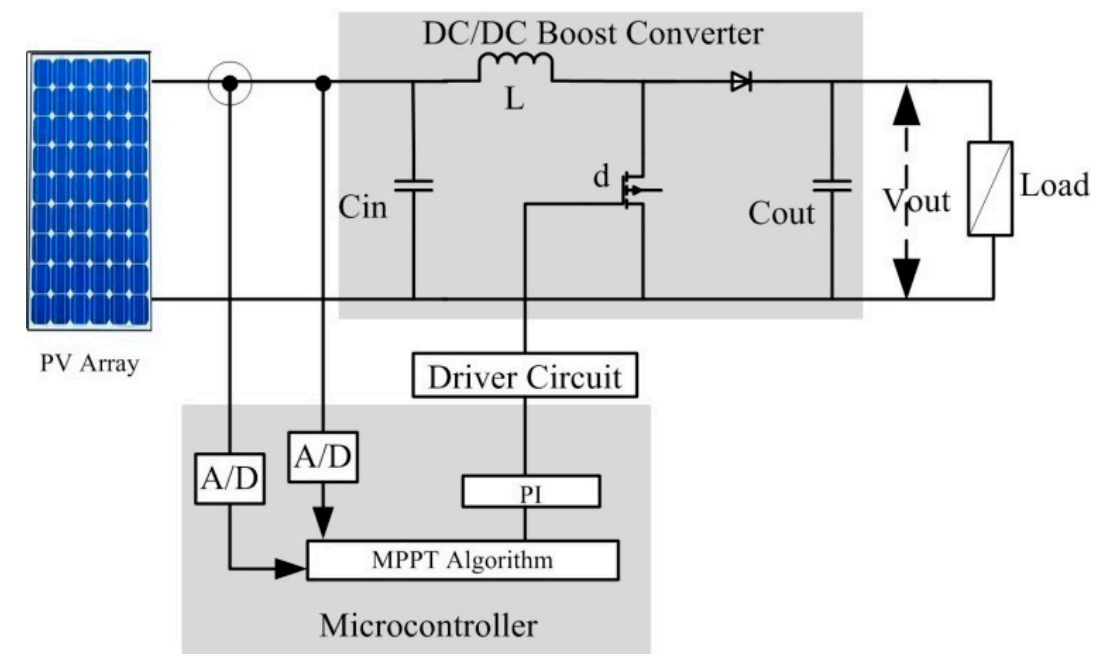

Figure 12. The boost converter with a PV module.

The mathematical relation for duty cycle is given as Equation (13):

$$
D=1-\frac{1}{C_{o} V_{b t}}\left(I_{L_{i}}+I_{p v}\right)
$$


The control parameter of a boost converter is either frequency or duty cycle (duty ratio). The control input parameters for PV systems, which are either in the stand-alone mode or in the grid integrated mode are voltage, current, and power (bi-directional power flow in grid integrated mode) [14-16]. In the existing literature, various models of a generic boost converter have been proposed. The conventional boost converter encounters a number of problems, such as less robust, less fault tolerant, and the output voltage control becoming challenging due to varying weather conditions as well as nonlinear characteristics of PV based systems. Figure 12 presents the model of a boost converter.

To reduce voltage stress and minimize unwanted ripples of input and output voltage, a suggested technique is an interleaved dual boost (IDB) power converter [17]. Another proposed model is a three-port bi-directional boost converter based on an interleaved technique that can reduce ripples and increase power conversion efficiency by reducing switching losses and voltage regulation [18]. In [19], a microinverter concept is realized by splitting the output capacitor into two parts to maximize efficiency. Mohammed et al. proposed a coupled inductor technique to minimize switching losses and facilitate voltage regulation during charging and discharging intervals [20]. In DC micro-grid systems, high voltage conversion gain is essential to meet the IEEE standard, and a three-port boost converter topology was investigated in $[21,22]$.

\subsubsection{Buck/Boost Converter}

The buck-boost converter is another power converter topology employed in renewable energy technology, significantly in PV-based energy generation systems. The buck-boost power converter is used to step-up or step-down the magnitude of the output voltage provided to the connected load depending upon the nature of applications. The power is delivered to the attached load in both the positions (ON or OFF) of the operating switch. The generic buck-boost converter model is shown in Figure 13. The voltage gain relationship is expressed in Equation (14):

$$
\frac{V_{b k-b t}}{V_{p v}}=\frac{I_{b k-b t}}{I_{p v}}=\frac{D}{1-D}
$$

where $V_{b k-b t}$ refers to the output voltage, $I_{b k-b t}$ refers to the output current, $V_{p v}$ is the input voltage, and $I_{p v}$ is the input current and also the duty cycle.

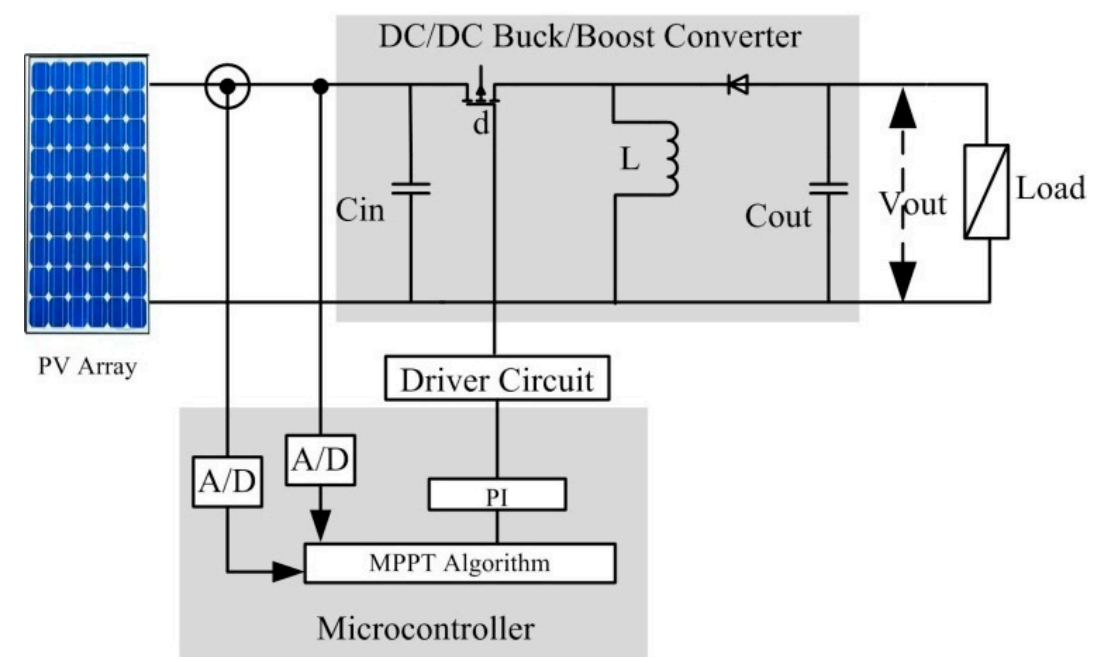

Figure 13. The buck-boost converter with a PV module.

The buck-boost topology is the most frequently used power converter topology for PV systems, which facilitates harvesting maximum power from solar panels that are severely affected by environmental factors [23,24]. Tsai-Fu et al. employed two buck-boost converter configurations for the DC micro-grid system to avoid voltage stress and maintain the DC bus voltage [25]. Unfortunately, 
the output current still contains ripples [25]. Juha et al. integrated an additional filter into a PV system to remove ripples [26]. David et al. introduced a concept of the non-inverting buck-boost converter with DC transformer to avoid sudden changes in voltage variations due to the transition between continuous and discontinuous mode of operation of the converter and switching of diodes from $\mathrm{ON}$ and OFF states [27]. In grid incorporated power systems, the frequency variation causes an immense decrement in power quality of PV based power generation systems. Moreover, extremely efficient and robust control is required to monitor the bi-directional flow of power to comply with IEEE standards [28]. An interleaved buck-boost converter topology proposed by Mohammad et al. allows the PV based power converter to operate as a multi-channel power converter in high power grid integrated systems [29].

\subsubsection{Cuk Converter}

The Cuk converter is another choice for integrating the PV module and the attached load. The Cuk power converter operates by a unique principle in the steady-state mode where the average values of the inductor voltage and capacitor current waveforms are zero. Figure 14 visualizes the generic model for the Cuk power converter. The Cuk converter operates in two modes. In the first mode, the power switch (MOSFET) is in ON state, forcing the capacitor to provide power to the connected load. In the other mode, the power switch (MOSFET) is in the OFF state and the power diode will be in a forward bias condition and transmits energy to the attached load. The mathematical formulation for voltage and current gain is given by Equation (15):

$$
\frac{V_{c k}}{V_{p v}}=\frac{I_{c k}}{I_{p v}}=-\left(\frac{D_{0}}{1-D_{0}}\right)
$$

where $V_{c k}$ refers to the Cuk power converter output voltage, $V_{p v}$ represents the PV module voltage, $I_{c k}$ is the output current of the converter, $I_{p v}$ is the PV current, and $D_{o}$ is the duty ratio.

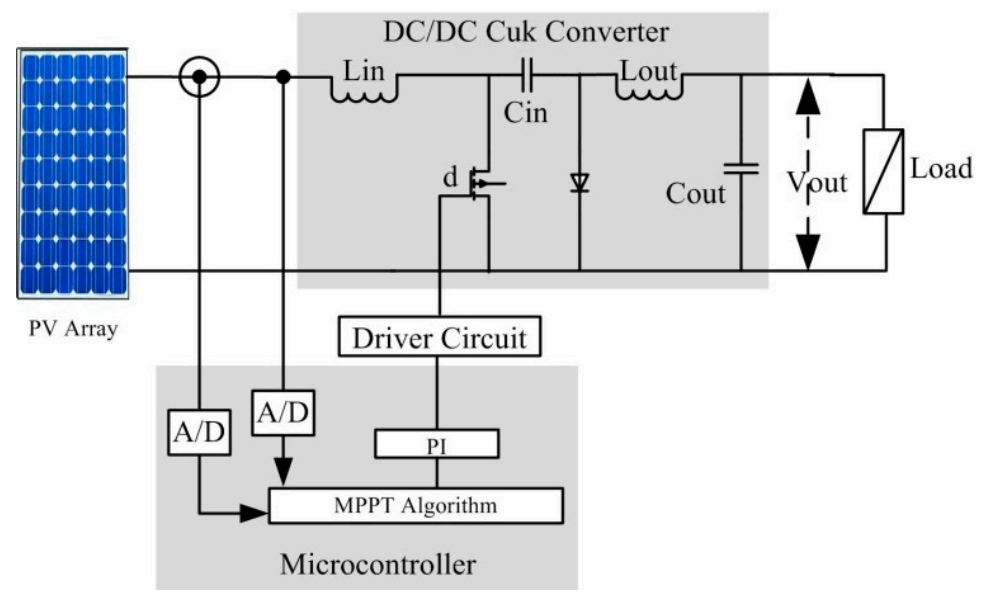

Figure 14. The Cuk converter with a PV module.

A Cuk converter operates in three modes. These modes include continuous current mode, discontinuous capacitor voltage mode, and discontinuous inductor current mode. Due to PV module characteristics and nonlinear behavior, the discontinuous capacitor voltage mode is most suitable and preferred over the other two operational modes for PV based power generation systems as it is highly efficient and suffers less from switching and conduction losses. The main advantage of using a Cuk converter for constant current applications is its dynamic behavior contributing by the output side inductor which ensures constant output current flow towards connected load specifically in discontinuous inductor current operational mode. In [30], the suggested Cuk converter is designed and tested with a modified optimal power tracking strategy. In [31], Cuk converter modeling is carried out using a variable 
parameter approach. The capacitor voltage and inductor current are considered as state variables to derive a state-space model of the Cuk converter in PV systems. The stability analysis revealed satisfactory results and the harmonic content in the output voltage is in accordance with IEEE standards, while the (Total Harmonics Distortion) THD level is maintained and strictly kept less than 5\% [32].

\subsubsection{Single Ended Primary Inductor Converter (SEPIC)}

The SEPIC power converter is also a type of power converter for PV-based energy generation systems. The SEPIC power converter has two operational modes. In these conduction modes, the electrical behavior of the SEPIC power converter is different for PV systems. In the Con mode of operation, the current through the MOSFET switch remains constant, but the inductor current $I_{L i}$ falls to almost zero value in uncertain weather conditions. The mathematical representation of voltage and current gain in conjunction with the duty cycle is given by Equation (16):

$$
\frac{V_{s p c}}{V_{p v}}=\frac{I_{s p c}}{I_{p v}}=\left(\frac{D_{0}}{1-D_{0}}\right)
$$

where $V_{s p c}$ refers to the SEPIC power converter output voltage, $V_{p v}$ represents the PV module voltage, $I_{s p c}$ is the output current of SEPIC converter, $I_{p v}$ is the PV current, and $D_{o}$ is the duty ratio. The generic model of a SEPIC power converter in conjunction with the PV system is shown in Figure 15.

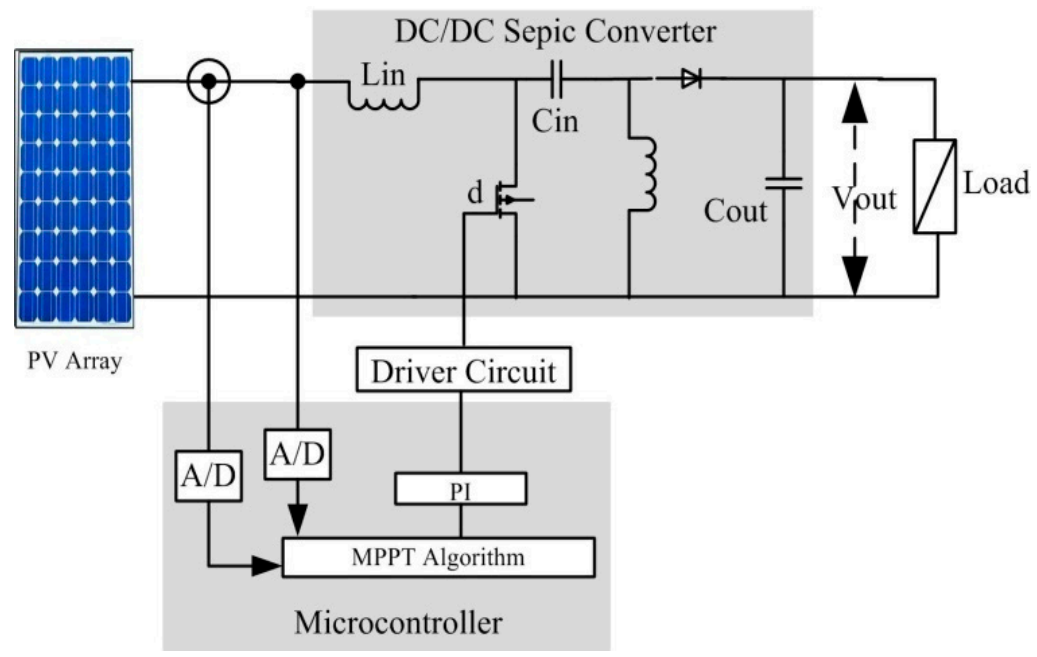

Figure 15. The Single Ended Primary Inductor Converter (SEPIC) with a PV module.

A comparative analysis based upon the critical evaluation of technology employed and user requirement for a specific application reveals that the buck converter is suitable for the situation where the required circuit voltage is lower than the voltage produced by the PV module. Conversely, the boost converter is more favorable for the case where the required circuit voltage is greater than the voltage developed by the PV module so that the circuit requirement must be fulfilled under varying weather conditions or under sudden or prolonged environmental changes and the boost converter efficiency must not be rendered down.

The Cuk power converter and buck-boost power converter both are used when the voltage is stepped up or stepped down in accordance with circuit or application compliance in PV energy-based systems. Their major drawback being reported in the literature is the presence of ripples in the output of the Cuk converter as well as a buck-boost converter. These output ripples drive the converter's power conversion efficiency to unacceptable limits. Moreover, they require a large inductor value to meet IEEE standards of output current and reduction in unwanted harmonics or current ripples [33].

To address the above-discussed issues regarding voltage requirement and harmonic reduction, a single switch based SEPIC power converter is employed. SS-SEPIC (Single switch SEPIC) facilitates 
reducing the output current ripples, thus maximizing the overall PV system efficiency and improving power quality available to local loads. In [34], a modified SEPIC power converter model is proposed that primarily focuses on an impedance matching principle to harvest maximum power from the PV module and facilitates maximum power delivery to the locally connected critical load. The conventional SEPIC power converter suffers from high switching losses due to the absence of proper value capacitor, which minimizes the switching stress on the power converter, thus increasing efficiency to a considerable amount. To diminish the switching losses and to achieve smooth output current with a very small percentage of ripples or harmonic, a coupled inductor based SEPIC power converter is proposed [35]. Moreover, CI-SEPIC also improves output power quality by reducing electromagnetic interference. A synchronous SEPIC converter model that enhanced the system robustness by regulating DC-link voltage value is suggested by Emilio et al. [36]. Chiang et al. proposed a SEPIC power converter model that is principally based on peak current mode control and suffices charging the system of the low power PV-based energy systems, thus increasing the life of the battery bank employed in the circuit [37].

\subsubsection{Flyback Converter}

The flyback converter is like the buck-boost converter in configuration and the number of components required. The only difference in the flyback converter is the use of a DC transformer. The operational modes of a flyback converter are almost similar to those of the buck-boost converter. In flyback based PV power systems, the primary winding transformer is connected to PV modules. When the MOSFET is in the OFF state, the diode $D$ is in reverse biased mode due to the secondary winding of the transformer. The output side capacitor is responsible for power provision to the attached load in this mode. When the power switch (MOSFET) is opened, the voltage induced in the secondary winding drops down, resulting in a reduction in secondary winding current and magnetic flux gets substantially weakened. The diode $D$ will be forward biased when the power switch is opened, resultantly developing a positive induced voltage in the secondary winding of the ideal transformer. The output side capacitor provides power to the connected load. The generic model of a flyback converter can be visualized by Figure 16. The voltage gain relationship for a flyback converter is given by Equation (17):

$$
\frac{V_{F B}}{V_{p v}}=\frac{I_{F B}}{I_{p v}}=N\left(\frac{D_{0}}{D_{0}^{*}}\right)
$$

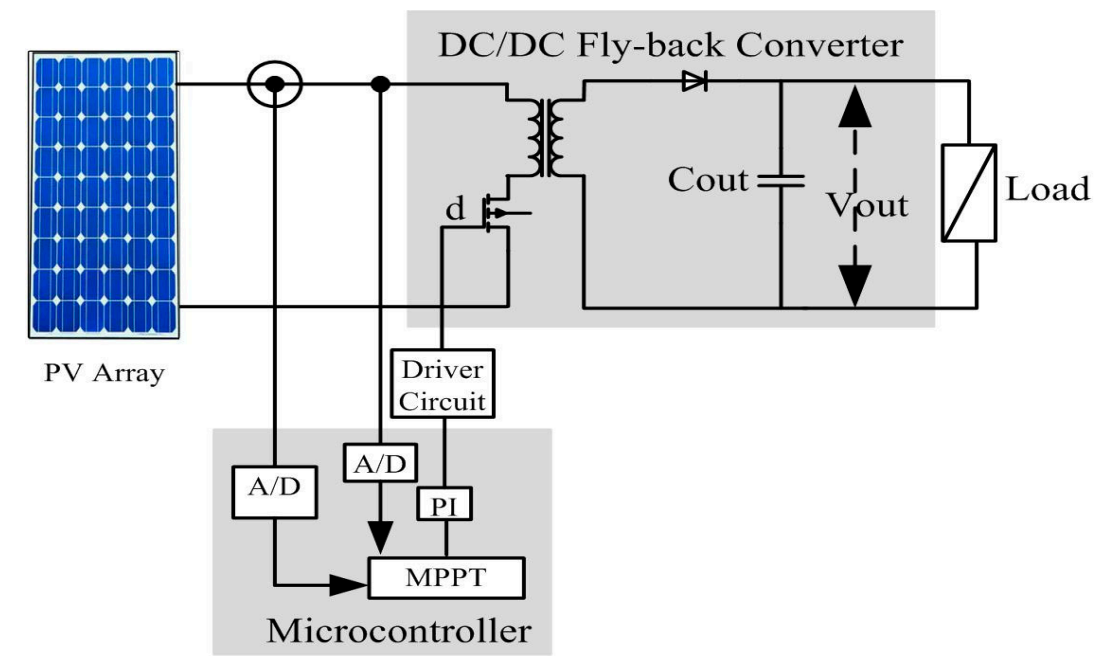

Figure 16. The flyback converter with a PV module.

Several fly-back converter models have been proposed in the literature and their pros and cons were provided. The fly-back converter consists of a lesser number of hardware components 
comparatively simplifying its operation, reducing hardware design complexity, and giving rise to its suitability and preferred choice over other existing topologies in PV based power generation systems. The major problem faced by the PV system employing fly-back converter is the presence of unwanted harmonic ripples at load current. To address this ripple current issue, Gab-Su et al. introduced a simple concept of placing a decoupled capacitor between PV module and a power converter to reduce harmonic ripples in the output current of the flyback converter. The performance of a flyback converter is severely affected by conduction losses. A module-based interleaved flyback converter method facilitates reducing conduction losses by controlling the flow of current through power switch, thus regulating power under varying environmental factors [38]. In [39], the proposed methodology consists of an active capacitor clamp circuit at the primary side of the transformer and at the secondary side of the transformer, a voltage multiplier circuit is attached to mitigate circulating current and switching losses due to conduction [40].

Another flyback converter is employed in [41] to restrict the power converter to enhance system robustness and efficiency under high and varying switching frequency (VSF). The VSF imposes complex circuit requirements causing accurate mathematical modeling to be a challenging and difficult task. Another flyback converter scheme is employed in [42] to decrease conduction loss; thus, maximizing power conversion and mathematical modeling becomes easier. An interleaved flyback module integrated power converter is discussed in [43] to avoid or mitigate DC-link voltage ripples as well as electromagnetic interference caused by transformer magnetizing and demagnetizing effect. In continuous conduction mode, power converter circuit components suffer from huge current stress, thus decreasing overall system efficiency. To resolve this overstress current issue, Guan et al. [44] employed two fly-back converter schemes based on frequency variation, and proper duty-cycle control will improve the battery life and mitigate the current stress on components of the converter. Jong et al. [45] introduced a novel strategy of a series-connected flyback converter to enhance the PV module voltage transfer gain. To avoid impedance mismatch condition which reduces power transfer capability of the PV module, a sub-module integrated flyback converter is suggested in [46] which compensates for the PV voltage by injecting current into the system under impedance mismatch scenario, or else the sub-module is switched off or isolated from the PV power generation system.

\subsection{Inverter Topologies}

Inverters are commonly used to develop an interlink between DC and AC systems [47]. Furthermore, these types of equipment are also used as a variable frequency drive (VFD) or variable speed drive (VSD), which are controlled by transistor switching. However, due to the switching of transistors, multiple harmonic contents appear in the output and distortion due to the harmonic content being known as total hormonic distortion (THD) [48,49]. Currently, inverters used in PV applications are either with transformers or transformer-less (with power electronics switches). Some transformer-less types are full-bridge, half-bridge, and multi-level inverters. The major requirements for inverters are high efficiency, have low harmonics, are cost-effective, and have a compact structure. Generally, PV based inverter topologies are categorized based on the number of power processing stages.

Figure 17 shows two different types of PV inverters. The single-stage inverter is also known as a micro-inverter, and it is shown in Figure 17a. In a single-stage inverter, the DC to DC converter and MPPT unit is integrated with the inverter [50]. Thus, there will be a single power processing stage installed, and no external converter is required to track the MPP. Moreover, those inverters have the capability to handle twice the nominal power of the grid as shown by Equation (18). The single-stage inverter has its own advantages and disadvantages. The major advantage of a single-stage inverter is: it is more economical than a two-stage inverter. However, its circuitry is complex, and there is high power loss during PSC. Hence, it becomes less reliable:

$$
P_{\text {grid }}=2 P_{\text {grid }} \operatorname{Sin}^{2}\left(\omega_{\text {grid }} t\right),
$$


where the peak power of the grid is denoted by $P_{\text {grid }}$ and the frequency of the grid is $\omega_{\text {grid }}$.

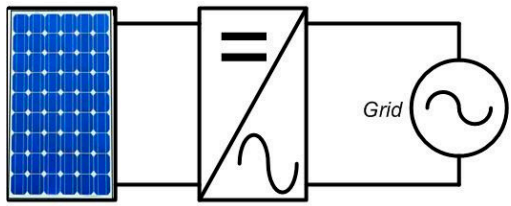

(a)

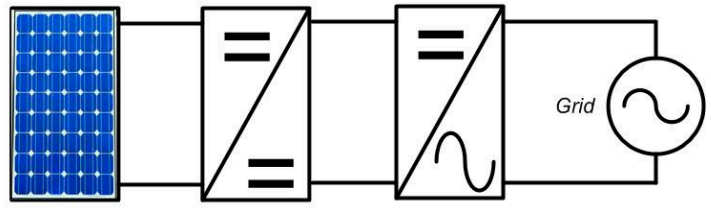

(b)

Figure 17. PV inverter types (a) single-stage inverter, (b) two-stage inverter.

On the other hand, the inverter with two power processing units is known as two-stage PV inverter, which is shown in Figure 17b. In the two-stage inverter, the DC-DC converter with the MPPT based charge control system being separately installed with the inverter [51]. In this inverter, the DC to DC converter performs two tasks i.e., voltage level adjustment and MPPT. However, the inverter adjusts the current according to the phase and frequency of the grid by injecting a pulse width modulated signal, and it will convert the DC to AC.

Although the basic control mechanism of the inverter is to convert DC into AC, the inverters with more than two levels are highly efficient and can be implemented with minimum cost [52,53].

Three commonly used multi-level inverters are i.e., Diode Clamped, Flying Capacitors, and Cascaded H-Bridge. In Diode Clamped inverters, series capacitors are used to build multiple voltage levels. In a single-phase n-level diode clamped inverter, n-number of capacitors are required for $n$ voltage levels [54]. Similarly, n-number of capacitors are required in n-level Flying Capacitor inverters [55]. However, the Cascaded Multilevel inverter (C-MLI) does not require any additional capacitors or diodes. Thus, it would be a good option for renewable energy applications such as photovoltaic (PV) systems. Multiple DC voltage sources are combined to generate required output in case of pf C-MLI [56,57]. Figure 18 shows the basic circuit diagram of Diode-clamped, flying capacitor, and cascaded h-bridge inverters. The output of the multilevel inverter is a staircase sinusoidal waveform with minimum harmonics. The multilevel inverter topologies are the most appropriate option for the PV system because of the modular structure of the PV array where multiple voltage levels can be easily produced.

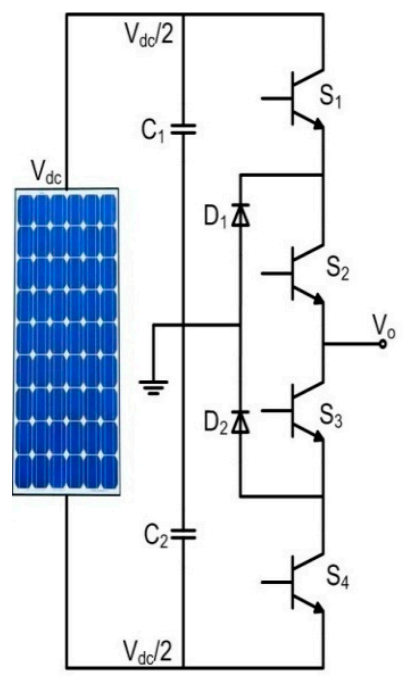

(a)

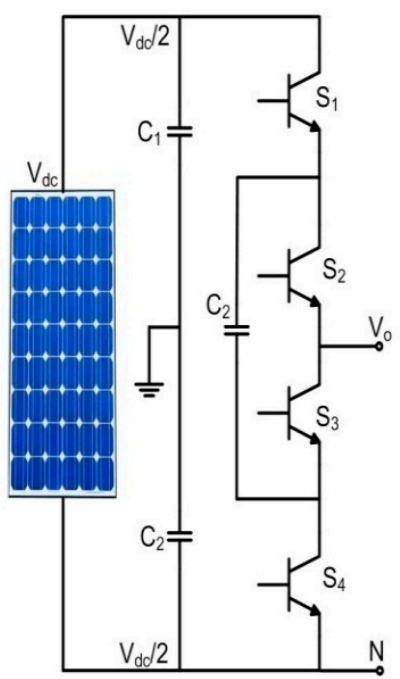

(b)

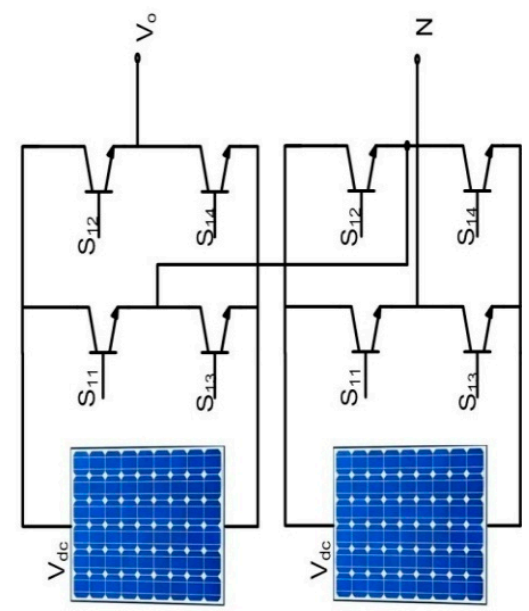

(c)

Figure 18. (a) diode clamped inverter, (b) fly-back inverter, and (c) cascaded bridge inverter. 


\section{Conventional MPPT Techniques}

The electricity produced by the PV system is nonlinear in nature because the position of the sun is not constant. Furthermore, the electricity produced by the PV system is dependent on solar light (irradiance) and environmental temperature [58]. Thus, it becomes a great challenge to harvest maximum power from the PV system [59]. Figure 19 shows the P-V characteristics curve of the PV panel. The figure depicted that there is a unique point in each curve where maximum power would be achieved. Thus, in order to force the PV system to work at that point, many Maximum Power Point Tracking (MPPT) algorithms are introduced by the researchers. Some conventionally used MPPT techniques are: the Fractional Open Circuit Voltage (FOCV), Factional Short Circuit Current (FSCC) [60], Hill Climbing (HC) method [61], Incremental Conductance ( $\mathrm{InC}$ ) technique [62], and the Perturb and Observe (P\&O) technique [63]. The aforementioned techniques are efficient, simple, and their response time is very fast in uniform environmental conditions, but their efficiency degrades in partial shading conditions and rapidly changing environmental conditions [64]. Moreover, even in UIC, these techniques will oscillate in steady-state conditions or at MPP $[60,65]$. However, many hybrid techniques have been developed in order to improve the performance of the above-mentioned techniques [58,66-68]. This hybrid approach is a combination of conventionally MPPT techniques and some artificial intelligence algorithms to improve PV system performance efficiency $[69,70]$. The detailed description of these conventionally used techniques and their pros and cons are discussed below.

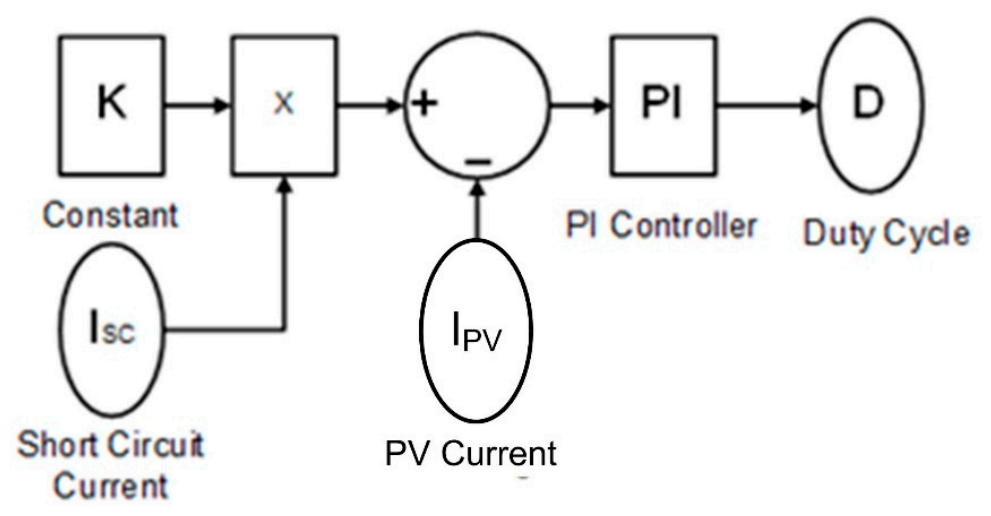

Figure 19. Block diagram of Factional Short Circuit Current (FSCC).

\subsection{MPPT by Using Conventionally Used Techniques}

\subsubsection{Fractional Short Circuit Current (FSCC)}

Fractional short circuit current is a direct MPPT technique. FSCC is a speedy, simple and offline approach to track MPP. It depends on the fundamental parameter of the PV array. However, it cannot detect the exact MPP [71]. It can be implemented by both discrete and analog methodology. The main principle of this technique comes from the observation that the MPP current $\left(I_{m p p}\right)$ is equal to some approximate value of PV panel short circuit current $\left(I_{s c}\right)$ [72], which is expressed by Equation (19) and the block diagram of FSCC is shown in Figure 19:

$$
I_{M P P} \cong k I_{S C},
$$

where $k$ is a constant that lies between 0.8 and 0.9. In order to compute $I_{s c}$, the load has to be shed and then the aforementioned equation yields the $I_{M P P}$. However, this method has its own drawbacks:

- The load interruption when measuring $I_{s c \text {, }}$

- The MPP obtained is not exactly accurate as the equation itself demonstrates. 


\subsubsection{Fractional Open Circuit Voltage (FOCV)}

The basic phenomenon of Fractional open-circuit voltage (FOCV) is the same as the FSCC technique. Thus, it is a direct MPPT technique that doesn't track MPP. Therefore FOCV is only an approximation based technique [67]. It can be implemented by both discrete and analog control methodology. However, FOCV is easier to implement as compared to FSCC. Furthermore, FOCV is a simple, fast and offline approach to find the Maximum Power Point that is based on an estimated value of the open-circuit voltage. This technique works on the principle that $V_{m p p}$ is approximately equal to some fractional value of Voc [71] that is illustrated in Equation (20):

$$
V_{M P P} \cong k V_{O C},
$$

where $k$ is the fractional value of open-circuit voltages usually it is between 0.7 to 0.8 time the open-circuit voltage [73]. Figure 20 presents the block diagram of FOCV. The main drawback of this technique is: it produces periodic power loss while measuring $V_{o c}$. Moreover, this technique is not feasible for PSC.

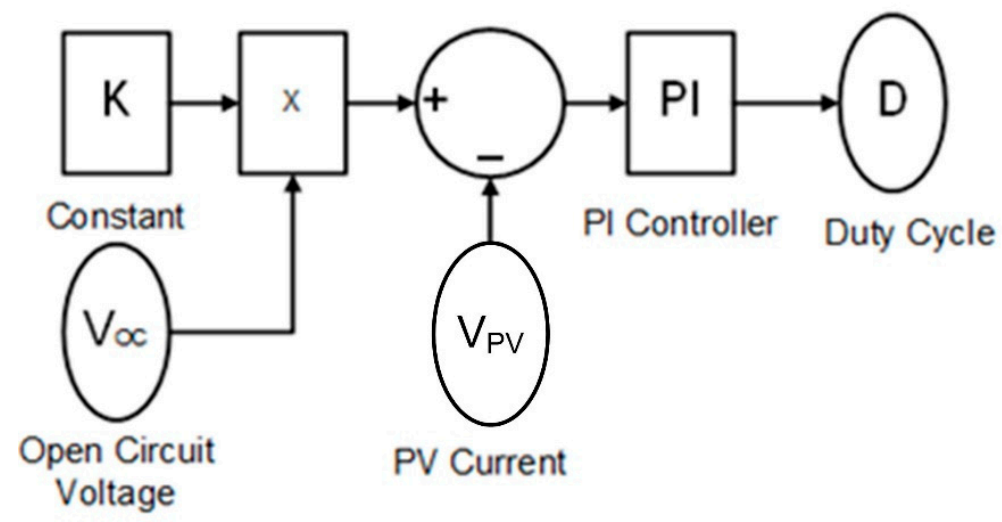

Figure 20. Block diagram of Fractional Open Circuit Voltage (FOCV).

\subsubsection{Perturb and Observe (PnO)}

The PnO technique is an extensively used technique for MPPT. The working principle of this technique is based on the hill-climbing mechanism. Initially, it measures the PV panel output power and then it perturbs the duty cycle of the DC-DC converter, which results in some variation in the output voltage and current and then new power will be calculated. Finally, it compares the new power with the previous power. If the new power is greater than the previous power, then it keeps on repeating the similar change in the duty cycle. However, when it reaches the peak of the hill, then the new power starts decreasing, and it reverses the perturbation process. Equations (21) and (22) illustrate the mathematical formula for $\mathrm{P} \& \mathrm{O}$ and Figure 21 shows the flow chart of $\mathrm{P} \& \mathrm{O}$ technique [74]. The overall performance of $\mathrm{P} \& \mathrm{O}$ algorithm degrades under partial shading conditions:

$$
\begin{aligned}
& V_{\text {new }}=V_{\text {prev }}-\Delta V P_{\text {new }}<P_{\text {prev }}, \\
& V_{\text {new }}=V_{\text {prev }}+\Delta V P_{\text {new }}>P_{\text {prev }},
\end{aligned}
$$

where $V_{\text {new }}$ is the new voltage and $d_{\text {prev }}$ is previous voltage. Similarly, $P_{\text {prev }}$ is the previous power and $P_{\text {new }}$ is a new power. However, $\Delta V$ is the achieved voltage change with the change in duty cycle at a step size $\Delta d$. 


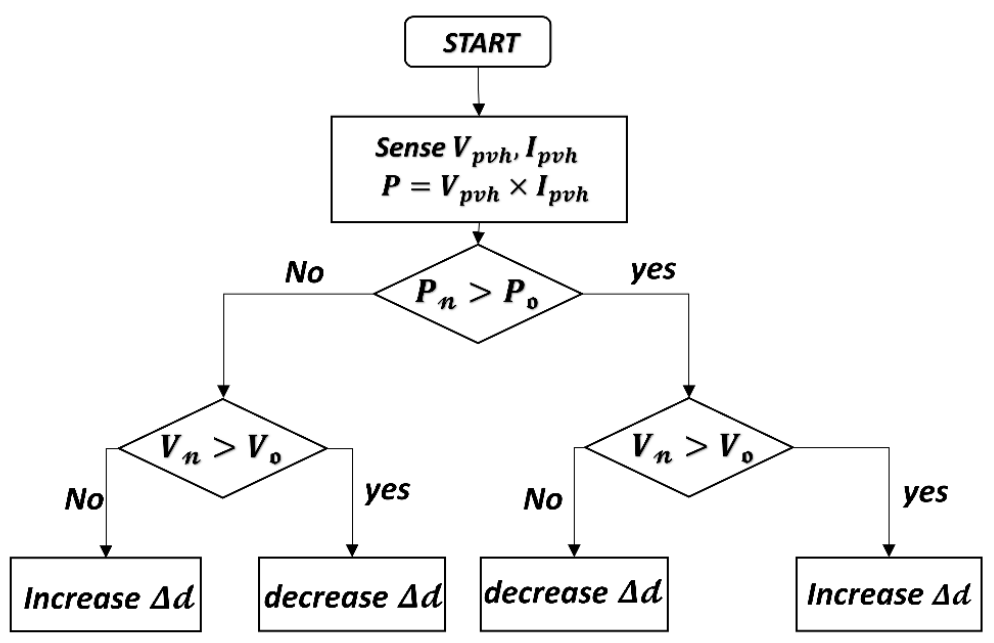

Figure 21. Flowchart of the Perturb and Observe (PnO)technique.

\subsubsection{Incremental Conductance (InC)}

The InC technique is widely used for MPPT applications because it is simple and more accurate than the P\&O technique. The working principle of $\mathrm{InC}$ is also based on the hill-climbing method. However, it calculates the incremental change in conductance by evaluating the effect of voltage change [7]. The conventional InC uses the slope of the P-V curve [51]. The slope P-V curve at MPP is zero; the slope is positive when MPP is on the right side and negative when MPP is on the left side. The controller injects a slight change in the duty cycle and observes the behavior of the conductance. The mathematical formulas for InC are shown in Equations (23)-(25). The flowchart of the whole algorithm is shown in Figure 22:

$$
\begin{gathered}
\frac{\Delta I}{\Delta V}>0, \mathrm{C}>\Delta C, \mathrm{~d}(k+1)=\mathrm{d}(\mathrm{k})-\Delta \mathrm{d}, \\
\frac{\Delta I}{\Delta V}>0, \mathrm{C}=\Delta \mathrm{C}, \mathrm{d}(k+1)=\mathrm{d}(\mathrm{k}), \\
\frac{\Delta I}{\Delta V}<0, \mathrm{C}>\Delta C, \mathrm{~d}(k+1)=\mathrm{d}(\mathrm{k})+\Delta \mathrm{d} .
\end{gathered}
$$

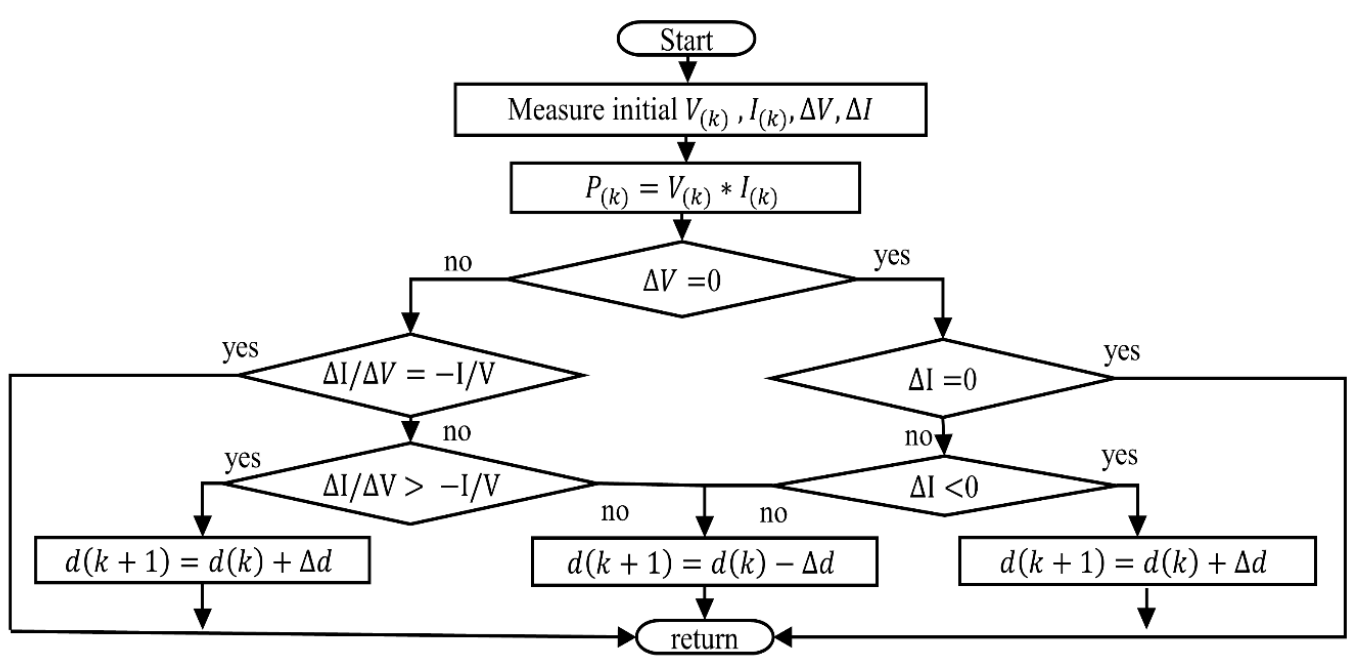

Figure 22. Flowchart for incremental conductance ( $\mathrm{InC})$. 


\section{Soft Computing Techniques for MPPT}

The conventional MPPT techniques are usually used for uniform irradiance conditions. However, for partial shading problems, soft computing techniques are used [75]. The robustness of these techniques is assessed in terms of its response time, tracking speed, efficiency, complexity, implementation cost, precision, and sensing elements required for its implementation [76]. Under uniform irradiance conditions, all techniques perform well. However, under partial shading conditions, their performance decrease [77,78]. Multiple peaks appear in the P-V curves during partial shading conditions. However, there is a single MPP that appears in each curve, which is known as global peak (GP) and remaining peaks are known as local peak (LP). Furthermore, in UIC, there is just one GP and no LP. However, under PSC, there are many LPs but only a single GP. The partial shading occurs due to multiple inevitable situations, such as the shadows of trees, buildings, birds or the dust, etc. $[60,79,80]$. Under partial shading, an MPPT algorithm is required to be efficient enough to detect the global maximum out of many local maxima [79]. In many cases, the PS problems become inescapable. For example, PV systems installed in Germany have almost 41\% partially shaded PV systems [81,82]. Numerous soft computing techniques have been developed to avoid PSC. The commonly used soft computing techniques for MPPT are based on artificial intelligence, fuzzy logic control and evolutionary algorithms like PSO, GA, DE, ACO, GWO, etc. Secondly, the overall performance of these techniques is good under partial shading conditions. Furthermore, these techniques work under the principle of evolution and use multiple iterations to find the optimum point $[83,84]$.

\subsection{Artificial Neural Network}

Artificial Neural network mimics a biological brain. Artificial Neural network (ANN) is the pioneer AI technique that is used to detect MPP of the PV systems. The fundamental models of ANN contain three layers, including an input layer, a hidden layer, and an output layer. Figure 23 shows the frequently used structure of ANN systems. Usually, ANN works on the bases of two essential processes named as training and testing. Initially, the neurons of the ANN system are trained based on some predefined weather conditions. After the training, it is expected that the algorithm will track the MPP of the PV array from any weather condition. The basic working principle of ANN is to use the key parameters of the PV array including open-circuit voltage, short-circuit current, temperature, and irradiance, as an input and the output is usually the duty cycle that can be used to manipulate the voltage or current of the PV array. However, in the training process, the weights are precisely computed in order to detect the exact MPP.

Recently, several techniques have been proposed to solve partial shading problems in the PV system. Mostly, ANN is used in combination with others for efficient performance. In [85], the gradient descent algorithm for training is used and the ANN technique is used for detecting MPP. Some researchers use ANN to improve the efficiency of $\mathrm{P} \& \mathrm{O}$ and InC under partial shading conditions such as [86] using a hybrid combination of ANN with $\mathrm{P} \& \mathrm{O}$, while, in $[87,88]$, the InC algorithm is improved by combining it with ANN to solve PSC. Similarly, fuzzy logic control (FLC) and ANN are combined in [89] to minimize fluctuation and improve stability. The majority of ANN algorithms [85-92] use backpropagation for training. Moreover, the accuracy of these systems with ANN is improved by increasing the number of hidden nodes, at the cost of increased computational complexity. ANN-based algorithms may not perform accurately in rapidly changing environmental conditions. Therefore, ANN-based algorithms are not suitable to be implemented on low-cost controllers. 


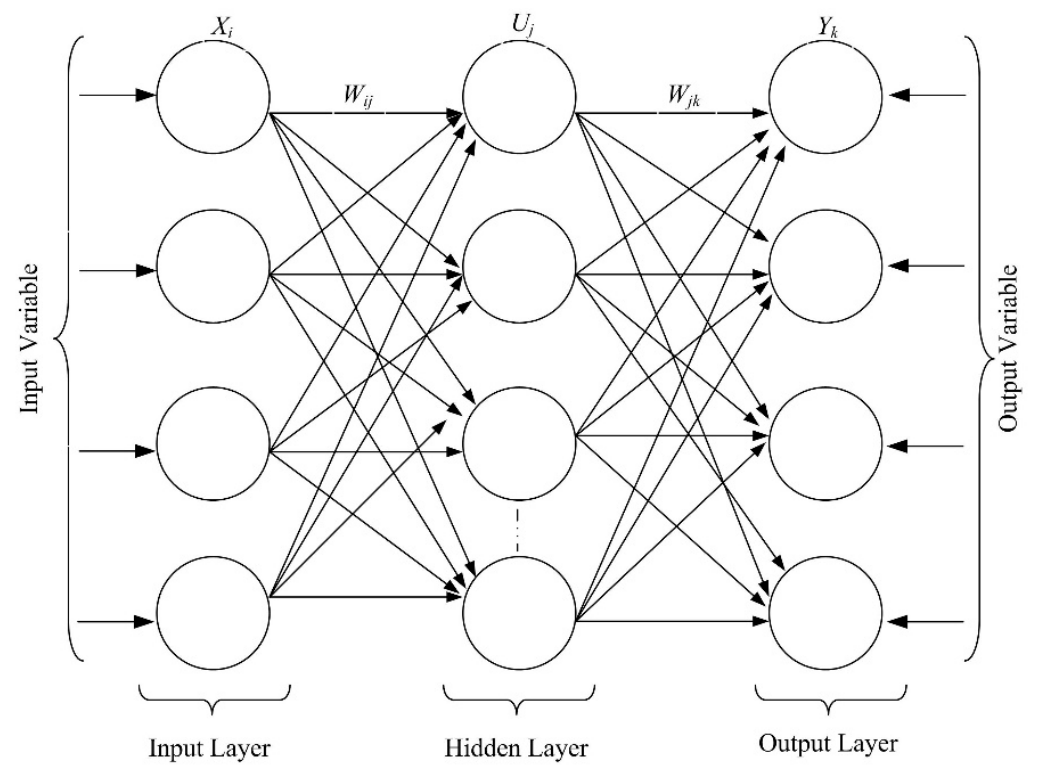

Figure 23. Artificial Neural Network (ANN) structure.

\subsection{Genetic Algorithm}

The Genetic algorithm (GA) was proposed by Holland in 1970 [93]. Its working principle is based on the theory of biological evolution, where the children with higher fitness value will have a higher chance to reproduce $[69,94-97]$. For the initial population, it randomly produces a parent's genes. After that, it uses parent genes to produce children genes based on the evolution process, like selection, crossover, and mutation, and computes fitness value. The best solution will be obtained based on the survival of the fittest by using some iteration. The main advantage of GA is that it does not require any derivative function. However, it is slow, especially when it is close to an optimum solution. Its computational complexity is high. Thus, a high-speed processor is required to implement this algorithm. The complete flowchart of GA is shown in Figure 24.

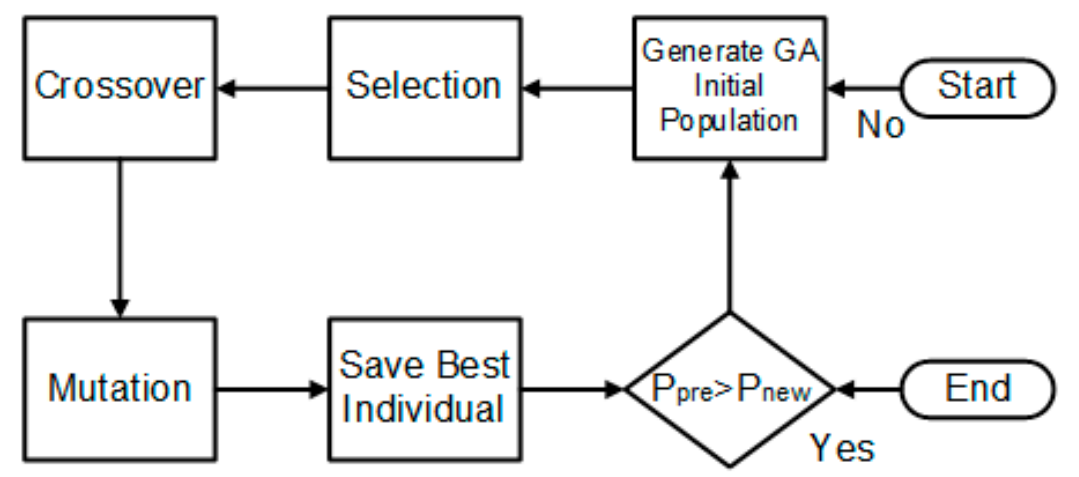

Figure 24. Flowchart of the genetic algorithm.

Initially, a set of chromosomes is defined to find an optimal solution from the search space. These chromosomes are either voltage or duty cycle in the MPPT problem. Usually, these chromosomes are encoded in the form of a binary code, while the fitness function is the PV equation. The chromosome population is dependent on the length of the binary code. A larger population will reduce convergence time but will increase the processing burden. Furthermore, the algorithm will perform the mutation and crossover to produce a new generation. The fitness function will evaluate the new generation, and a new fitness value would be assigned. This process repeats itself until the highest fitness value is achieved and that will be the MPP. Usually, a genetic algorithm is used to optimize ANN and FL 
techniques $[98,99]$. Both of these techniques show superior performance to classical P\&O but are complex and require high processing time. The authors in [100] proposed the MPPT method in which the $\mathrm{P} \& \mathrm{O}$ algorithm is integrated into the GA algorithm to create a single algorithm; by integrating $\mathrm{P} \& \mathrm{O}$ into GA, the population and number of iterations decreased, thus resulting in finding the global MPPT in less time. The efficiency of the proposed method is almost the same as of classical P\&O, but it can find the GMPP even in partial shading conditions that the classical method failed to track.

\subsection{Particle Swarm Optimization}

Particle Swarm Optimization (PSO) is a highly efficient optimization technique. Particle Swarm optimization is a stochastic based evolutionary technique used for the optimization problem. The design of this scheme is based on swarm intelligence. It is stimulated based on the social behavior of shoaling fish and flocking birds where each particle is a function of its position and velocity and attempts to follow the current best optimum solution. Initially, the particles are uniformly or randomly distributed in the state space. Each particle position is adjusted by using Equations (26) and (27). The details of the whole algorithm are shown in the flowchart in Figure 25:

$$
\begin{gathered}
x^{i+1}=x^{i}+\varphi^{k+1}, \\
\varphi^{k+1}=w^{k+1}+\varphi^{k}+C_{1} r_{1}\left(P_{\text {best }}-x^{k}\right)+C_{2} r_{2}\left(G_{\text {best }}-x^{k}\right) .
\end{gathered}
$$

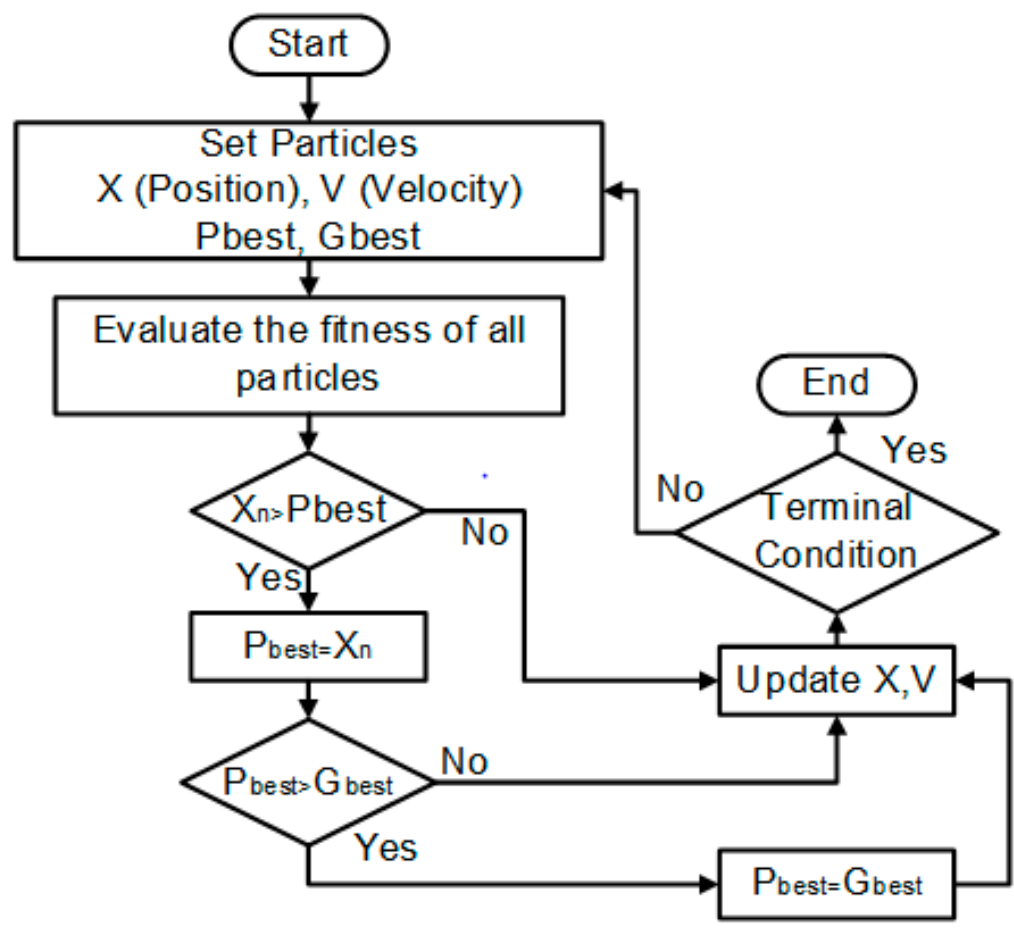

Figure 25. Flowchart of the particle swarm optimization (PSO) algorithm.

The swarm particles search in the space and identify the local best $\left(P_{\text {best }}\right)$ and global best $\left(G_{\text {best }}\right)$ by using Equations (26) and (27). For MPPT, the case position of the particle is defined as the duty cycle for the converter and its value is adjusted by using Equations (28) and (29) [101]. Equations (30) and (31) show the particle best and global best array, respectively. Thus, this technique may not yield desirable performance regarding the convergence speed and tracking ability to detect the optimal point:

$$
d_{k}^{i+1}=d_{k}^{i}-\Delta d_{k^{\prime}}^{i}
$$




$$
\begin{gathered}
\Delta d_{k}^{i+1}=\omega d_{k}^{i}+c_{1} r_{1}\left(P_{b e s t}-d_{k}^{i}\right)+c_{2} r_{2}\left(G_{b e s t}-d_{k}^{i}\right), \\
P_{\text {best }}=\left(P_{1}, P_{2}, P_{3}, P_{4}, P_{5} \ldots \ldots P_{i}\right), \\
G_{\text {best }}=\left(G_{1}, G_{2}, G_{3}, G_{4}, G_{5} \ldots \ldots G_{i}\right) .
\end{gathered}
$$

Authors in [102] proposed a PSO based MPPT technique whose main advantage is the elimination of PI control because of the direct duty cycle control method. The proposed technique overcomes the drawbacks of the conventional MPPT methods that cannot track GMMPT in partial shading conditions.

\subsection{Crow Search Algorithm Tuned MPPT Controller}

In [103], the authors designed a crow search algorithm (CSA) based MPPT controller used with a grid-connected PV system to tune the gains of associated controllers. The Incremental Conductance technique is used to track maximum power, and the controller is used to mitigate the limitations of Incremental Conductance based MPPT. In the proposed work, CSA is used to tune the gains of the integral controller at the power generation side and a DV voltage regulator at the other grid side to minimize power error at the power generation side.

Crows are thought to be most intelligent among all bird species. Crows predict unforeseen situations and have the ability of face recognition. Crows track and watch other crows to hide their food and track those places to steal. They communicate with each other in a systematic way to warn about some unfriendly approaches and can recall food hiding places even after long periods of time. Consider a flock of size $N$ and the position of a specified crow $i$ at the iteration $k$ in a $d$-dimensional space being indicated by $x^{i, k}=\left[x_{1}^{i, k}, x_{2}^{i, k}, \cdots, x_{d}^{i, k}\right]$. The best position achieved by a crow $i$ to hide its food can be indicated by $m^{i, k}$. Suppose that at iteration $k$ crow $j$ wants to go to its food hiding place and crow $i$ wants to follow it to its hiding place; then, the following two situations may happen:

Situation 1: if the crow $j$ does not know that crow $i$ is tracking it, then crow $i$ will track and find the food hiding place of crow $j$. In this situation, new place obtained by crow $i$ is as follows:

$$
x^{i, k+1}=x^{i, k}+r_{i} \times f l^{i, k} \times\left(m^{i, k}-x^{i, k}\right),
$$

where $f l^{i, k}$ is the flight length of the crow $I$ and $r_{i}$ is the uniform distribution random number between 0 and 1.

Situation 2: if crow $j$ knows that crow $i$ is tracking it, crow $j$, in order to protect its food from being stolen, will fool the crow $i$ and take it to another place in the search space. Both situations can be expressed as follows:

$$
x^{i, k+1}=\left\{\begin{array}{l}
x^{i, k}+r_{i} \times f l^{i, k} \times\left(m^{i, k}-x^{i, k}\right) r_{j} \geq A P^{i, k} \\
a \text { random position otherwise }
\end{array} .\right.
$$

$A P$ is called awareness probability. The algorithm searches in the local region if its value is taken to be small, and, if taken to be large, then the algorithm searches in a much larger global search space.

\subsection{An MPPT Method with Improved Gravitational Search Algorithm}

Authors in [104] proposed a method based on the improved gravitational search algorithm (IGSA). Classical GSA possesses some disadvantages and lacks the search capability in local search space and an effective acceleration mechanism. The proposed method exhibits good tracking speed as well as good tracking efficiency as compared to other MPPT methods.

The gravitational search algorithm (GSA) is based on the principle of gravity that a particle close to the optimum point has the largest mass. The particles move closer to the optimum point where its mass is also getting large. According to the law of gravity, the particles attract each other due to gravitational force and the larger the mass, the larger the gravitational force. The particles attract towards the particle with the largest mass and that particle is said to be at the optimum point. 
In the GSA, the initial population of particles is randomly generated in a $d$-dimensional search space, and the gravitational force between two particles is given as follows:

$$
F_{i j}^{d}(t)=G(t) \times \frac{M_{i}(t) \times M_{j}(t)}{R_{i j}(t)+\varepsilon} \times\left(x_{j}^{d}(t)-x_{i}^{d}(t)\right),
$$

where $d=1,2, \cdots D, G(t)$ is the gravitational constant at a specified time $t, M_{i}(t)$ and $M_{j}(t)$ are the inertial masses of the particles $i$ and $j, R_{i j}(t)$ defines the distance between particle $j$ and $i, \varepsilon$ is the small constant, and $x_{j}^{d}(t)$ and $x_{i}^{d}(t)$ are positions of particles $j$ and $i$, respectively.

Inertial mass $M_{i}(t)$ is defined by Equations (35) and (36):

$$
\begin{gathered}
m_{i}(t)=\frac{\operatorname{fitness}_{i}(t)-\operatorname{worst}(t)}{\operatorname{best}(t)-\operatorname{worst}(t)}, \\
M_{i}(t)=\frac{m_{i}(t)}{\sum_{j=1}^{N} m_{j}(t)},
\end{gathered}
$$

where $\operatorname{fitness}_{i}(t)$, best $(t)$, and worst $(t)$ are the fitness values of the $i$ th particle, and best and worst fitness values of all $N$ particles.

The gravitational constant is defined by Equation (37):

$$
G(t)=G_{0} \times e^{\left(-\alpha \times \frac{t}{T}\right)},
$$

where $G_{0}$ and $\alpha$ are the user defined parameters and $T$ is the total number of iterations.

The total force acting from other particles on the $i$ th particle is as expressed by Equation (38):

$$
F_{i}^{d}(t)=\sum_{j=1, j \neq i}^{N} \operatorname{rand}_{j} \times F_{i j}^{d}(t),
$$

where the Random number rand is from range [0, 1].

Acceleration of an $i$ th particle at a given time $t$ is as listed by Equation (39):

$$
a_{i}^{d}(t)=\frac{F_{i}^{d}(t)}{M_{i}(t)} .
$$

Finally, position and velocity of the $i$ th particle can be defined by Equations (40) and (41):

$$
\begin{gathered}
V_{i}^{d}(t+1)=\operatorname{rand}_{i} \times V_{i}^{d}(t)+a_{i}^{d}(t), \\
x_{i}^{d}(t+1)=x_{i}^{d}(t)+V_{i}^{d}(t+1) .
\end{gathered}
$$

$\alpha$ is a very important parameter in GSA directly impacting the global search mechanism that affects the convergence speed and precision. If its value is set too large, the convergence speed is high with low precision, and, if its value is set small, then its precision is high with slower convergence speed. Thus, the authors in [104] propose an $\alpha$ which takes on the values dynamically. If the particle is near optimum value, then the value of $\alpha$ becomes small, and, if the particle is far from the optimum point, then the value of $\alpha$ becomes large to converge faster.

Authors in [105] used GSA with the traditional P\&O method. PV curve is scanned through GSA and, afterward, the best-attained solution is transferred to $\mathrm{P} \& \mathrm{O}$. The hybrid method results in better tracking performance.

\subsection{Cauchy and Gaussian Sine Cosine Based MPPT Method}

Authors in [106] proposed a Cauchy and Gaussian Sine Cosine based MPPT method which is a hybrid Sine Cosine algorithm (SCA) with Cauchy density and Gaussian distribution function. SCO is 
used to create the initial population for which the mechanism of SCA tracks MPP. Cauchy density is used to improve exploration search ability to avoid getting trapped in local optima and for fast convergence to the global optimum point and Gaussian distribution function is used to improve the exploitation phase of the search mechanism.

Initially, SCA is used to create an initial population of track MPP through the sine cosine algorithm mechanism. For search space exploration and exploitation phases, expressions presented in Equation (42) are used:

$$
X_{i}^{k+1}=\left\{\begin{array}{l}
X_{i}^{k}+\alpha \times \sin (\beta) \times\left|\psi \times P_{i}^{k}-X_{i}^{k}\right| \varphi<0.5 \\
X_{i}^{k}+\alpha \times \cos (\beta) \times\left|\psi \times P_{i}^{k}-X_{i}^{k}\right| \varphi<0.5
\end{array} .\right.
$$

The sine and cosine range in the above equations can be defined by Equation (43) to balance the exploration and exploitation. Figure 26 shows populations trajectory path of SCA:

$$
\alpha=\lambda-k \times \frac{\lambda}{K} \mathrm{k} \forall \in K,
$$

where $X_{i}^{k}$ is the updated position of the $i$ th population in the $k+1$ th iteration. $P_{i}^{k}$ is the fitness function of corresponding $X_{i}^{k} . \psi, \varphi$, and $\beta$ are the random numbers. $K$ and $k$ are the total number of iterations and current iteration, respectively. To improve exploration searchability and exploitation phase of the search mechanism, CGF is incorporated in SCA in position updating. Cauchy density and Gaussian distribution are defined by Equations (44) and (45):

$$
\begin{gathered}
f_{c}(v)=\frac{1}{\pi} \frac{\gamma}{\gamma^{2}+\left(v-v^{2}\right)}, \\
f_{N}(v)=\frac{1}{\sqrt{2 \pi \sigma}} e^{\left[-(v-u)^{2} /\left(2 \sigma^{2}\right)\right]},
\end{gathered}
$$

where $N\left(u, \sigma^{2}\right)$ is a normal distribution with variance $\sigma^{2}$ and mean $u . V_{0}$ is the mean value for Cauchy distribution $\left(C\left(V_{0}, \gamma^{2}\right)\right)$. This work focuses on the single sensor (current) based MPPT to improve the lead-acid battery charging. In a lead-acid battery, $90 \%$ to $95 \%$ of the voltage remains constant at any state of charge. Thus, by this method, the charging power and duty cycle has been estimated to maximize the power as power is the function of the current. Due to only a single sensor in use, the cost of the MPPT system is less as well as due to less computational burden this method can be implemented on a less expensive microcontroller.

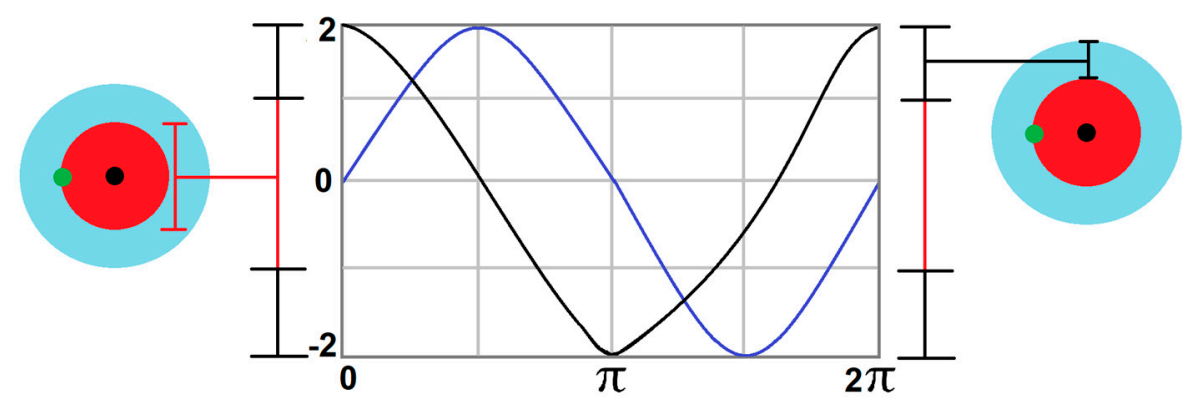

Figure 26. Trajectory path of population of SCA [106].

\subsection{Human Psychology Optimization Algorithm Based MPPT Method}

In [107], the authors proposed a single sensor-based technique based on the novel Human optimization psychology (HPO) algorithm that is based on the mental states and psychology of an ambitious person. HPO is used to track MPP from PV panels to efficiently charge a lead-acid battery. The proposed work is a highly efficient, quick, and single sensor-based technique. The proposed 
technique is compared with other recently developed state-of-the-art MPPT techniques, hybrid P\&O-PSO, and Lagrange interpolation with PSO (POPSO and LIPSO) on uniform as well as partial shading conditions using MATLAB (version, Manufacturer, City, US State abbrev. if applicable, Country) and a developed hardware platform. The proposed technique is found to be quick, requires less computational burden because only one sensor is being used, and has an efficient battery charging technique.

\subsection{Hybrid JayaDe Algorithm Based MPPT}

In [108], the authors proposed a hybrid method of "Jaya" and "Differential evolution" known as JayaDe for MPP tracking of PV systems. The proposed method is tested on MATLAB as well as a developed hardware platform with other state-of-the-art recently developed techniques (ACO-P\&O, FPA, and PSO) in uniform and partial shading environmental conditions are the same temperature and irradiance, have the same hardware conditions, and are found to be better than others.

\subsubsection{JayaDe Optimization}

The Jaya (Sanskrit word, meaning victory) technique works on the best solution by avoiding the worst solutions which come in searching the path in very few steps. Suppose at any iteration $k$ there are $i$ number of design variables and $J$ number of population or candidate solutions. Candidate best and worst obtained the best and worst values, respectively. $X_{i, j}^{k}$ is the value of the $i$ th variable for the $j$ th candidate, then the variable updates itself on the basis of past worst and best solutions. The equation for solution updating is given by Equation (46):

$$
X_{i, j}^{k+1}=X_{i, j}^{k}+\operatorname{rand}_{1} \times\left(X_{i, b e s t}^{k}-\left|X_{i, j}^{k}\right|\right)-\operatorname{rand}_{2} \times\left(X_{i, \text { worst }}^{k}-\left|X_{i, j}^{k}\right|\right),
$$

where $X_{i, b e s t}^{k}$ and $X_{i, w o r s t}^{k}$ are the values of variable $i$ for the best and worst candidates during the $k$ th iteration. The final selection process is represented by Equation (47):

$$
X_{i, j}^{k+1}=\left\{\begin{array}{l}
X_{i, j^{\prime}}^{k} \text { if } f\left(X_{i, j}^{k}\right)>f\left(X_{i, j}^{k+1}\right) \\
X_{i, j}^{k+1}, \text { Otherwise }
\end{array} .\right.
$$

\subsubsection{Differential Evolution}

$\mathrm{DE}$ is a global search algorithm and the proposed technique to improve the performance of Jaya algorithm by pulling all population candidates toward the MPP. DE selects three solution candidates $X_{j 1}(k), X_{j 2}(k)$, and $X_{j 3}(k)$ from the population of the Jaya and passes on through the mechanism of the $\mathrm{DE}$ algorithm. DE mechanism consists of three steps: mutation, crossover and selection. Jaya pushes all solutions away from the worst values and DE pulls the solutions of Jaya toward the global solution as well as the mutation operator closely observing the movements and very perfectly updating the final solutions.

\subsection{Flower Pollination Algorithm (FPA) Based MPPT}

The authors in [109] proposed a novel method based on a new flower pollination algorithm developed by Xie Yang. Pollination is a process in which pollen from one species of the flowers transfers to the other species. New flower species depend on the pollination process and the flowers involved in it. Transfer of pollens within the same species is referred to as self-pollination and transfer of pollens between different flower species is referred to as cross-pollination. Flowers adapt different methods to spread pollen grains-one of which is the abiotic method in which pollens are transferred through winds and the second one is the biotic which involves insects, birds, and animals to spare pollen grains. Transfer of pollens in cross-pollination observed levy flights because they have to travel long distances. 
The main goal of the flower pollination is the survival of the fittest as per the biological evolution point. The following are the main rules and steps that are involved in the development of FPA:

1 Biotic and cross-pollination is categorized as the global pollination process where pollens take a levy flight to transfer to other followers. Global pollination is defined by Equation (48):

$$
\begin{gathered}
x_{i}^{t+1}=x_{i}^{t}+\gamma L(\lambda)\left(g_{\text {best }}-x_{i}^{t}\right), \\
L(\lambda)=\frac{\lambda \Gamma(\lambda) \sin (\pi \lambda / 2)}{\pi} \frac{1}{S^{1+\lambda}}\left(S>>S_{0}>0\right) .
\end{gathered}
$$

$L(\lambda)$ shown in Equation (49) is the levy distribution that helps to increase the strength of the pollination and is responsible for the transfer of the pollens to greater distances. $\gamma$ is the scaling factor to control step size and $\Gamma(\lambda)$ is the standard gamma function.

2 The abiotic and self-pollination process is categorized as local pollination and is defined by Equation (50):

$$
x_{i}^{t+1}=x_{i}^{t}+\varepsilon\left(x_{k}^{t}-x_{j}^{t}\right)
$$

where $x_{k}^{t}$ and $x_{j}^{t}$ are the pollens from the same species. $\varepsilon$ is used for local search between [0, 1].

3 Pollinators are attributed to creating flower constancy and the reproduction probability of new species will improve the similarity of flowers involved in pollination.

4 Probability switch $P \in[0,1]$ controls the switching between local and global pollination and is found to be 0.8 in most of the cases.

FPA is well suitable for nonlinear optimization problems such as the output of the PV systems because it involves two stages of calculation of the control variable i.e., global and local pollination. No other optimization algorithm has the mechanism of dual search in a single-stage process. The FPA method is compared with PSO and P\&O methods to verify its superiority over other methods using simulation and hardware experimental results under different environmental conditions.

\subsection{Ant Colony Optimization (ACO) Based MPPT}

In [110], authors proposed an ACO based MPPT technique. ACO is an optimization technique based on the foraging behavior of ants in real-time. An ant colony is a swarm of ants and can be used for solving the optimization problems that can be expressed as finding good paths through graphs. Ants move randomly leaving pheromone trails behind and try to find the shortest path between the food source and its nest. As the ants on the shortest path leave the pheromone faster than other ants, it gets rapidly reinforced with more pheromones and becomes appealing for future ants. Longer paths' pheromone trails evaporate. If an ant finds the shortest path, the other ants are more likely to follow that path.

The authors compare ACO with PSO using a MATLAB/Simulink environment and found out that ACO is more efficient than PSO.

Authors in [111] proposed a hybrid ACO with conventional P\&O. This technique successfully merged $\mathrm{ACO}$ for global search and $\mathrm{P} \& \mathrm{O}$ for local search to improve overall tracking time and efficiency.

\subsection{Shuffled Frog Leap Algorithm (SFLA) Based MPPT}

SFLA, a new metaheuristic population-based evolutionary technique, is an embodiment of a memetic approach and PSO algorithm. It has the advantage of fast-tracking speed, few parameters, a simple concept, and good global searching ability. Each frog represents a solution to the problem in SLFA and the whole frog pollution is divided into small groups called meme groups and each group has the ability to locate a food source that is affected by other groups [112].

The authors in [113] proposed an SLFA based MPPT technique for finding global maxima under partial shading conditions. The proposed technique was benchmarked with other well-known MPPT 
techniques like DE, PSO and P\&O. Results of SLFA were found to be better in performance than other techniques in terms of efficiency, convergence, oscillations, and response.

\subsection{Glowworm Swarm Optimization (GSO) Based MPPT}

Glowworm swarm optimization is a bionic algorithm inspired from a natural phenomenon in which glowworms exchange information with their peers about searching for food. The GSO attributed excellent performance in finding the optimal solution. The GSO has been proposed in the [114] as the optimization algorithm to track and extract maximum power from PV-T systems under the non-uniform irradiation and thermal distribution. GSO uses glowworms with a luminescent quantity called luciferin as their agents. A flowchart of the GSO is depicted in Figure 27.

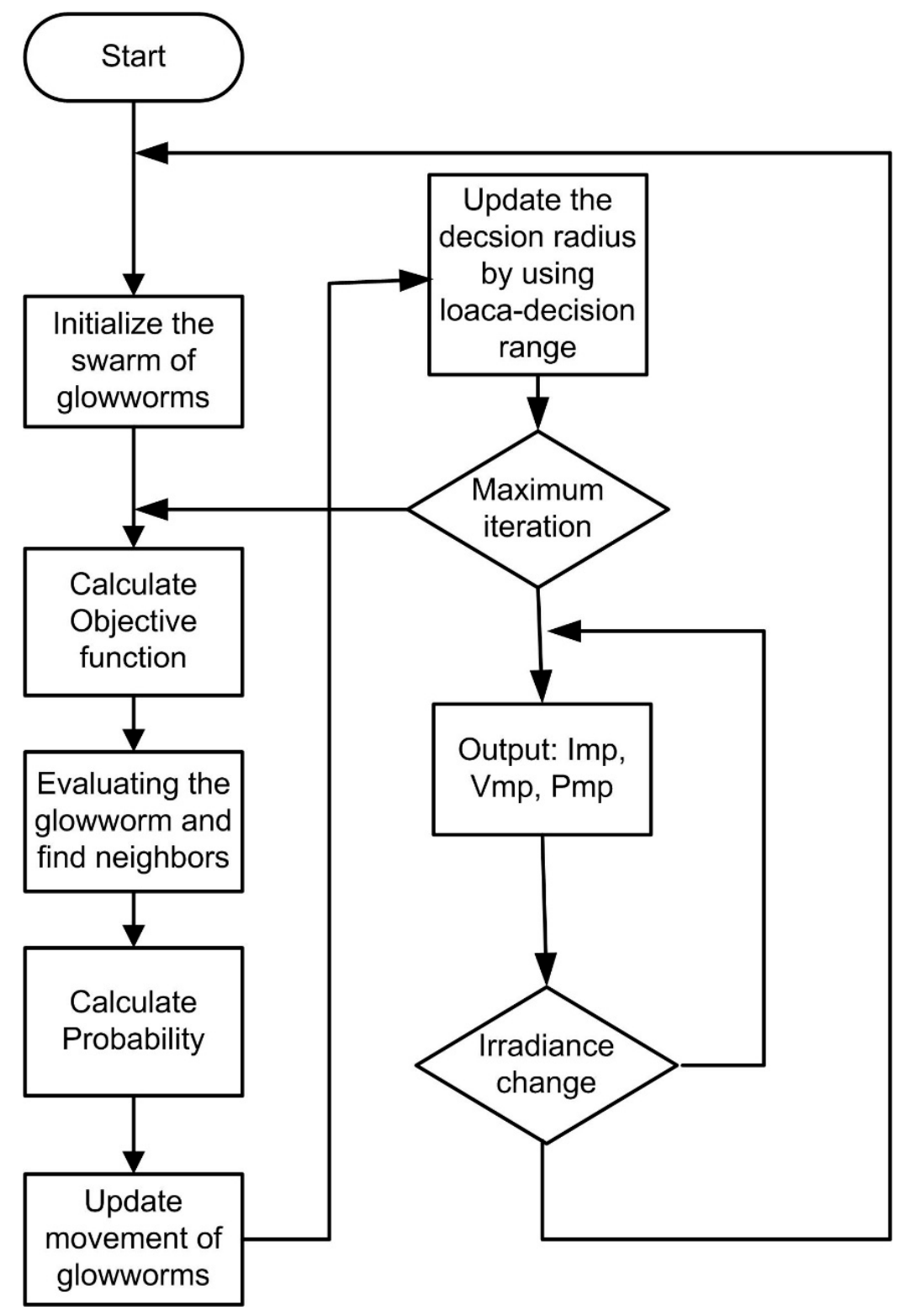

Figure 27. The flowchart of the Glowworm Swarm Optimization (GSO) algorithm.

Luciferin Update Phase: The luciferin carried by glowworms depends on the objective function value of the current position and is updated by Equation (51):

$$
I_{i}(t+1)=(1-\rho) \times I_{i}(t)+\gamma * F\left(x_{i}(t+1)\right),
$$


where $\rho$ represents the luciferin decay constant, $\gamma$ is the luciferin enhancement constant, $I_{i}(t)$ is luciferin at iteration $\mathrm{t}$, and $F\left(x_{i}(t+1)\right)$ is the objective function.

Movement Phase: Each glowworm moves towards better individuals and the probability that agent $i$ is moving towards agent $j$ is expressed by Equation (52):

$$
p_{i j}=\frac{I_{j}(t)-I_{i}(t)}{\sum_{m \in N_{i}(t)} I_{m}(t)-I_{i}(t)} .
$$

$N_{i}(t)$ shown in Equation (53) represents the neighbor agent of the agent $i$ :

$$
N_{i}(t)=\left\{j: d_{i, j}(t)<r_{d^{\prime}}^{i} I_{i}(t)<I_{j}(t)\right\} .
$$

$d_{i, j}(t)$ represents the Euclidean distance between glowworms $i$ and $j . r_{d}^{i}$ is the range of the glowworm $i$ at time $t$.

Glowworms are attracted and move towards the neighbor that has the larger luciferin quantity and glows brighter. The movement update rule is as follows:

$$
x_{i}(t+1)=x_{i}(t)+s^{*}\left(\frac{x_{j}(t)-x_{i}(t)}{\left\|x_{j}(t)-x_{i}(t)\right\|}\right),
$$

where $s$ is the step size.

\subsection{MPPT Using Model Predictive Control}

The study presented in [115] is an efficient MPPT technique of a PV system by using model predictive control (MPC) that is applied to the DC-DC converter. The stochastic nature and high variability of solar energy affect PV output and require that the MPPT technique constantly tracks maximum power and adjusts the power converter duty cycle. The major contribution of the proposed method is a model predictive based controller with a fixed step size combined with a conventional incremental conductance (INC) technique. Figure 28 shows the flowchart of the proposed technique. This technique enhances tracking speed significantly at which the controller can track MPPT in rapidly changing environmental conditions resulting in efficiency improvement of the PV system. 


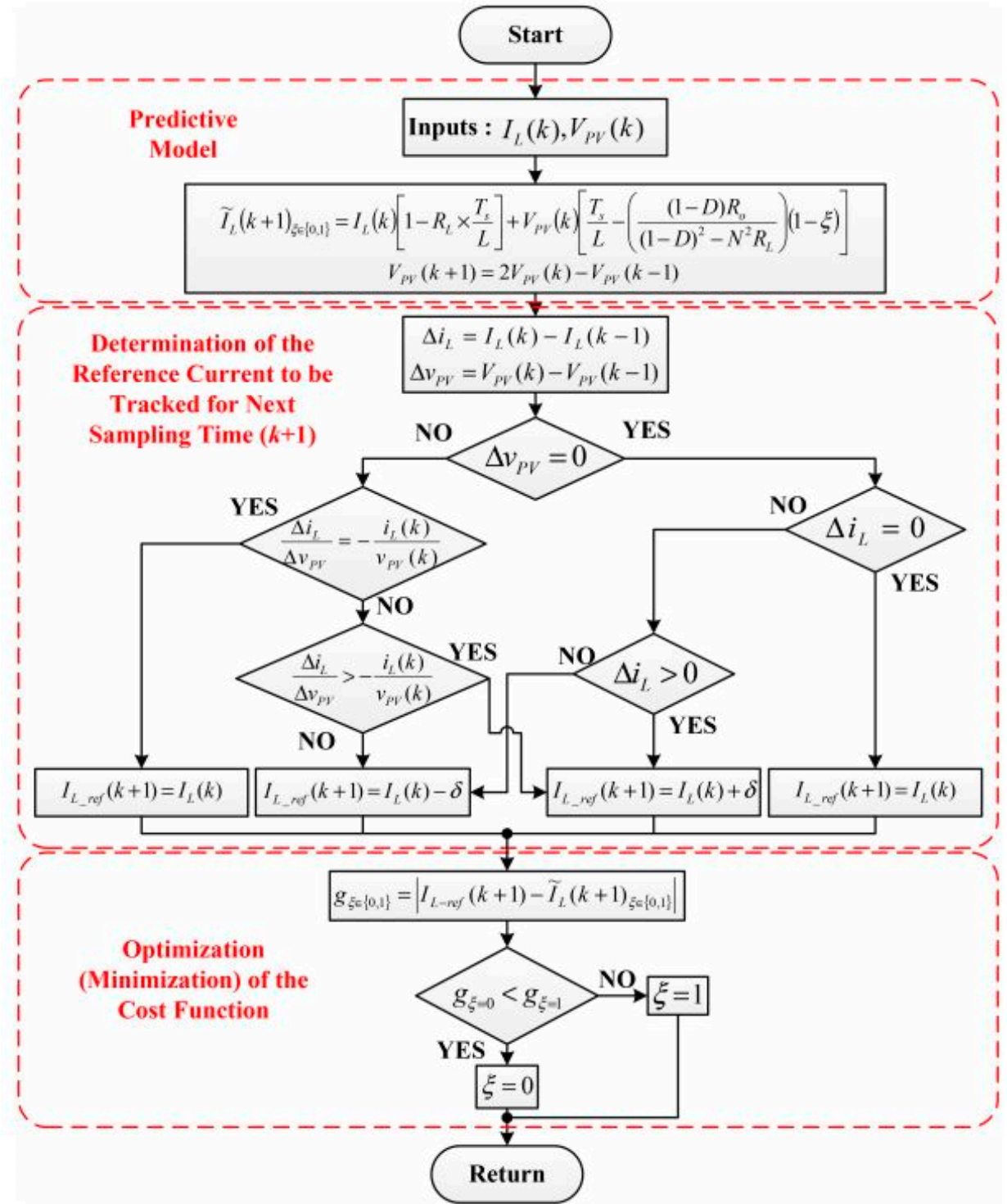

Figure 28. Flowchart of Model Predictive Control (MPC) based MPPT.

\subsection{Whale Optimization Algorithm (WOA) Based MPPT}

Authors in [116] proposed an MPPT technique based on a Whale Optimization Algorithm (WOA) inspired from the humpback whales hunting strategy of bubble-net feed. The humpback whale has the unique feeding technique of spiral bubble-net feeding. These whales create bubbles in a spiral-like movement around the prey to eat schools of krills and fish on the surface. Their movement can be mathematically modeled by Equations (55) and (56):

$$
\begin{gathered}
\vec{D}=\left|\vec{C} \cdot X^{*}(k)-\vec{X}(k)\right|, \\
\vec{X}(k+1)=X^{*}(k)-\vec{A} \cdot \vec{D},
\end{gathered}
$$

where $A, C$, and $D$ are the coefficient vectors, $X^{*}$ is the optimum solution and updates if a better solution is obtained, $k$ is the current iteration, and $X$ is the current position vector of the whales. $A$ and $C$ can be calculated by Equations (57) and (58):

$$
\vec{A}=2 \vec{a} \cdot \vec{r}-\vec{a},
$$




$$
\vec{C}=2 \cdot \vec{r}
$$

$r$ is the random vector between $[0,1]$, a linear decrease from 2 to 0 as iterations move on $X^{*}$ is the optimum solution with knowledge of the prey. A flowchart describing detailed methodology WOA based MPPT is shown in Figure 29. The proposed technique is tested on 6S, 3S2P and 2S3P PV configuration under dynamic and partial shading environmental conditions and benchmarked with GWO and PSO techniques. Results clearly showed its superiority over other techniques with respect to accuracy and tracking speed. The authors in [117] introduce a whale optimization with differential evolution technique (WODE) based MPPT method for rapidly changing environmental conditions and PSC. The WODE technique is good for fast convergence as well as oscillation free tracking of GMPP. It has some unique advantages over other techniques such as fast convergence, less steady-state oscillation, and less computational burden.

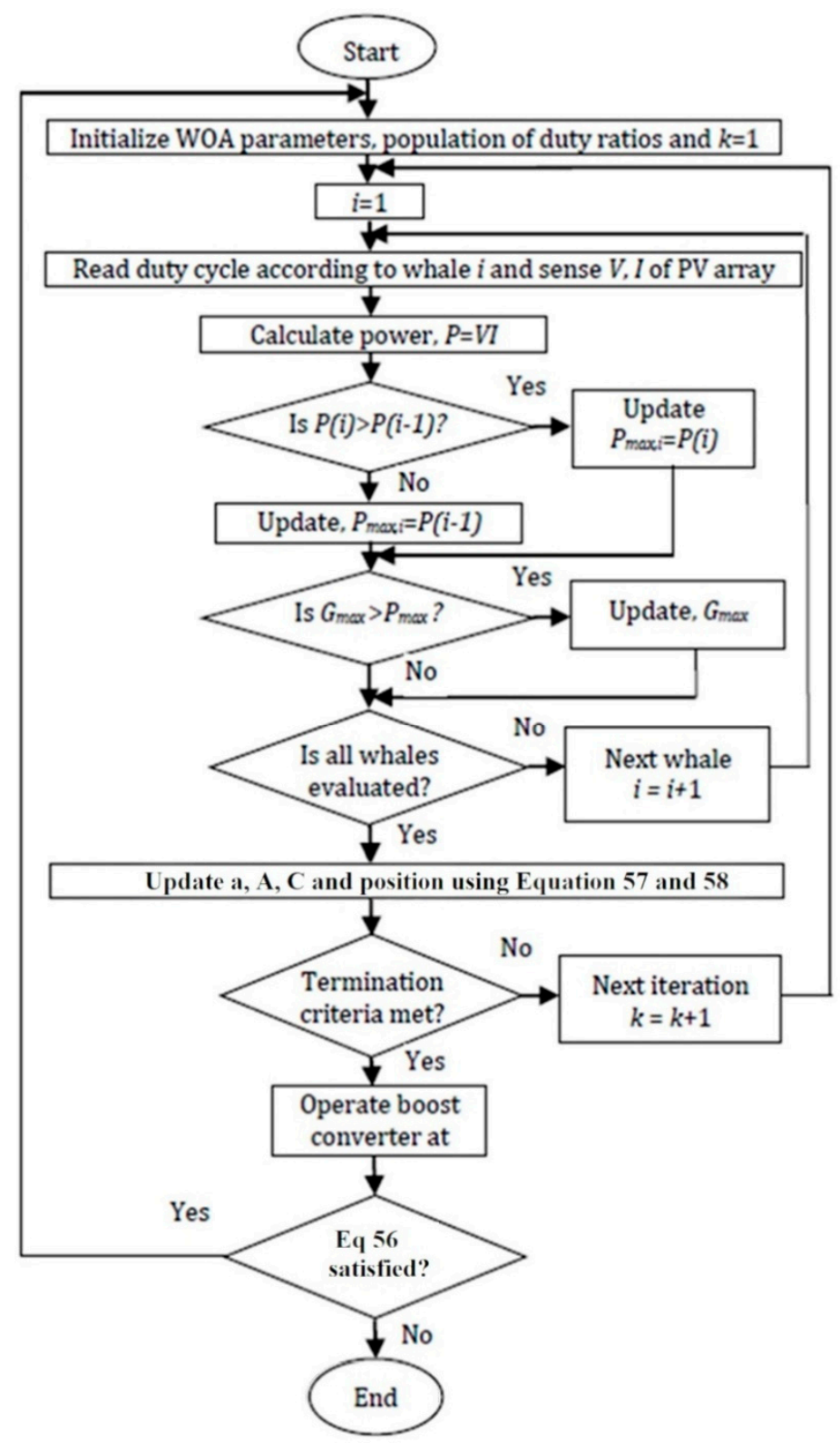

Figure 29. Flowchart of Whale Optimization Algorithm (WOA) based MPPT. 


\subsection{Grey Wolf Optimization (GWO) Based MPPT}

Authors in [118] proposed a tracking technique under a partially shaded environment based on the Grey Wolf Optimization (GWO) algorithm which replicates the hunting behavior and mechanism and leadership hierarchy of grey wolves in nature. Grey wolves love to live in a pack and hunt together. To simulate leadership and social hierarchy in GWO, four types of grey wolves are employed, namely alpha $(\alpha)$, beta $(\beta)$, delta $(\delta)$, and omega $(\omega)$. Fittest, second best, and third best solutions are considered as the alpha $(\alpha)$, beta $(\beta)$, and delta $(\delta)$, respectively, while the rest of the population is considered as omega $(\omega)$. There are three main steps of algorithms, namely chasing and tracking of prey, encircling, and attacking prey.

Grey wolves encircle a prey to attack, and this behavior can be expressed by Equations (59) and (60):

$$
\begin{gathered}
\vec{D}=\left|\vec{C} \cdot \vec{X}_{p}(t)-\vec{X}_{p}(t)\right|, \\
\vec{X}(t+1)=\vec{X}_{p}(t)-\vec{A} \cdot \vec{D},
\end{gathered}
$$

where $t$ is the current iteration, $A, C$, and $D$ denote the coefficient vectors, $X_{p}$ and $X$ denote the prey position vector and grey wolf position vector, respectively. $A$ and $C$ vectors are calculated by Equations (61) and (62):

$$
\begin{gathered}
\vec{A}=2 \vec{a} \cdot \overrightarrow{r_{1}}-\vec{a}, \\
C \stackrel{\vec{C}}{=} 2 \cdot \vec{r}_{2,}
\end{gathered}
$$

where $a$ linearly decreases from 2 to 0 as the iterations move on, and $r_{1}, r_{2}$ are the random number between $[0,1]$. Alpha usually guides the hunt followed by beta and delta which also occasionally take part in the hunting process. Alpha is referred to as the best candidate solution because it has the best knowledge of the prey location. Delta and omega take care of the wounded wolves. Wolves finish the process by attacking when the prey stops moving.

To assess the effectiveness of the proposed technique, its performance is benchmarked with $\mathrm{P} \& \mathrm{O}$ and IPSO based MPPT techniques and, from the results, it was found that the GWO based technique shows superior performance to other MPPT methods. Table 2 shows the performance comparison of the proposed technique with other techniques.

Table 2. Performance comparison of the proposed technique with other techniques.

\begin{tabular}{ccccccc}
\hline $\begin{array}{c}\text { Shading } \\
\text { Pattern }\end{array}$ & $\begin{array}{c}\text { Maximum } \\
\text { Power from } \\
\text { P-V Curve (W) }\end{array}$ & $\begin{array}{c}\text { Tracking } \\
\text { Technique }\end{array}$ & $\begin{array}{c}\text { Maximum } \\
\text { Power (W) }\end{array}$ & $\begin{array}{c}\text { Maximum } \\
\text { Voltage (v) }\end{array}$ & $\begin{array}{c}\text { Maximum } \\
\text { Current (I) }\end{array}$ & $\begin{array}{c}\text { \% Tracking } \\
\text { Efficiency }\end{array}$ \\
\hline \multirow{2}{*}{1} & \multirow{2}{*}{320} & P\&O & 100.2 & 24.2 & 4.14 & 31.30 \\
& & IPSO & 319.2 & 110.52 & 2.888 & 99.75 \\
& & GWO & 319.4 & 110.55 & 2.889 & 99.81 \\
\hline \multirow{2}{*}{2} & \multirow{2}{*}{330} & P\&O & 180 & 23.07 & 7.80 & 54.54 \\
& & IPSO & 329.5 & 112.3 & 2.934 & 99.84 \\
& & GWO & 329.6 & 112.3 & 2.934 & 99.87 \\
\hline
\end{tabular}

\subsection{BAT Algorithm Based MPPT}

The bat algorithm is a newly developed metaheuristic algorithm based on the echolocation phenomenon of the microbats to locate their foods [119]. Small bats or microbats usually feed on insects and locate them using echolocation. The distance and direction of the prey are determined by the direction and intensity of the returned signal from the prey. The bat emits the ultrasonic pulses of a specific rate and amplitude. It receives the feedback pulses and pulses by the other bats in the swarm in between its transmitting pulses by echolocation and decodes them. If the feedback pulses 
have a low amplitude and strong rate, then it is very likely that the prey is located, and the bat should move in the same direction. By approaching the prey, the bat gradually increases the rate of pulses and reduces the amplitude.

The bat algorithm is developed by idealizing characteristics of the echolocation of the microbats. This algorithm has a swarm of $N$ microbats, randomly flies at the position of $x_{i}$ with velocity of $v_{i}$, amplitude $A_{i}$ and pulse rate $\mathrm{r}_{\mathrm{i}} \in[0,1]$ depending on the proximity of the prey. Every bat is uniformly assigned a frequency from $\left[f_{\min }, f_{\max }\right]$ and position and velocity are updated with respect to Equations (63)-(65):

$$
\begin{gathered}
f_{i}=\text { fminmax }_{\min }, \\
v_{i}^{t+1}=v_{i}^{t}+\left(x_{i}^{t}-x_{*}\right) f_{i}, \\
x_{i}^{t+1}=x_{i}^{t}+v_{i}^{t+1},
\end{gathered}
$$

where $\beta \in[0,1]$ is a uniformly distributed random vector and $x_{*}$ is the global best position which is updated by comparing all the $N$ bats at each iteration.

In the exploitation phase, the new best solution is generated using Equation (66):

$$
x_{\text {new }}=x_{*}+\varepsilon A^{t},
$$

where $\varepsilon$ is random number from $[-1,1]$ or Gaussian distribution and $A^{t}$ is average loudness. Loudness decreases and pulse rate decreases as the bat moves towards the global optimal position.

Loudness $A_{i}$ and pulse rate $r_{i}$ is updated by Equations (67) and (68):

$$
\begin{gathered}
A_{i}^{t+1}=\alpha A_{i}^{t}, \\
r_{i}^{t+1}=R_{i}[1-\exp (-\gamma t)],
\end{gathered}
$$

where $\alpha$ is a constant in the range of $[0,1]$ and $\gamma$ is a positive constant.

It is shown in [119] that BA has high accuracy and quick convergence because of its dynamic and automatic switching between exploration and exploitation. The proposed technique is compared with other techniques like P\&O and PSO and shows its superiority in tracking GMPP in under dynamic and partial shaded conditions. In most cases, it achieves $99.9 \%$ efficiency and results were verified through practical implementation. The bat algorithm has also been implemented and tested [120] and shows that the proposed method is an efficient, faster, sustainable, and reliable method.

\subsection{Symbiotic Organism Search Algorithm Based MPPT}

Authors in [121] propose a new metaheuristic Symbiotic Organisms Search (SOS) optimization technique for tracking the MPP under dynamic and partial shaded environmental conditions. One of the main advantages of this technique is that it does not have a tuning parameter like other soft computing techniques. The proposed technique was implemented using MATLAB/Simulink platform under different irradiance and temperatures. The proposed technique is compared with $\mathrm{P} \& \mathrm{O}$, and results show its superiority in terms of tracking speed, tracking accuracy, and efficiency.

\subsection{Random Forest (RF) Based MPPT}

Authors in [122] proposed a new random forest-based MPPT technique to enhance the maximum power tracking performance of the PV systems. The RF model has the ability to capture the nonlinear association of patterns between predictors, such as irradiance and temperature, to determine accurate MPP. In this study, a random forest algorithm based MPPT is designed using the MATLAB/Simulink platform and then its accuracy and dynamic response are tested and validated under actual environmental conditions. The RF-based MPPT model is also benchmarked with ANN and ANFIS for further validation. The proposed MPPT technique is found to be superior over other techniques. 
In addition, the RF model passes the Bland-Altman test, with more than 95 percent acceptability. The decision tree for regression, classification is shown in Figure 30.

\section{Random Forest Simplified}

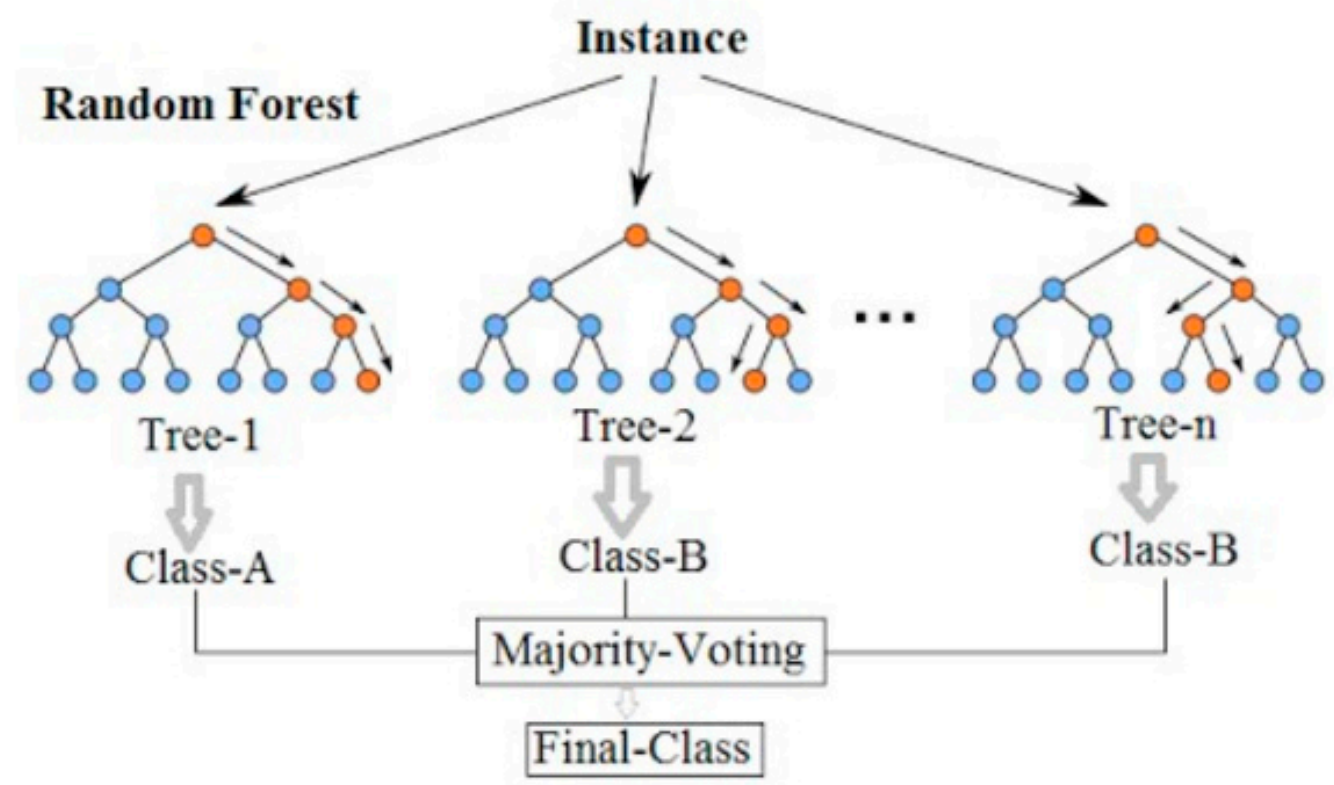

Figure 30. Random forest algorithm [122].

\subsection{Artificial Bee Colony Based MPPT}

Artificial bee colony $(\mathrm{ABC})$ is a new population-based metaheuristic algorithm developed to solve multimodal and multidimensional optimization problems simulating the foraging behavior of honeybee colonies. Artificial bees can be categorized into three groups: employed bees, onlooker bees, and scouts. Bees that are on the search for food sources are employed bees and those which are waiting in the hives to choose food sources are the onlooker bees. Scouts are those employed bees whose food sources cannot be improved through a predetermined trial. The number of food sources are equal to the number of employed and onlooker bees. The position and nectar of the food source represent the solution and value of fitness function of the optimization problem, respectively.

$\mathrm{ABC}$ randomly produces an initial population of $\mathrm{SN}$ solutions by Equation (69):

$$
x_{i}^{j}=x_{\min }^{j}+\operatorname{rand}[0,1]\left(x_{\max }^{j}-x_{\min }^{j}\right),
$$

where $i=\{1,2, \cdots, S N\}, j=\{1,2, \cdots, D\}$ and $x_{\max }^{j}, x_{\min }^{j}$ and $D$ are the maximum and minimum of the parameter $j$ and number of optimization parameters, respectively. For each cycle $C=1,2, \cdots, M C N$, every employed bee produces a new solution according to the following equation and evaluate its fitness $f i t_{i}$ :

$$
v_{i j}=x_{i j}+\phi_{i j}\left(x_{i j}-x_{k j}\right),
$$

where $k \in\{1,2, \cdots, S N\}, j \in\{1,2, \cdots, D\}$ and $\phi_{i j} \in[-1,1]$.

Employed bees shared the information and then onlookers found the new positions with the probability given in Equation (71):

$$
P_{i}=\frac{f_{i t_{i}}}{\sum_{n=1}^{S N} f i t_{n}} .
$$

The fitness function of each new candidate is compared with the old one and, if it is better than the old one, then it is updated in the memory; otherwise, the old solution is retained. If the fitness of 
a solution cannot be improved at the end of each cycle, then the new solution is randomly searched using Equation (70). The flowchart of the $\mathrm{ABC}$ based MPPT technique is shown in Figure 31. The ABC based MPPT technique is proposed in [123]. The proposed technique is a simple and robust technique that successfully overcomes the problems associated with conventional MPPT techniques. Results showed that the proposed technique has better performance than PSO based MPPT. Furthermore, it only requires two control parameters and its convergence is independent from the initial conditions.

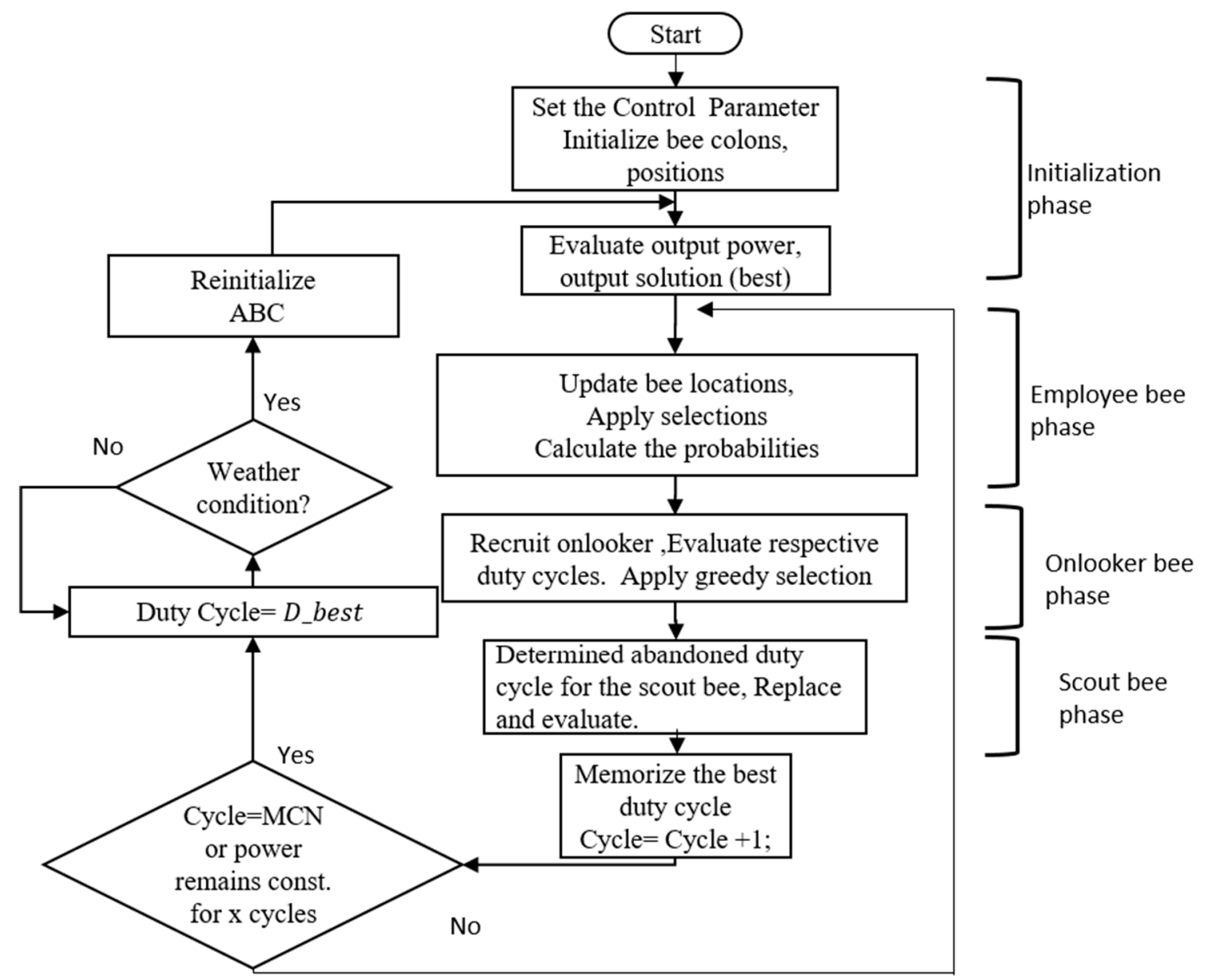

Figure 31. Flowchart of the Artificial Bee Colony (ABC) based MPPT Algorithm [123].

\subsection{Simulated Annealing}

Simulated Annealing (SA) is a powerful optimization technique motivated by annealing phenomenon in metals for strengthening the solids. If you heat a metal up to its melting point and then cool it, the structural properties of the metal depend on its cooling rate. If melted metal is cooled quickly, it will contain imperfections and, if cooled slowly, large crystals will be formed [124].

In the SA algorithm, the annealing process of the metals is simulated based on the initial and final temperatures and cooling rate. The algorithm performs multiple perturbations in the voltage by changing the duty cycle and measuring output power. The new power is compared with the previous power. If the new power has less energy than the reference operating energy point, then it will be accepted, deepening on the acceptance probability. The acceptance probability is shown in Equation (72):

$$
P_{r}=\exp \left[\frac{P_{k}-P_{i}}{T_{k}}\right]
$$


$P_{k}, P_{i}$, and $T_{k}$ is the power at the current voltage, power at the last best operating point, and current temperature, respectively. The SA algorithm requires a cooling schedule that may be either static or adaptive. The common geometric cooling schedule is given by Equation (73), where $T_{k}$ and $T_{k-1}$ are the temperature for step for $k, k-1$ respectively and $\alpha<1$ is some constant:

$$
T_{k}=\alpha T_{k-1} .
$$

After four perturbations, the temperature value is updated, and the author implements the inhomogeneous SA. In inhomogeneous SA, equilibrium is not required at each temperature level. The SA algorithm is shown in Figure 32.

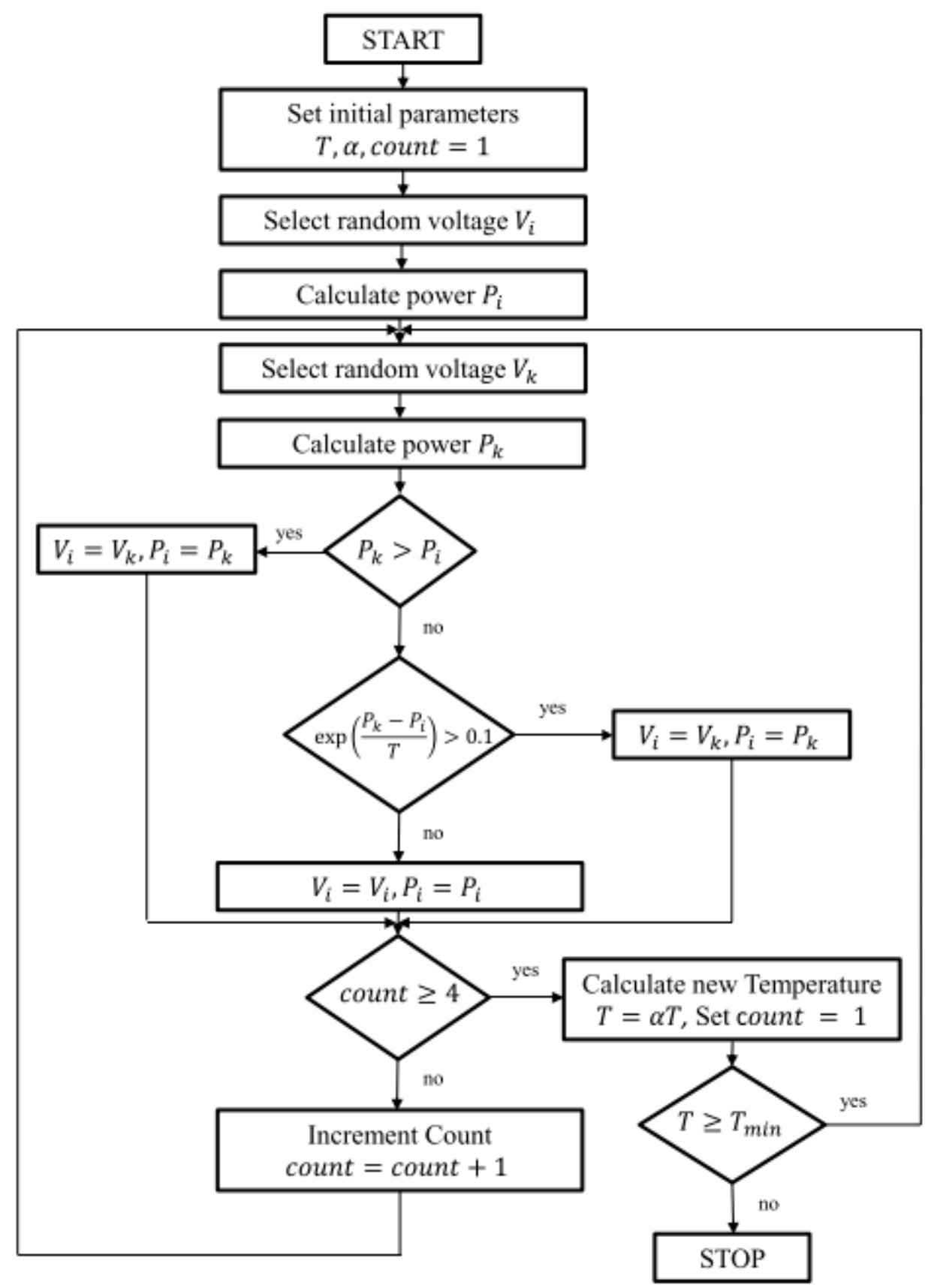

Figure 32. Flowchart of the proposed Simulated Annealing (SA) based MPPT technique. 


\subsection{Fireworks Algorithm Based MPPT}

The fireworks algorithm (FWA) is an intelligent metaheuristic optimization algorithm based on intelligent behavior of swarms. FWA simulates the fireworks explosions in the night sky to find an optimal solution. In FWA, in the search space, initially a number of fireworks are generated, and a stochastic explosion process is started for each firework. A shower of parks is generated and filled the local space surrounding the exploded fireworks in the result of fireworks explosion. The newly generated sparks and fireworks both are the potential solutions of the problem in the search space. For efficiently searching the global optimal point in the search space, the algorithm uses the explosion sparks produced by an explosion operator and Gaussian mutation sparks by the Gaussian mutation operator. A proper balance between the exploration and exploitation process is the main feature of this algorithm. Exploration is the ability of the algorithm to search for a big region for the global optimum solution, and exploitation refers to the process to search for a smaller region to avoid big jumps and refine the solution. Gaussian mutation sparks are generated to enhance the local search capability as well as to ensure the diversity of the swarm. Figure 33 shows the flowchart of FWA.

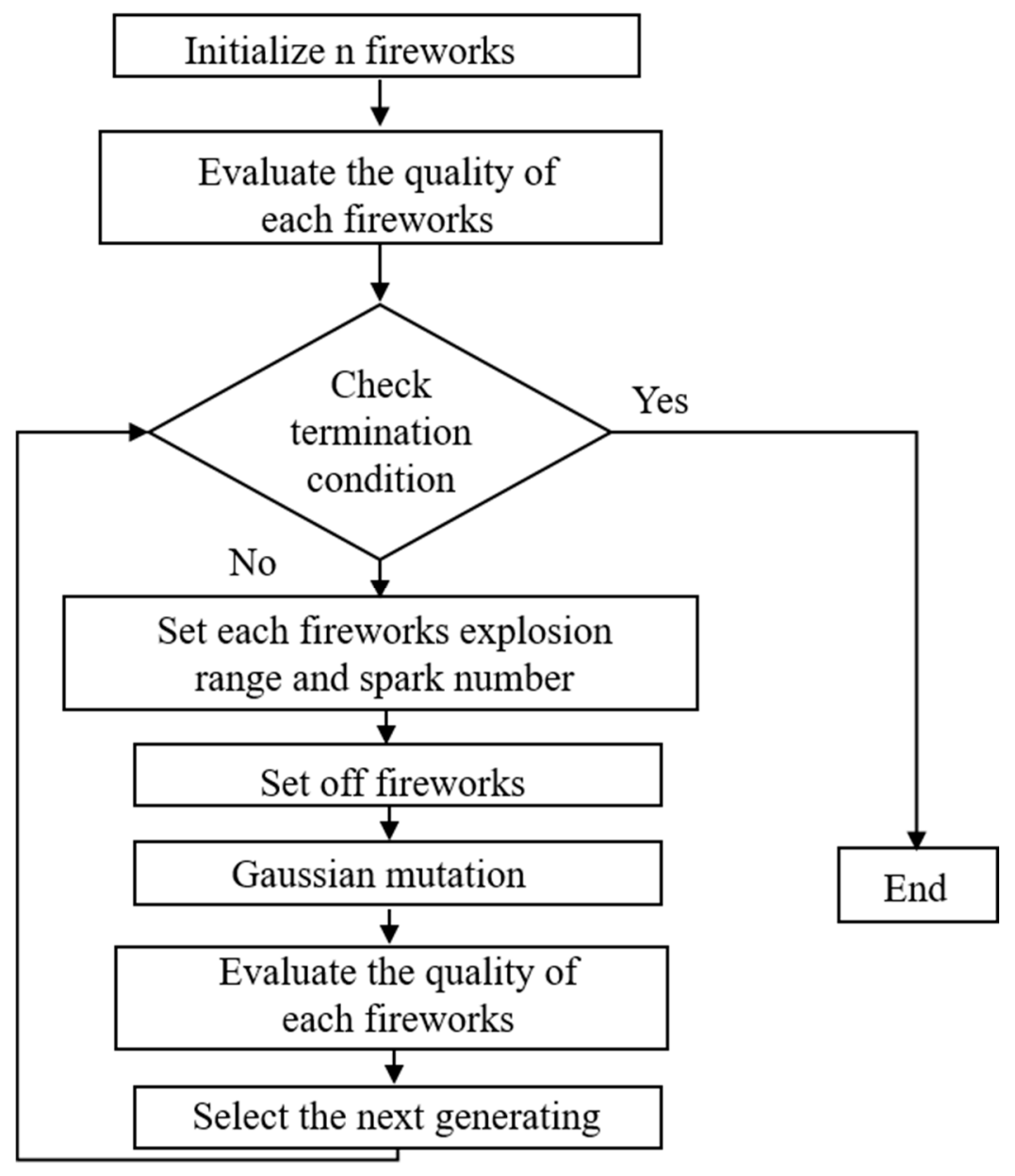

Figure 33. Flowchart of the Fireworks Algorithm.

\subsection{Dragon Fly Algorithm Based MPPT}

Dragon fly (DF) is a swarm intelligence-based algorithm in order to deal with nonlinear problems. The movement of the swarm is classified as static and dynamic. A swarm of a few DF in a small locality searching for food is classified as the static swarm. Their movement is constrained to small jumps that imitate the exploitation of search space [125]. 
To explore search space, if there are many DF moves in a specific direction, it is said to be dynamic swarm imitating exploration. It forms the basic structure of the Dragon Fly Algorithm (DFA). Mathematical modeling of DF swarm is done by characterizing five unique features of swarms. For $i$ number of individuals, surrounded by $N$ number of neighbors, the Separation which gives the distance between adjacent DF to avoid collision and maximize search space is $S_{i}$ of the $i$ th individual given by Equation (74):

$$
S_{i}=-\sum_{K=1}^{N}\left(X-X_{k}\right),
$$

where the location of individual particle DF is represented by $X$ and, for the $k$ th position, it would be $X_{k}$.

Alignment: For matching the velocities of moving DF exhibiting synchronization given by Equation (75):

$$
A_{i}=\frac{\sum_{k=1}^{N} V_{k}}{N}
$$

where $V_{k}$ is the velocity of the $k$ th individual.

Cohesion: All the particles tend to move to the midpoint of neighborhood mass. The cohesion $\mathrm{C} i$ is shown in the Equation (76):

$$
C_{i}=\frac{\sum_{k=1}^{N} X_{k}}{N}-X
$$

Food Attraction at location $X_{\text {Food }}$ is shown by Equation (77) where Individuals tend to move towards food:

$$
F_{i}=X_{\text {Food }}-X
$$

Enemy: Individual particle tends to detach from the enemy. Enemy location $X_{\text {enemy }}$ is shown by Equation (78):

$$
E_{i}=X_{\text {enemy }}+X .
$$

Combining the effects of these five traits, the final upgraded location of individual particle DF is given by Equation (79):

$$
X_{i}=X_{i}+\Delta X_{i}
$$

where the mathematical formula of $\Delta X_{i}$ is shown in Equation (80):

$$
\Delta X_{i}=\left(s S_{i}+\alpha A_{i}+c C_{i}+f F_{i}+e E_{i}\right)+w \Delta X_{i} .
$$

The explanation of all symbols of Equation (80) is given in Table 3. The stepwise procedure of implementing DFA algorithm implemented by [126] is shown in Table 4. Figure 34 demonstrates the flowchart of the DFA algorithm.

Table 3. The symbols of Equation (80).

\begin{tabular}{cc}
\hline Symbol & Acronym \\
\hline $\mathrm{s}$ & Separation weight \\
$\mathrm{S}_{\mathrm{i}}$ & Separation of ith Dragon Fly \\
$\mathrm{a}$ & Alignment weight \\
$\mathrm{A}_{\mathrm{i}}$ & Alignment of ith Dragon Fly \\
$\mathrm{c}$ & Cohesion weight \\
$\mathrm{C}_{\mathrm{i}}$ & Cohesion of ith Dragon Fly \\
$\mathrm{f}$ & Food factor \\
$\mathrm{F}_{\mathrm{i}}$ & Food attraction \\
$\mathrm{e}$ & Enemy factor \\
$\mathrm{E}_{\mathrm{i}}$ & Enemy position \\
$\mathrm{w}$ & Inertial weight \\
$\Delta \mathrm{X}_{\mathrm{i}}$ & Step size of Dragon Fly movement \\
\hline
\end{tabular}


Table 4. Stepwise implementation of DFA with description.

\begin{tabular}{|c|c|c|}
\hline Sequence & Calculation & Description/Purpose \\
\hline Step 1 & initialization & $\begin{array}{l}\text { In first step population is initialized in search } \\
\text { space }\left(D_{\min }-D_{\max }\right)\end{array}$ \\
\hline Step 2 & Step size calculation & the values of step size is initialized. \\
\hline Step 3 & Power calculation & $\begin{array}{c}\text { Power of each DF calculated by respective duty cycle to } \\
\text { determine best output power and enemy factor }\end{array}$ \\
\hline Step 4 & Weights assigned & Values of $\mathrm{s}, \mathrm{a}, \mathrm{c}, \mathrm{f}$, and e are assigned. \\
\hline Step 5 & $\begin{array}{l}\text { Individual DF characters } \\
\text { calculated }\end{array}$ & $\begin{array}{c}\text { Values of } S_{i}, A_{i}, C_{i}, F_{i}, E_{i} \text { are calculated using } \\
\text { Equations }(75)-(80)\end{array}$ \\
\hline Step 6 & Neighbor Radius & Neighbor radius is updated for exploitation/exploration \\
\hline Step 7 & $\begin{array}{l}\text { Position of DF updated (change in } \\
\text { duty-cycle) }\end{array}$ & $\begin{array}{l}\text { Position of DF are updated by eq. } 23 \text { and if it lies outside the } \\
\text { search limits, DF are initiated at opposite boundary. } \\
\text { If the termination conditions are met, exit algorithm. }\end{array}$ \\
\hline Step 8 & Check termination & $\begin{array}{l}\text { (Termination condition } 5 \% \text { change is Steady State power for } \\
\text { certain amount of time) }\end{array}$ \\
\hline Step 9 & restart & An abrupt change in input power. \\
\hline
\end{tabular}

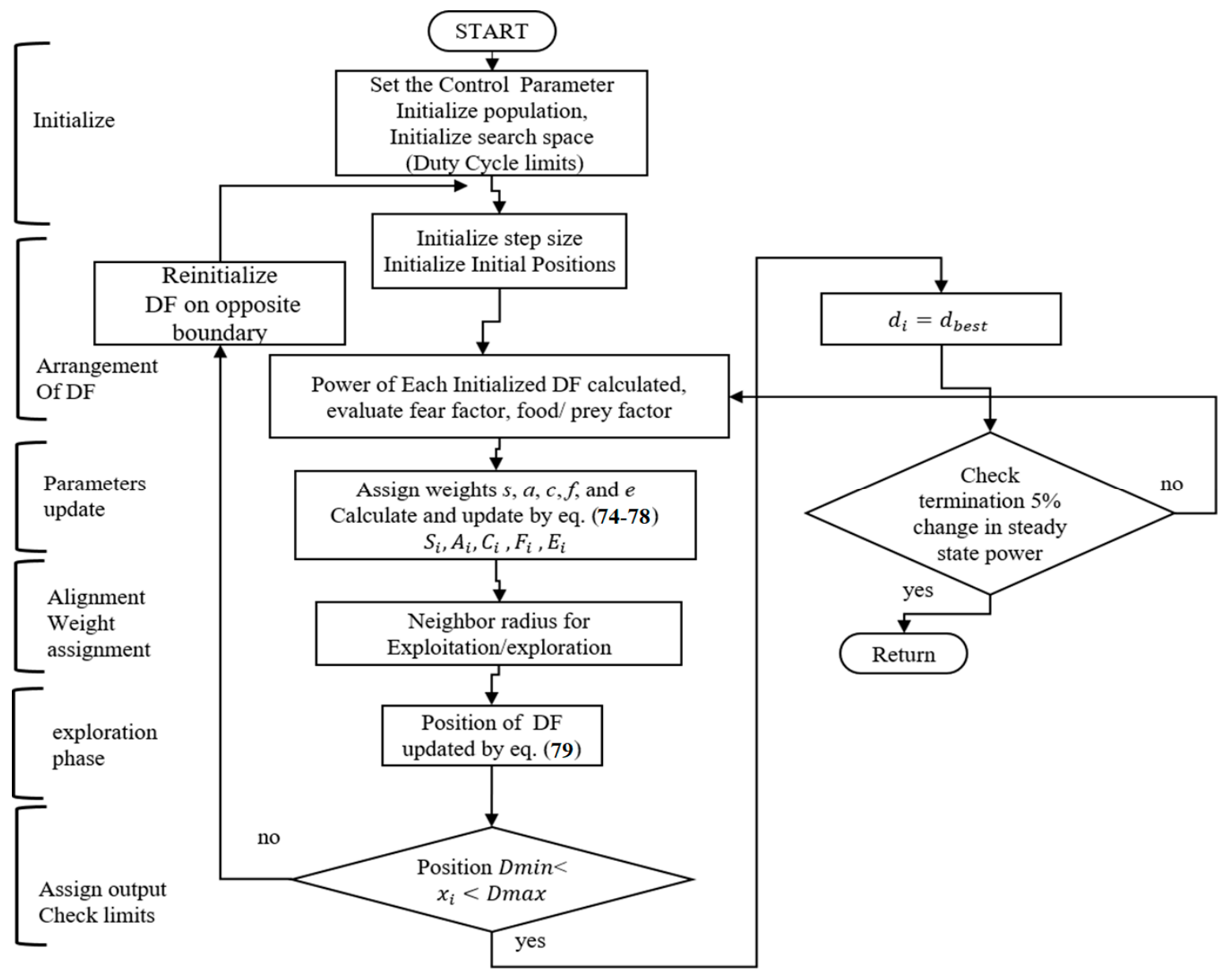

Figure 34. Flowchart of the Dragon Fly (DF) algorithm [125].

\subsection{Cuckoo Search Algorithm Based MPPT}

The cuckoo search (CS) is an algorithm that is developed on the aggressive reproduction behavior of the cuckoo bird. CS was implemented on MPPT by [77,127]. The strategy of the cuckoo bird is imitated in the form of optimization. The cuckoo bird pursues finding the nest of a host bird, to lay eggs in time favorable for earlier hatching, and new cuckoo bird chicks destroyed the eggs of the 
host bird to increase the accessibility more food and better-quality survival. The major benefit of this algorithm is its rapid convergence speed, accuracy, and required minimum parameter tuning.

The mathematical model known as Lévy flight is utilized for searching for the host nest. Usually, swamp intelligence is used for the search-space in which single-particle move in space with some velocity and direction random function. To put a check on the rate of displacement, a weight $\mathrm{w}$ is associated, which limits and characterizes a moving particle. Furthermore, CS applies the Lévy flight function which uses random step sizes that are extracted by distribution according to power law given by Equation (81):

$$
y=l^{-\lambda}
$$

where 1 is the length of flight and variance is represented by $\lambda$. However, the value of $\lambda$ is between 1 and 3. The new generation is represented by $x^{(t+1)}$ as shown in Equation (82). $\alpha$ is used for initial step change:

$$
x_{i}^{(t+1)}=x_{j}^{t}+\alpha \oplus \operatorname{Levg}(\lambda),
$$

where $\alpha$ is calculated by Equation (83):

$$
\alpha=\alpha_{0}\left(x_{j}^{t}+x_{i}^{t}\right)
$$

\subsection{Adoptive Cuckoo Search Algorithm for MPPT}

To improve the convergence efficiency of the cukoo's method, an adaptive cuckoo search algorithm is proposed by the researchers in $[125,128]$. The flow chart of this Adoptive Cuckoo Search Algorithm (ACCO) is shown in Figure 35. In this technique, the fixed switching parameters of the cuckoo search algorithm are frequently updated in order to remove the unwanted glitches in power and voltage outputs.

The switching parameter to linearly increase its values as CS iterations increase is defined by Equation (84):

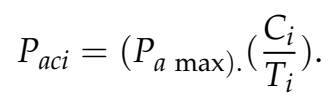

The switching parameter to increase exponentially with respect to increase in iterations is given by Equation (85):

$$
P_{a c i}=\left(P_{a \max )} \operatorname{Exp}\left(\frac{C_{i}}{T_{i}}\right) .\right.
$$

In addition, to represent the switching parameter that uses cubic power, Equation (86) is provided:

$$
P_{a c i}=\left(P_{a \max }\right) \cdot\left(\frac{C_{i}}{T_{i}}\right)^{3} \text {. }
$$

The fitness function (J) is the value of PV power at MPP, where $D$ is the duty cycle and $n$ is the number of samples. Voltage Samples generated based on Lévy distribution are given by Equations (87) and (88):

where

$$
\begin{aligned}
D_{i}^{(t+1)} & =D_{i}^{t}+\alpha \oplus \operatorname{Levy}(\lambda), \\
\alpha & =\alpha_{o}\left(d_{\text {best }}-d_{i}\right) .
\end{aligned}
$$




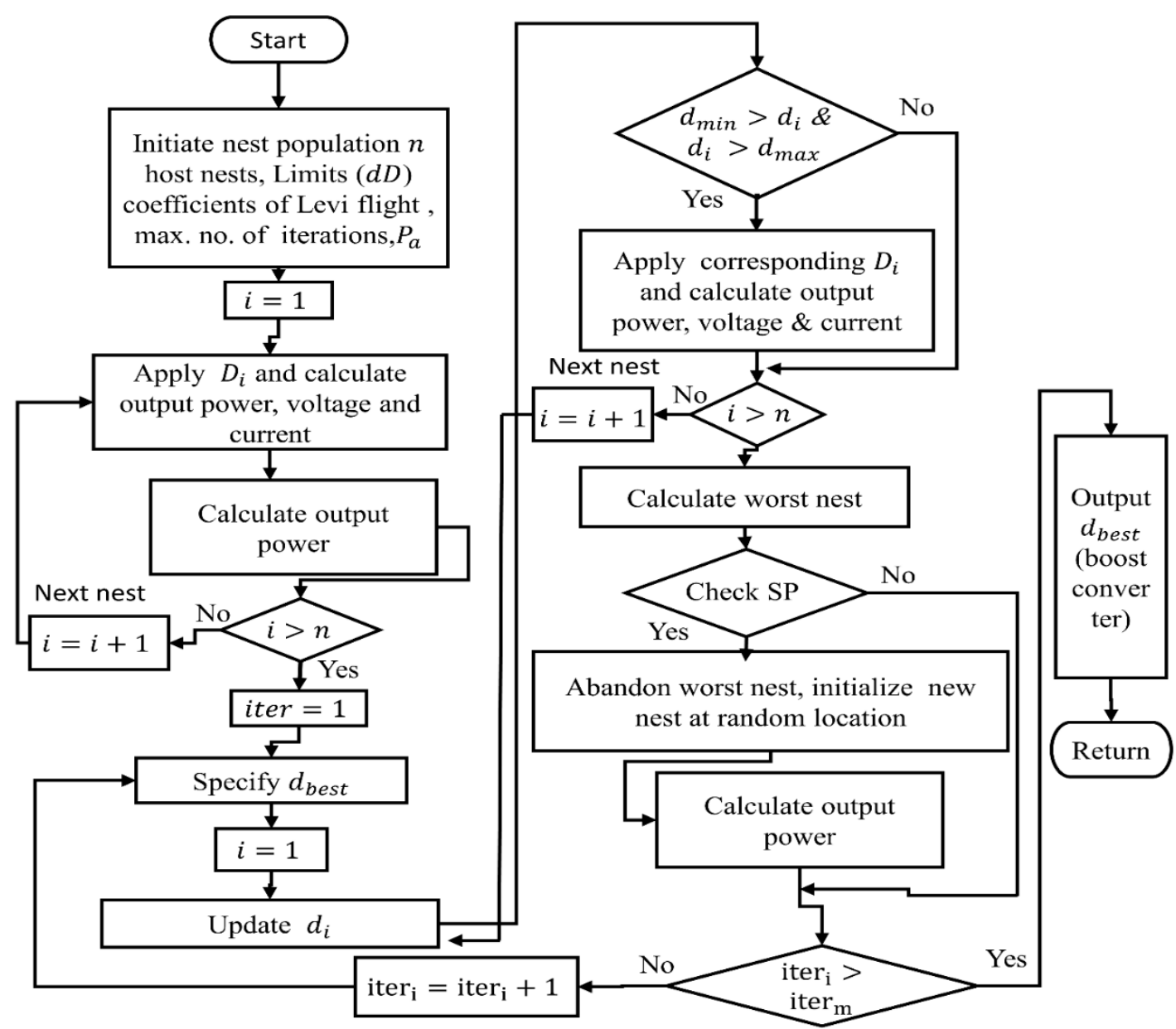

Figure 35. Flowchart presentation of the proposed Adoptive Cuckoo Search Algorithm (ACOA) based MPPT control for the PV system.

\subsection{Particle Swarm Optimization Gravitational Search (PSOGS) Based MPPT}

Particle swamp optimization is a bio-inspired model for the optimization of problems in which the collective intelligence of identical individuals is utilized to maximize the efficiency of operation. In PSO, particle swamp optimization particles are associated to be a flock of birds. Each particle with individual direction and velocity is initialized in a search space. Search space is confined mathematically and contains the best possible solution. In every iteration, the best position and direction are updated to the neighboring swarm particles i.e., sharing of intelligence enhances the candidate solution. Each particle represents a candidate solution. The PSOGS is implemented on the MPPT problem by [129].

The PSO mathematical model with GS is made in which each particle is initialized with randomized velocity and direction and represents a candidate solution. $\mathrm{N}$ is the number of initialized particles that are also exhibiting candidate solutions. The position of particle I is given by $x_{i}=\left(x_{i 1}+x_{i 2}+\cdots+x_{i N}\right)$ and corresponding velocity of particle $v_{i}=\left(v_{i 1}+v_{i 2}+\cdots+v_{i N}\right)$ Bound by $v_{\max }$ in an $N$ dimensional search space.

Position and velocity are updated by Equations (89) and (90):

$$
\begin{gathered}
v_{i}^{k}=w v_{i}^{k}+c_{1} \tau_{1}\left(\text { pbest }^{k}-x_{i}^{k}\right)+c_{2} \tau_{2}\left(\text { gbest }^{k}-x_{i}^{k}\right), \\
x_{i}^{(k+1)}=x_{i}^{k}+v_{i}^{(k+1)},
\end{gathered}
$$

where current solution is the $x_{i}^{k}$ (position of particle) at the kth iteration, while $c_{1}, c_{2}$ represent positive constants, $r_{1}, r_{2}$ are two random variables range $[0,1], w$ is the inertial weight which impacts the vector 
of velocity on new velocity direction and magnitude, velocity is kept in limit by bounding $v_{\max }$ limit on vectors, which is initialized as a function of the range of the problem.

Gravitational Search Algorithm (GSA) is a heuristic algorithm and it was introduced in 2009. The mathematically modeling GSA is based on Newton's law of gravity, and motion is used; the system starts with random agents $(\mathrm{Na})$ and the gravitational forces are informed from the agent $k$ to $l$. The general equation of GSA is given by Label (91):

$$
F_{l k}^{d}=G(t) \frac{M_{p l}(t) * M_{a t}(t)}{R_{l k}(t)+\varepsilon}\left(x_{k}^{d}(t)-x_{l}^{d}(t)\right) .
$$

Using the general form of law of gravity as in Equation (92),

$$
F=G \cdot\left(M_{1} M_{2}\right) / R^{2}
$$

In GSA, R is used instead of $R^{2}$ which gives better results, $G(t)$ is instantaneous gravity, and $M_{a k}, M_{p l}$ are active gravitation and passive gravitation, respectively. $R_{l k}$ is Euclidian distance from agent $l$ to $k$. $\varepsilon>1$ is a small constant. The insertion of $\varepsilon$ is necessary to avoid division by zero, which otherwise occurs for agents in the same exact location. The $\left(x_{k}^{d}(t)-x_{l}^{d}(t)\right)$ gives distances of active agent positions. Instantaneous gravitational constant is given by Equation (93):

$$
G(t)=G_{0} * \exp \left(-\frac{\alpha * i t e r}{\max _{i t e}}\right),
$$

where $G_{0}$ is the initial value of gravity. $\alpha$ is descending coefficient, iter is current iteration, max $_{i t e}$ is maximum number of iterations. Hence, total force being induced upon candidate $l$ is given by Equation (94):

$$
F_{l}^{d}(\mathrm{t})=\sum_{k=1, l \neq k}^{N_{a}} r_{k} F_{l} k^{d}(t),
$$

where $d$ is problem search space dimension, $r_{k}$ is random number. The general equation of Newtonian acceleration is deduced by Equation (95):

$$
=m a \rightarrow a=\frac{F}{m} .
$$

The GSA expression can be written as Equation (96):

$$
a c_{l}^{d}(t)=\left(F_{l}^{d}(t)\right) /\left(M_{l}(t)\right),
$$

where $M_{l}$ is mass of agent $l$ as fuction of time $t$.

Velocity and position of each agent are given by Equations (97) and (98), respectively:

$$
\begin{aligned}
& V_{l}^{d}(t+1)=r_{l} * V_{l}^{d}(t)+a c_{l}^{d}(t), \\
& X_{l}^{d}(t+1)=X_{l}^{d}(t)+V_{l}^{d}(t+1) .
\end{aligned}
$$

The reason for PSO-GSA combination was to utilize the attractive social intelligence of PSO and incorporate this social intelligence with precise local search capability i.e., $a c_{l}(t)$ of GSA; hence, an effective approach is to maximize the search for GM and avoid trapping in LM; in addition, oscillations due to perturbation and power loss are minimized. GSA's local search ability $a c_{l}(t)$ is a representation of duty cycle, and the velocity and positions of agents is updated using Equations (99) and (100), respectively:

$$
V_{l}(t+1)=w * V_{l}(t)+c_{1}^{\prime} * r * a c_{l}(t)+c_{2}^{\prime} * r *\left(g \text { best }-x_{l}(t)\right),
$$




$$
\mathrm{X}_{1}(\mathrm{t}+1)=\mathrm{X}_{1}(\mathrm{t})+\mathrm{V}_{1}(\mathrm{t}+1) .
$$

\subsection{Generalized Pattern Search (GPS) Based MPPT}

GPS is a metaheuristic population-based derivative-free soft computing technique used to solve optimization problems. Initially, it was introduced to resolve non-differentiable and discontinuous problems. However, in 1997, Torczon upgraded this technique to resolve nonlinear unconstrained problems [130]. The main advantage of this technique is its convergence speed and high efficiency. The GPS algorithm works in two different phases i.e., poll and search phase. In the search phase, using a finite set of mesh points, the objective function is evaluated for the optimum solution. For the new best value, an existing value is updated, and the process is repeated for a globally best solution. If it fails to do so, the poll phase is used in which all mesh points are assigned a new set of values and then the objective function is evaluated. The basic flow chart of GPS algorithm for MPPT is shown in Figure 36 [131]. Algorithm 1 shows the pseudo code of the GPS algorithm. Equation (101) depicts the basic equations for the new and previous duty cycles.

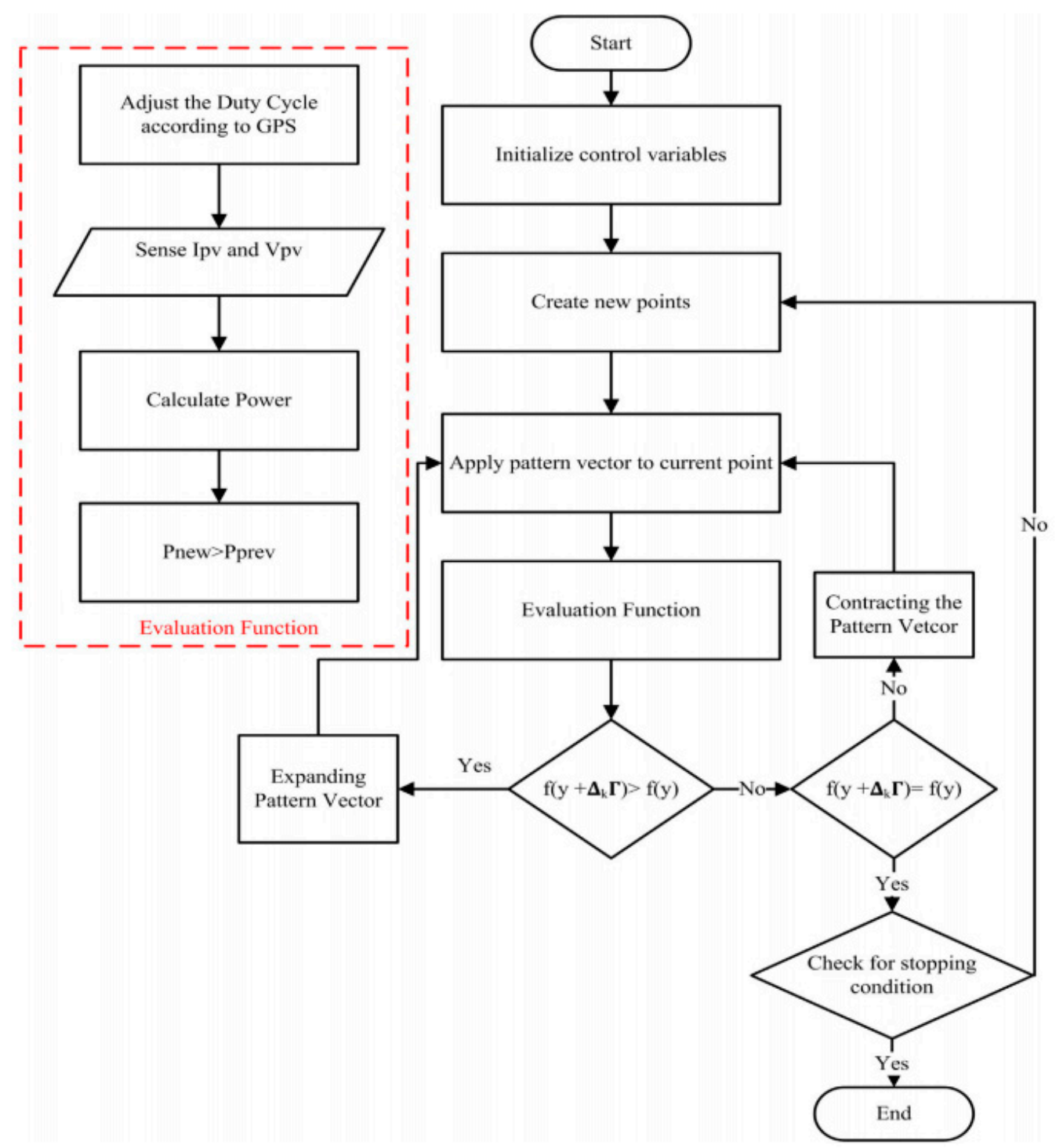

Figure 36. Flow chart of Generalized Pattern Search (GPS) for MPPT of the PV system [131]. 


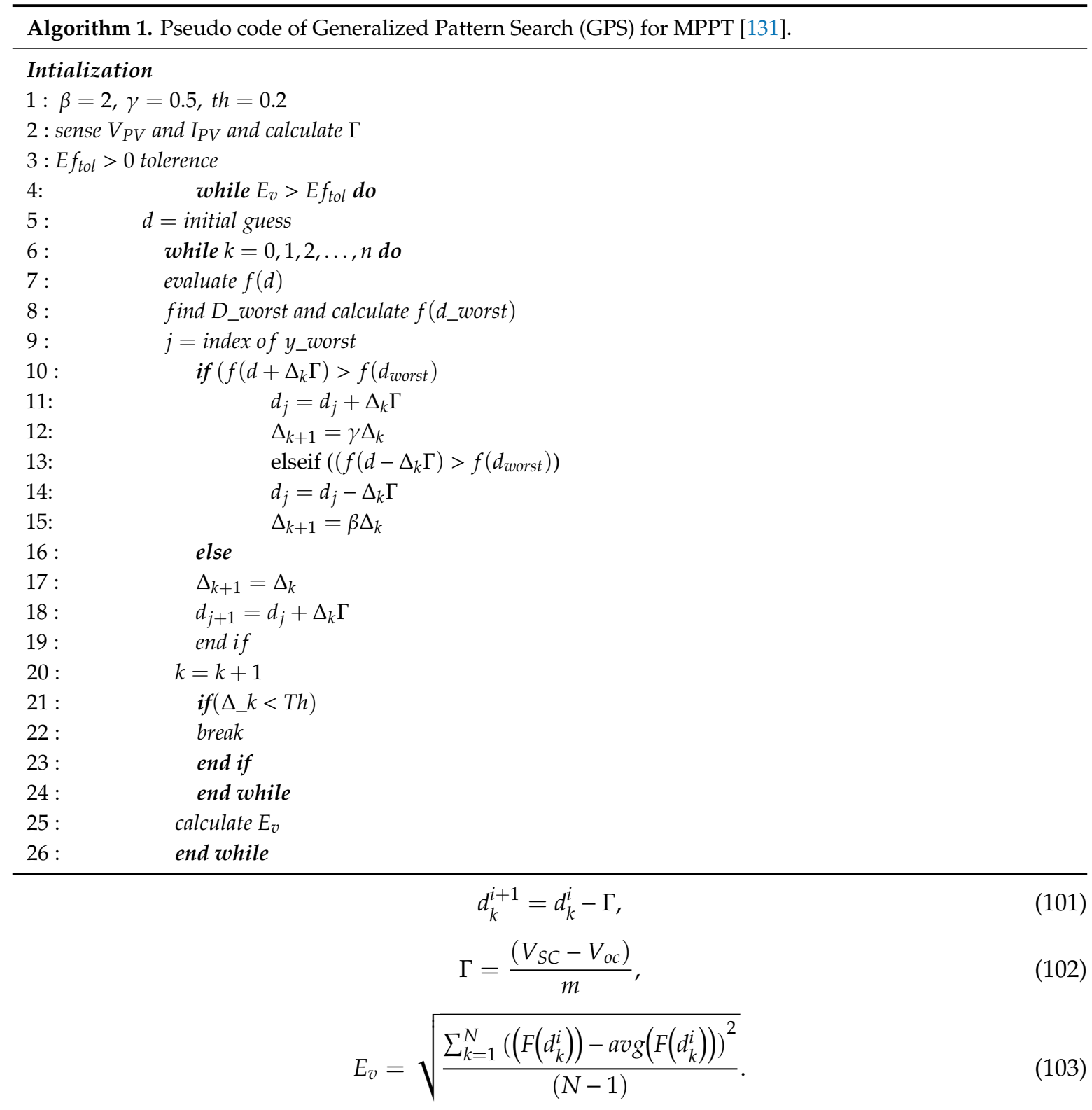

The two control variables of the algorithm are voltage and current. Equations (101) to (103) depict the basic equations for an updated control parameter i.e., duty cycle.

\subsection{Comparison between Different Techniques}

There are no specific criteria to judge which is the best technique. All the techniques have their pros and cons. We have tried here to give each technique rating or scoring based on their performance indicators specified in Table 5 .

It will help the reader to judge and select a comparatively better technique among others. Scoring criteria is as follows:

1. All the performance indicators are evaluated on the scale of 1-3.

2. Number of sensors required $=1$ the score is 3 , if number of sensors required $>1$ the score is 1 .

3. Score for Complexity Level, Tracking Accuracy and Tracking Speed is given as per following criteria: Low $=3$, Medium $=2$ and High $=1$.

4. Efficient for partial shading $=3$, not efficient for partial shading $=1$.

5. Final Score $=$ Score for "Sensed Variables" + score for "Complexity Level" + score for "Tracking Accuracy" + score for "Tracking Speed" + score for "Efficient for Partial Shading". 
Table 5. Comparison between different techniques.

\begin{tabular}{|c|c|c|c|c|c|c|c|c|c|}
\hline Ref No. & Year & $\begin{array}{c}\text { MPPT } \\
\text { Technique }\end{array}$ & $\begin{array}{c}\text { Sensed } \\
\text { Variables }\end{array}$ & $\begin{array}{c}\text { Complexity } \\
\text { Level }\end{array}$ & $\begin{array}{l}\text { Tracking } \\
\text { Accuracy }\end{array}$ & $\begin{array}{l}\text { Tracking } \\
\text { Speed }\end{array}$ & Converter & $\begin{array}{c}\text { Efficient } \\
\text { for Partial } \\
\text { Shading }\end{array}$ & $\begin{array}{c}\text { Score } \\
(\text { Total = 15) }\end{array}$ \\
\hline [74] & 2013 & $P \& O$ & $\mathrm{~V} / \mathrm{I}-1$ & Low $/ 3$ & Medium/2 & Fast/3 & Boost & $\mathrm{No} / 1$ & 10 \\
\hline [67] & 2014 & FOCV & $\mathrm{V}-3$ & Low $/ 3$ & Medium/2 & Medium/2 & Boost & $\mathrm{No} / 1$ & 11 \\
\hline [71] & 2015 & FSCC & $\mathrm{I}-3$ & Low $/ 3$ & Medium/2 & Medium/2 & Boost & No/1 & 11 \\
\hline [87] & 2013 & ANN & $\mathrm{V} / \mathrm{I}-1$ & $\mathrm{High} / 1$ & High/3 & Fast $/ 3$ & Buck & Yes/3 & 11 \\
\hline [103] & 2017 & CSA & $\mathrm{V} / \mathrm{I}-1$ & Low/3 & High/3 & Fast/3 & Boost & $\mathrm{No} / 1$ & 11 \\
\hline [104] & 2018 & IGSA & $\mathrm{V} / \mathrm{I}-1$ & $\mathrm{High} / 1$ & $\mathrm{High} / 3$ & Fast/3 & Boost & Yes/3 & 11 \\
\hline [106] & 2017 & CGSCO & $\mathrm{I}-3$ & Low/3 & $\mathrm{High} / 3$ & - & Boost & Yes/3 & 12 \\
\hline [107] & 2017 & HPO & $\mathrm{I}-3$ & Low $/ 3$ & High/3 & Fast $/ 3$ & Boost & Yes/3 & 15 \\
\hline [108] & 2017 & JayaDe & $\mathrm{V} / \mathrm{I}-1$ & Low/3 & $\mathrm{High} / 3$ & Fast/3 & Boost & Yes/3 & 13 \\
\hline [116] & 2016 & WOA & $\mathrm{I} / \mathrm{V}-1$ & & $\mathrm{High} / 3$ & Fast/3 & Boost & Yes/3 & 10 \\
\hline [118] & 2015 & GWO & $\mathrm{V} / \mathrm{I}-1$ & Medium/2 & $\mathrm{High} / 3$ & Fast/3 & Boost & Yes/3 & 12 \\
\hline [119] & 2017 & BA & $\mathrm{V} / \mathrm{I}-1$ & High/1 & $\mathrm{High} / 3$ & Fast/3 & Buck-Boost & Yes/3 & 11 \\
\hline [121] & 2015 & sOS & $\mathrm{V} / \mathrm{I}-1$ & $\mathrm{High} / 1$ & High/3 & Fast/3 & Boost & Yes/3 & 11 \\
\hline [122] & 2017 & RF & $\mathrm{G} / \mathrm{T}-1$ & $\mathrm{High} / 1$ & $\mathrm{High} / 3$ & & & No/1 & 6 \\
\hline [123] & 2015 & $\mathrm{ABC}$ & $\mathrm{V} / \mathrm{I}-1$ & $\mathrm{High} / 1$ & $\mathrm{High} / 3$ & Fast/3 & Boost & Yes/3 & 11 \\
\hline [134] & 2015 & SA & $\mathrm{V} / \mathrm{I}-1$ & Low/3 & $\mathrm{High} / 3$ & Medium/2 & Boost & Yes/3 & 12 \\
\hline [135] & 2016 & FWA & $\mathrm{V} / \mathrm{I}-1$ & Medium/2 & High/3 & Fast/3 & Boost & Yes/3 & 12 \\
\hline [125] & 2019 & NN-FFOA & $\mathrm{V} / \mathrm{I}-1$ & Medium/2 & $\mathrm{High} / 3$ & Fast/3 & Boost & Yes/3 & 12 \\
\hline [136] & 2019 & $\mathrm{P} \& \mathrm{O}-\mathrm{ABC}$ & $\mathrm{V} / \mathrm{I}-1$ & Medium/2 & $\mathrm{High} / 3$ & Fast/3 & Boost & Yes/3 & 12 \\
\hline [137] & 2018 & PSO & $\mathrm{V} / \mathrm{I}-1$ & High/1 & Medium/2 & Fast/3 & Boost & Yes/3 & 10 \\
\hline [129] & 2019 & PSOGS & $\mathrm{V} / \mathrm{I}-1$ & High/1 & High/3 & Fast/3 & Boost & Yes/3 & 11 \\
\hline [131] & 2016 & GPS & $\mathrm{V} / \mathrm{I}-1$ & Medium/2 & $\mathrm{High} / 3$ & Fast/3 & Boost & Yes/3 & 12 \\
\hline
\end{tabular}

\section{Comparison Results and Discussion}

In this section, four distinct cases are studied. After several results and trails, four distinctive cases are carefully chosen for the comprehensive formulation of the problem and performance measurement of bio-inspired algorithms. A PV based simulation model is developed in MATLAB/Simulink with an MPPT embedded block. Four different cases are developed to check the robustness of six commonly used MPPT techniques. Figure 37a illustrates the MATLAB/Simulink model of the PV system and Figure $37 \mathrm{~b}$ shows the P-V curve of Case 1-2, which are used to check the validation of MPPT techniques in that model. Case 1 is for fast varying irradiance, case 2 and case 3 are for partial shading, and case 4 is studied for a complex form of partial shading (CPS). Conclusions are made on the basis of comparative analysis. A detailed performance analysis is presented in Table 8. The results are analyzed for tracking and settling time, power efficiency, oscillations, transients of voltage, current, and energy. Using the results, conclusions are made regarding the overall performance of the MPPT by bio-inspired optimizers.

\subsection{Case 1 Uniform Irradiance}

In case 1, all PV modules receive equal irradiance levels and it changes over time. It is known as fast varying irradiance. The test pattern is given in Table 6 and corresponding PV model and P-V curves are presented in Figure 37. The irradiance level is changed after every $2 \mathrm{~s}$. The initial level is $1000 \mathrm{w} / \mathrm{m}^{2}$ in interval $0-2 \mathrm{~s}$, which drops to 700 watts at $2 \mathrm{~s}$ and remains constants until the 4 th $\mathrm{s}$, it further drops to $300 \mathrm{w} / \mathrm{m}^{2}$ and remains constant from 4-6 s. The calculated maximum power in each interval is $1260 \mathrm{w}, 882 \mathrm{w}$, and 378 watts. Since the GM is located on the knee of this I-V and P-V curve, it is therefore relocated according to actual irradiance and temperature. Resultantly, MPPT techniques need to re-track the GM. This is the right test to check the robustness of applied techniques. Since all applied techniques are programmed using similar re-initialization criteria which depends upon 
the change in power level with respect to current operating power, the sensitivity of re-initialization remains the same.

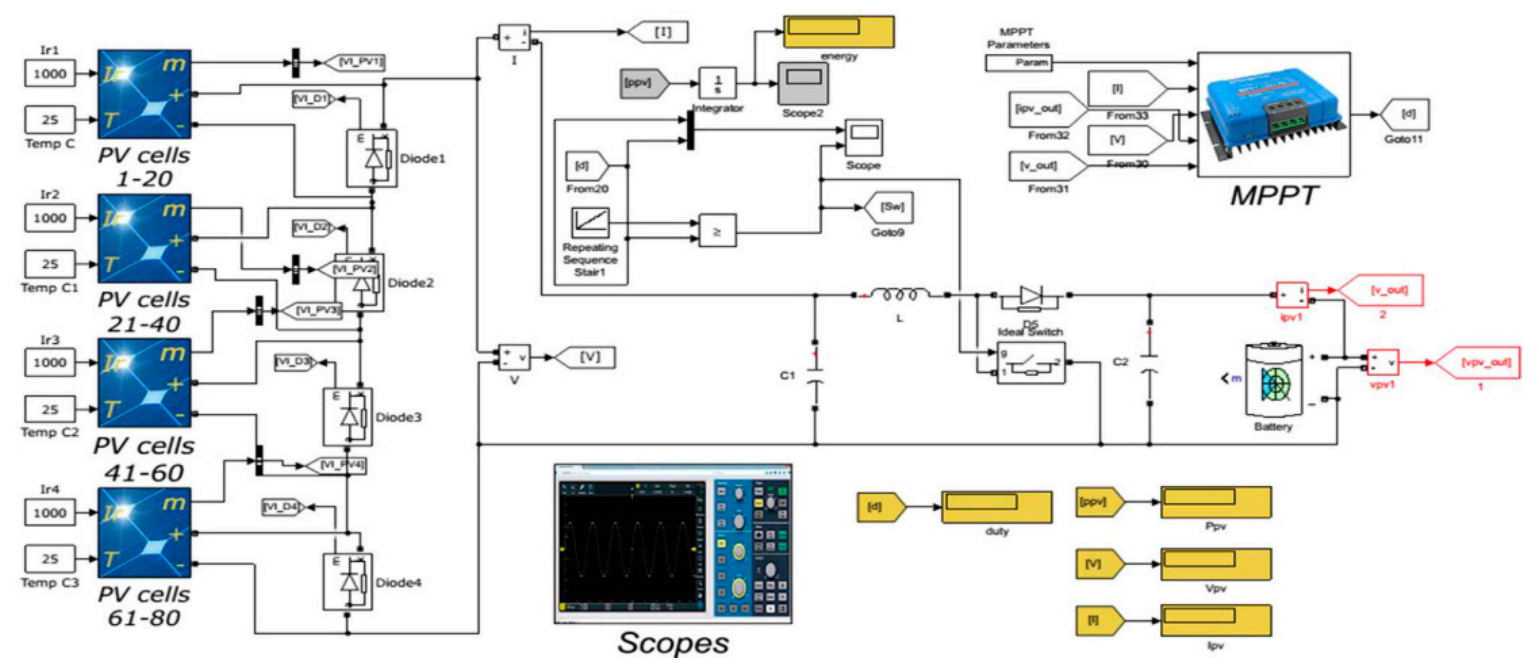

(a)

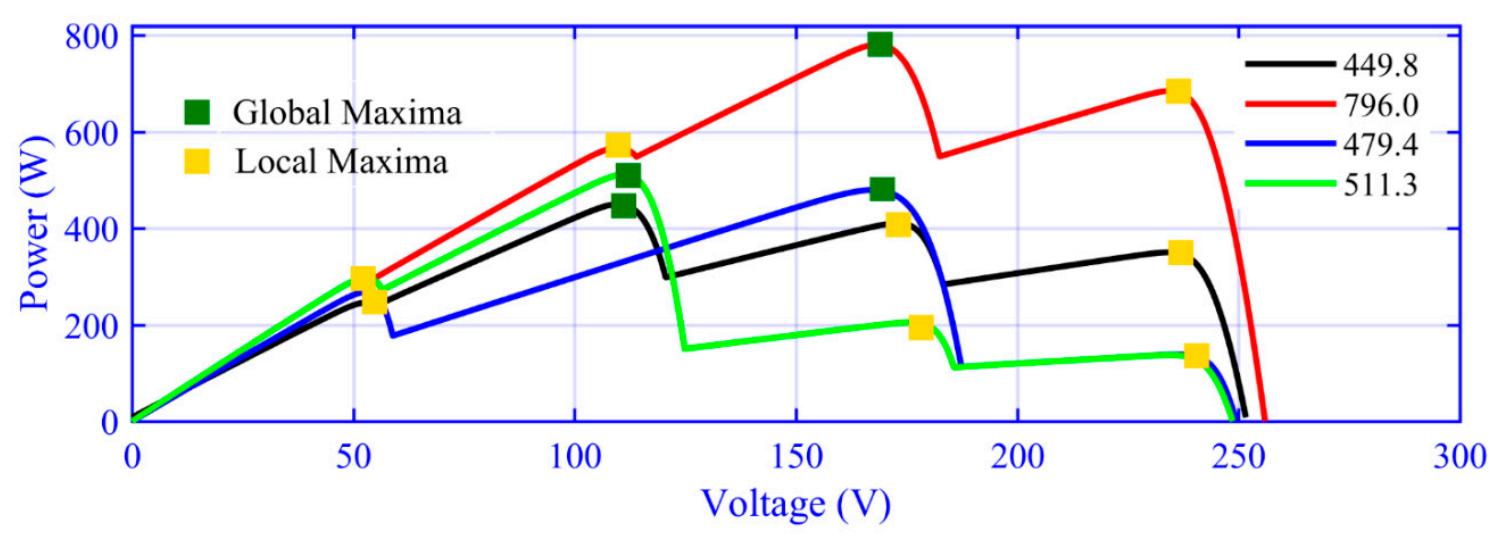

(b)

Figure 37. (a) PV system simulated model; (b) PV curves under partial shading.

Table 6. Irradiance levels for Cases 1 to 3.

\begin{tabular}{|c|c|c|c|c|c|}
\hline \multirow{2}{*}{$\begin{array}{c}\text { Case } \\
C_{1-3}\end{array}$} & \multicolumn{4}{|c|}{ Irradiance $S_{i}\left(\frac{\mathrm{kW}}{\mathrm{m}^{2}}\right)$} & \multirow{2}{*}{$\begin{array}{c}P_{\max } \\
(\mathrm{W})\end{array}$} \\
\hline & PV1 & PV2 & PV3 & PV4 & \\
\hline Case 1: Rapid changing & $1,0.7,0.3$ & $1,0.7,0.3$ & $1,0.7,0.3$ & $1,0.7,0.3$ & $1260,882,378$ \\
\hline Case 2: Partial Shading & 0.5 & 0.8 & 1 & 0.9 & 796 \\
\hline Case 3: Partial Shading & 0.8 & 025 & 0.7 & 0.4 & 449.5 \\
\hline
\end{tabular}

The comparison of power is made in Figure 38 and detailed zoomed power transients are presented in Figure 39. The control action provided by the boost converter's duty cycle is presented by Figure 40, and zoomed behavior is given in Figure 41. In the first interval, the power efficiency achieved is $1259 \mathrm{w}$, 1248 w, 1258 w, 1259 w, 1257 w, and 1258 w achieved by DFO, P\&O, ABC, PSO-GS, PSO, and CS. Case 1 has three distinct regions of operation, the average value $(832 \mathrm{w})$ is a better indicator of performance. DFO, P\&O, ABC, PSO-GS, PSO, and CS achieve 822.9 w, 828 w, 822.4 w, 820.7 w, 829.9 w, and 802 w watts of average power, respectively. Competing as per power, the sequence of performance is DFO > PSOGS $>$ ABC $>$ CS $>$ PSO $>$ P\&O. 


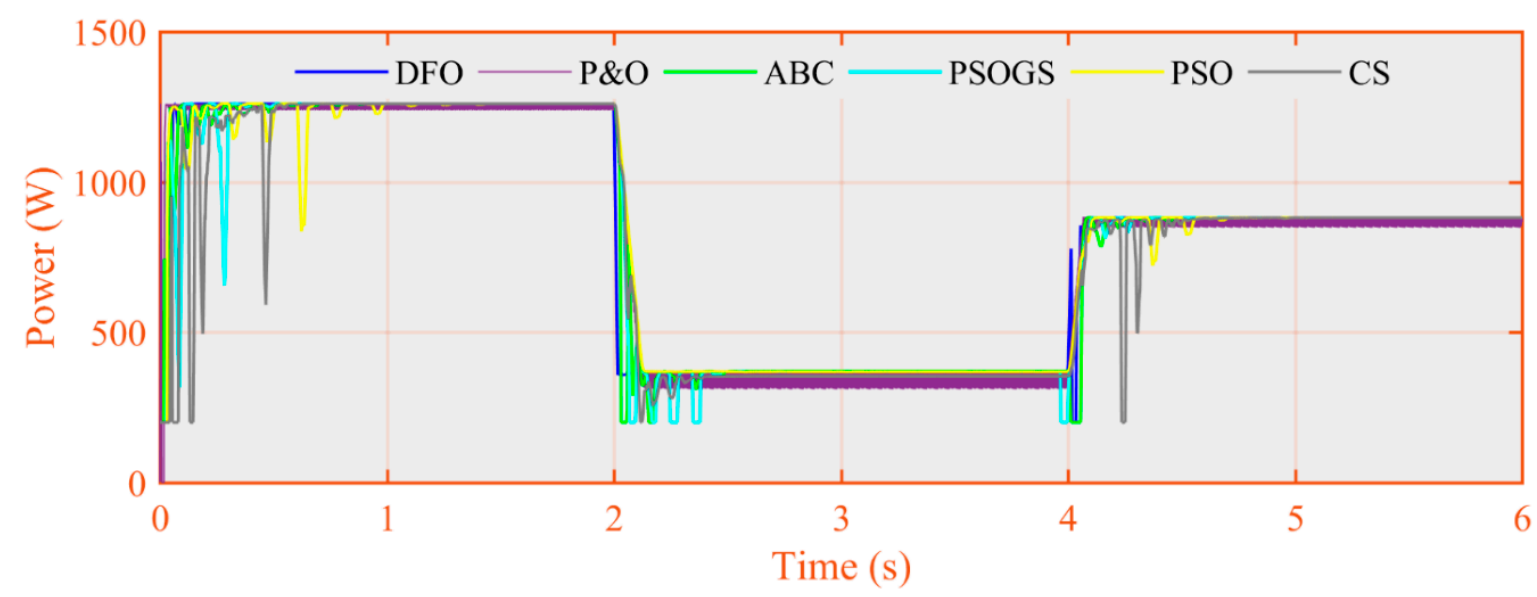

Figure 38. Case 1 power comparison.

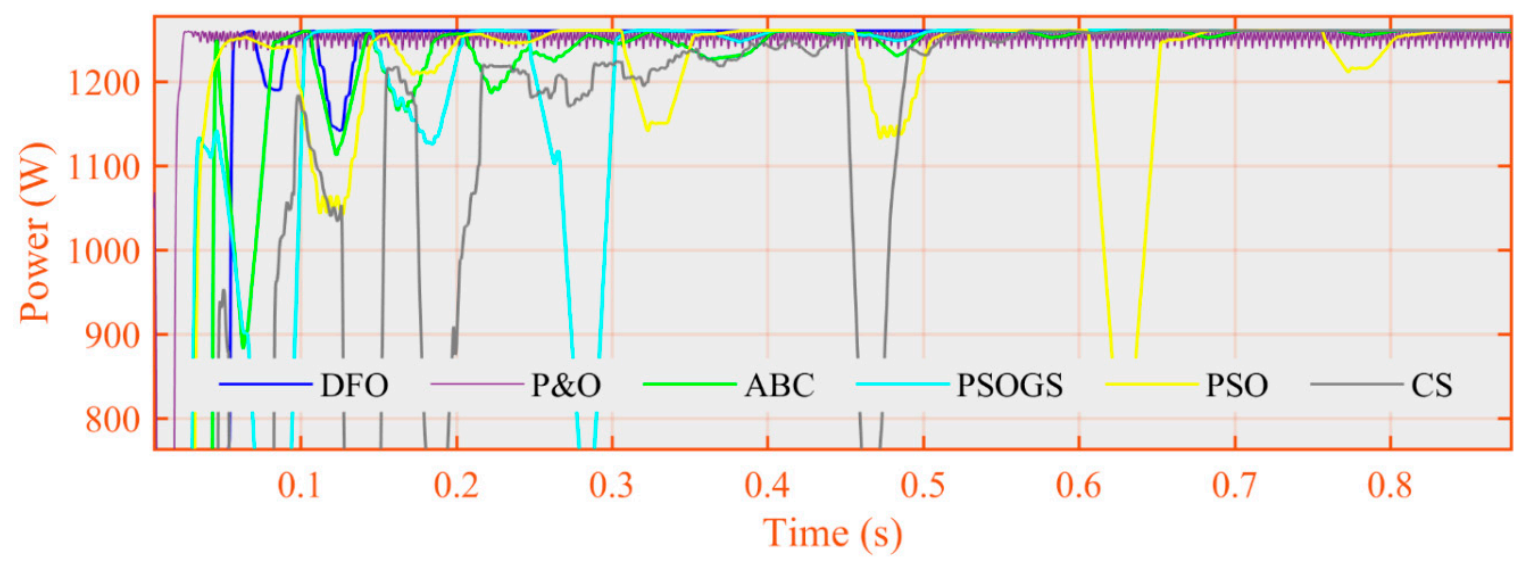

Figure 39. Case 1 zoom view power comparison.

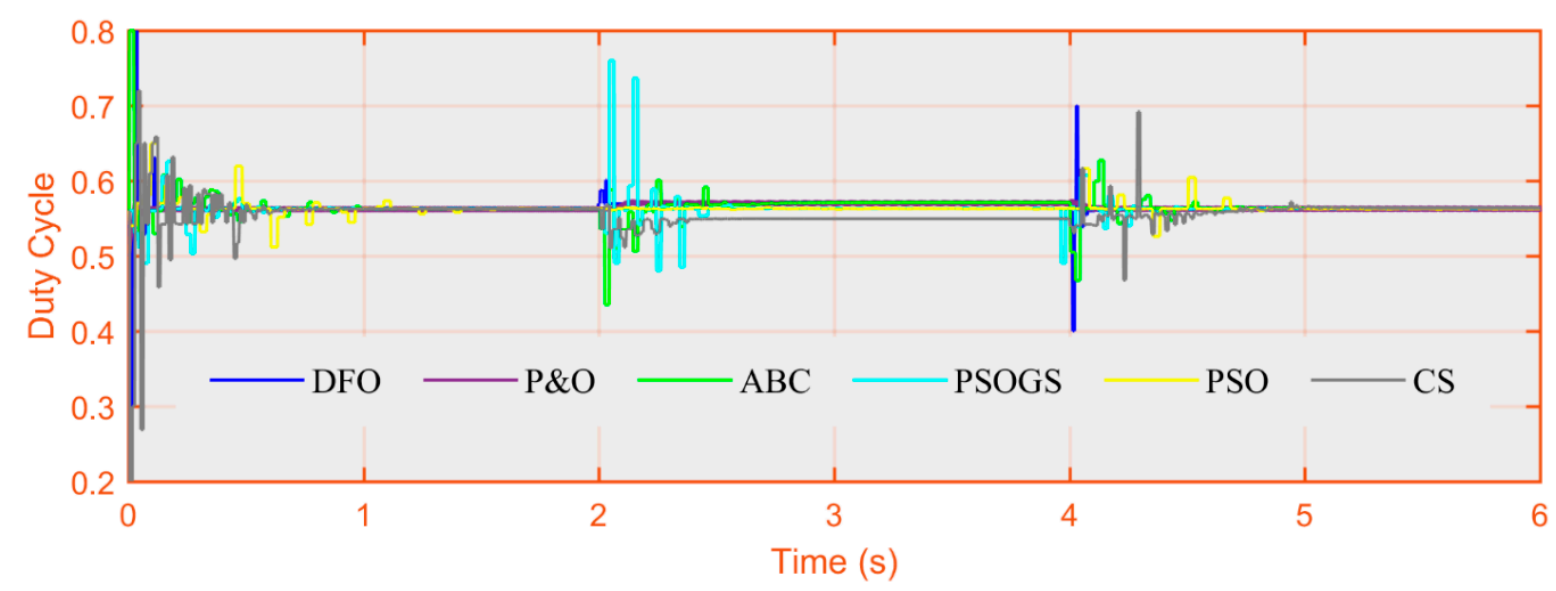

Figure 40. Case 1 Duty Cycle comparison.

The tracking time is measured from the time of initialization until GM is reached. The settling time includes the time duration in which particles settle on GM point without oscillations. Settling time for DFO, ABC, PSO-GS, PSO and CS is $0.28 \mathrm{~s}, 0.38 \mathrm{~s}, 0.62 \mathrm{~s}, 0.70 \mathrm{~s}$, and $0.69 \mathrm{~s}$, respectively. The ABC and DFO have a minimum difference between tracking and settling times. This indicated that the coherence properties and onlooker bee of DFO and ABC play a significant role to converge at MPP. 


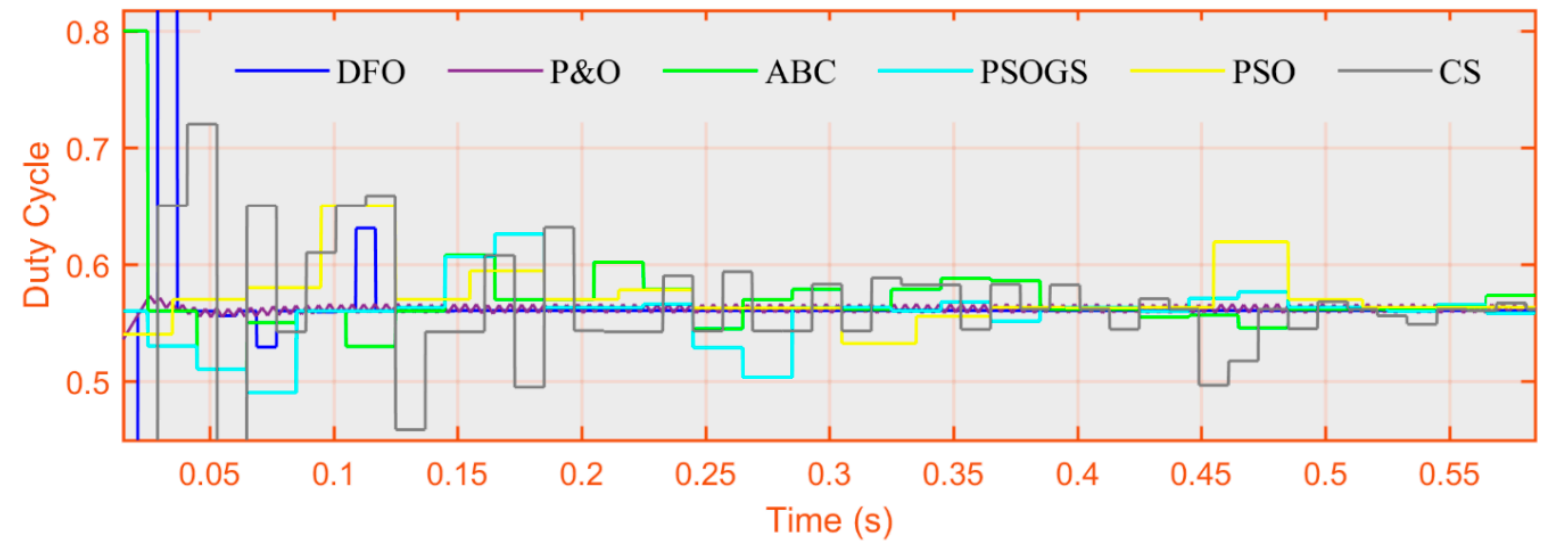

Figure 41. Case 1 zoom view duty cycle comparison.

The P\&O converges to GM but can't settle down at GM due to oscillations produced by continuous perturbation. To reduce oscillations, the step size has to be reduced considerably, but, consequently, $\mathrm{P} \& \mathrm{O}$ tracking time drops. Undesired oscillations dissipate power causing power loss and reduce efficiency. To balance tracking time and efficiency, the step size of the boost converter is kept inside a range that only generates oscillations within $2-5 \%$ of PV arrays stated power. The oscillations produced by $\mathrm{P} \& \mathrm{O}$ are 22 watts in this case. DFO and PSOGS reduce the magnitude of the oscillations by $<1$ watt, achieving a $94 \%$ reduction in oscillations. Random oscillations by PSO remain significantly high. Figures 40 and 41 indicate that PSO has the highest oscillations among bio-inspired algorithms. The oscillations in voltage and current are is the duty observed in Figures 42 and 43 . The control parameter that updates in each iteration cycle is shown in Figure 40 and indicates that the proposed technique effectively tracks the MPP in lesser iterations. PSOGS performs slightly better than PSO. In Figure 41, it is observed that the DFO, ABC, and CS also effectively track GM in fast varying irradiance. The prominent effect of Levy flight is observed in Figure 40 during an interval of $0.2-0.5 \mathrm{~s}$. A large fluctuation by CS technique is because of Levy flight. We can conclude that quick re-tracking, least oscillations, and high efficiency are results of higher information sharing among swarm particles and organized structure enhanced by features like alignment in DFO. In Figures 42 and 43 , current and voltage transients are presented for comparison. The oscillations produced by $\mathrm{P} \& \mathrm{O}$ are successfully minimized by bio-inspired techniques.

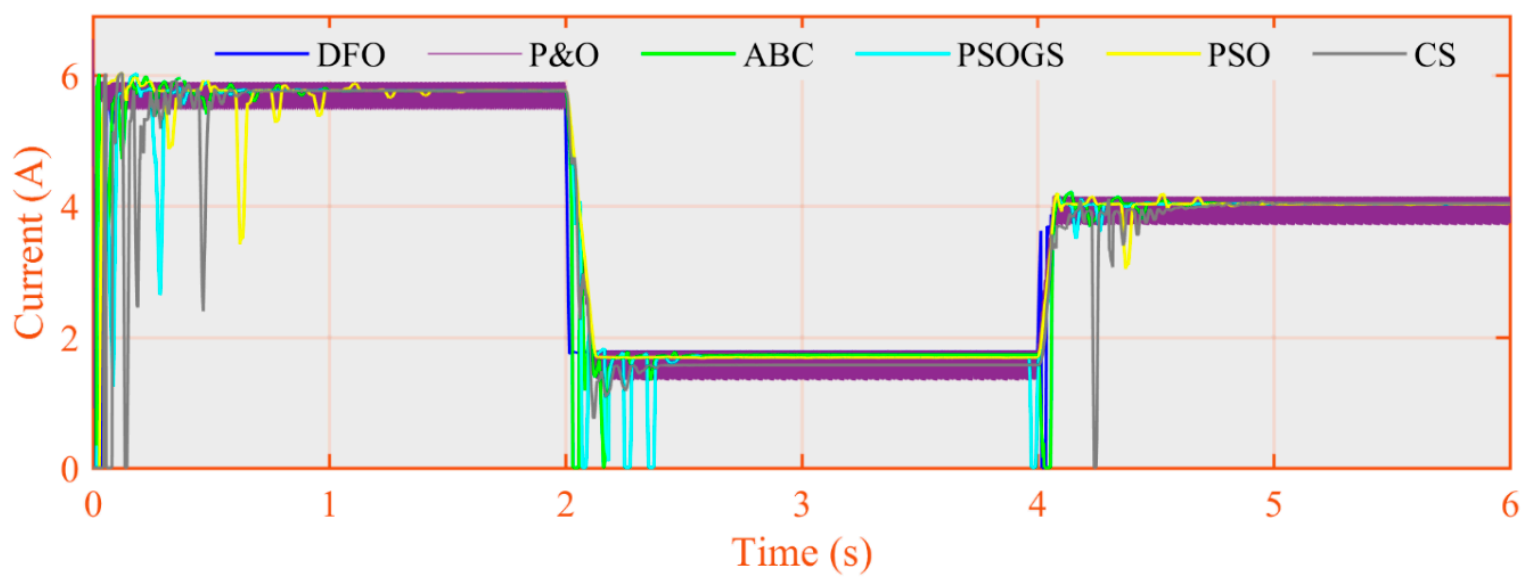

Figure 42. Case 1 current comparison. 


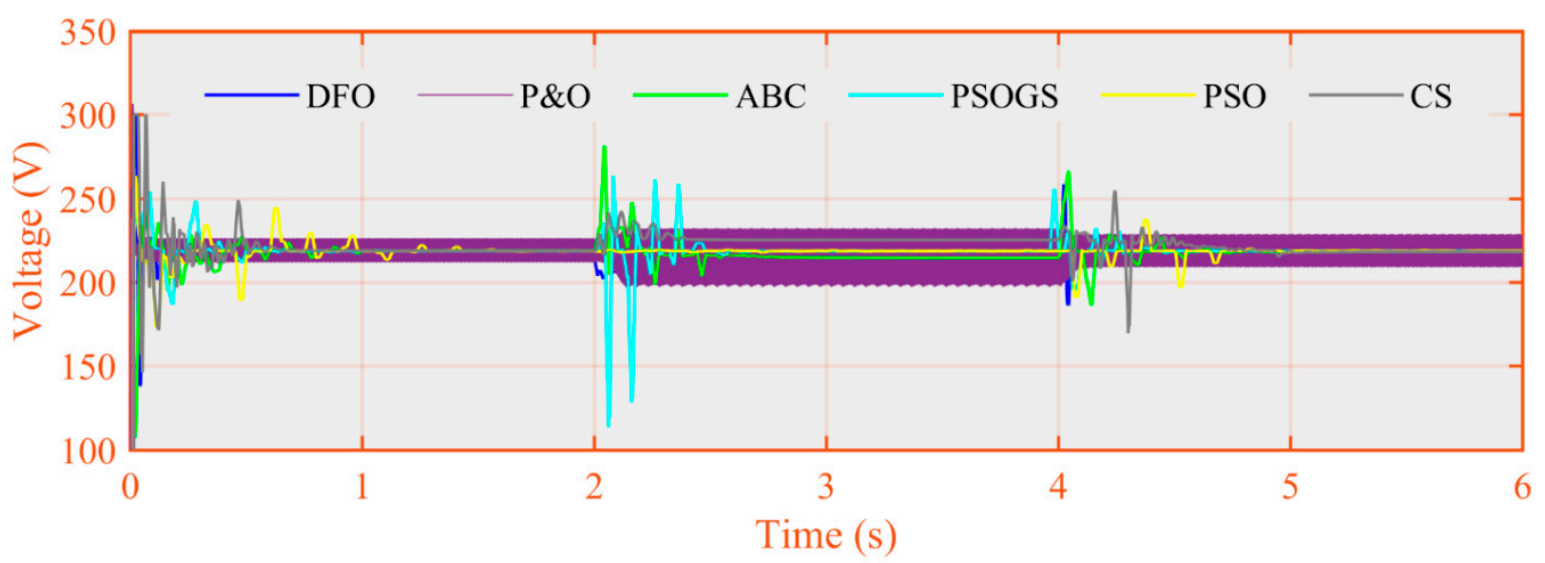

Figure 43. Case 1 voltage comparison.

\subsection{Case 2 Partial Shading}

Partial shading is dealt with in case 2. The test pattern is given in Table 6, and the corresponding PV curve is presented in Figure 37. PS occurs when the modules of PV array don't receive equal irradiance levels. During PS and mismatch, underperforming modules are isolated by the activation of bypass diodes. Multiple peaks appear on curves making the tracking complicated. The peaks are classified as local and global maxima. Classical MPPT techniques can't distinguish between LM and GM due to which efficiency is dropped significantly. The P-V curves contain three LM and one GM. The corresponding power of LM $1=393 \mathrm{w}, \mathrm{LM} 2=565 \mathrm{w}, \mathrm{LM} 3=683.2 \mathrm{w}$, and GM $=795$ watts.

Results for power comparison are given by Figure 44, and the control provided by the duty cycle is shown in Figure 45. The detailed comparison of the duty cycle and power is given by Figures 46 and 47, respectively. Current transient is shown in Figure 48 and the Voltage transient is shown in Figure 49.

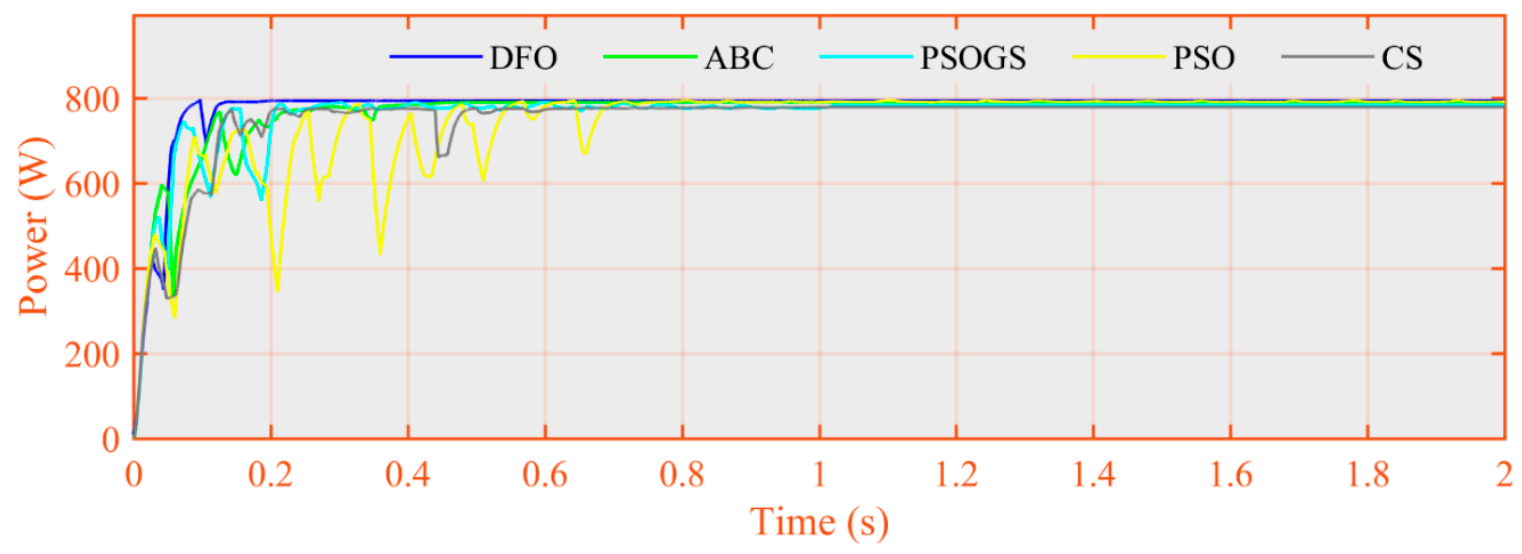

Figure 44. Case 2 PS1 power comparison.

The maximum power obtained under PS conditions by DFO, P\&O, ABC, PSOGS, PSO, and CS is $793.8 \mathrm{w}, 393 \mathrm{w}, 789.4 \mathrm{w}, 783.8 \mathrm{w}, 791.5 \mathrm{w}$, and $778.6 \mathrm{w}$, respectively. The highest efficiency is achieved by DFO while it is $99.4 \%$ by PSO. The lowest efficiency achieved by $\mathrm{P} \& \mathrm{O}$ is $49.3 \%$, which is trapped in LM1 because $\mathrm{P} \& \mathrm{O}$ is stuck at LM1. The ABC, PSOGS, and CS produce $99.1 \%, 98.4 \%$, and $97.81 \%$ respectively. 


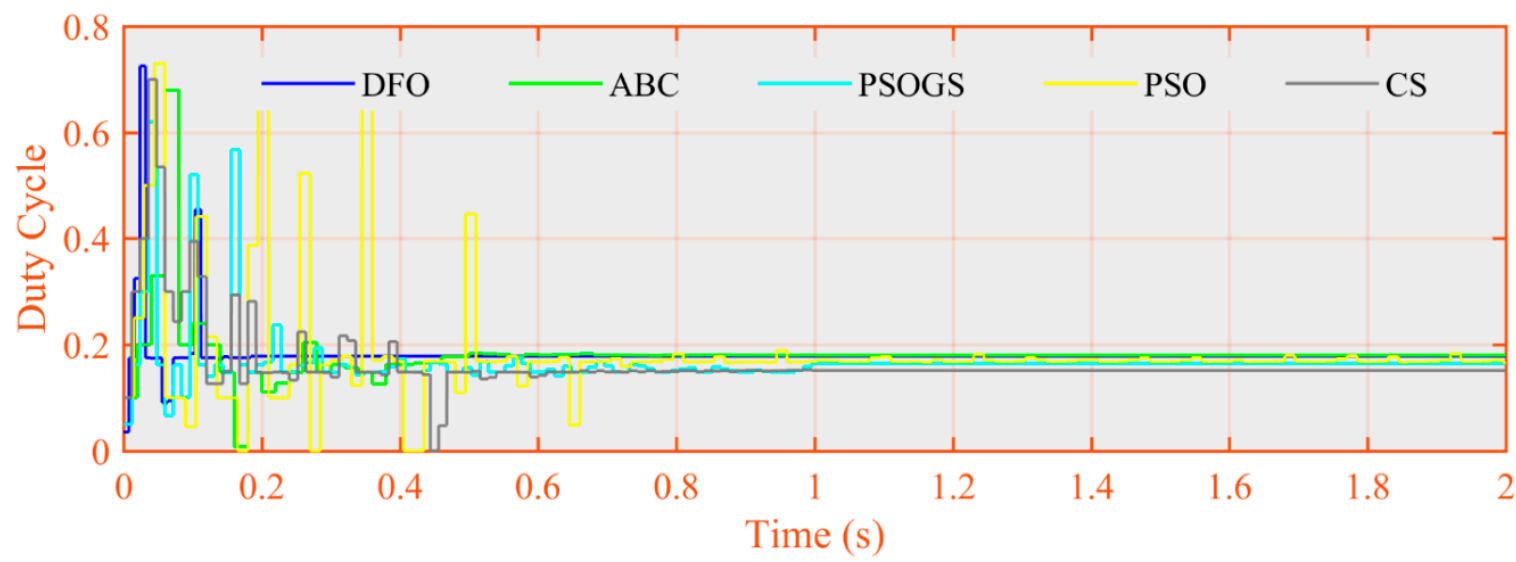

Figure 45. Case 2 duty cycle comparison.

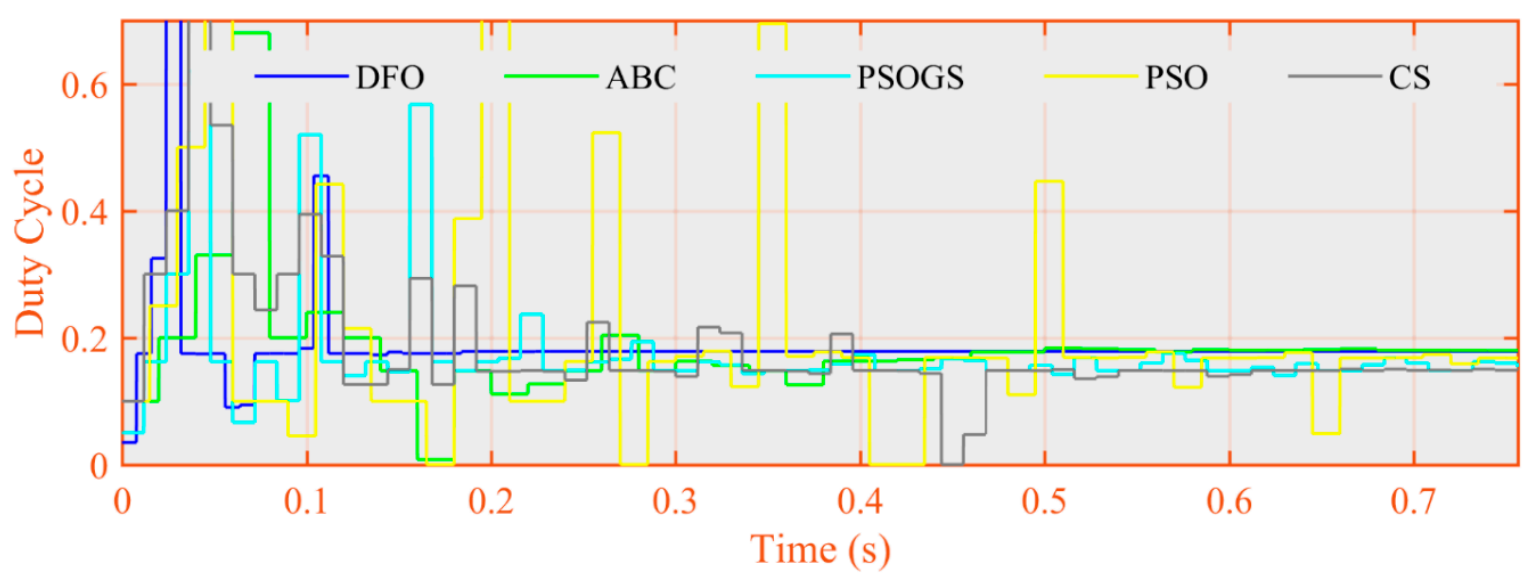

Figure 46. Case 2 zoom duty cycle comparison.

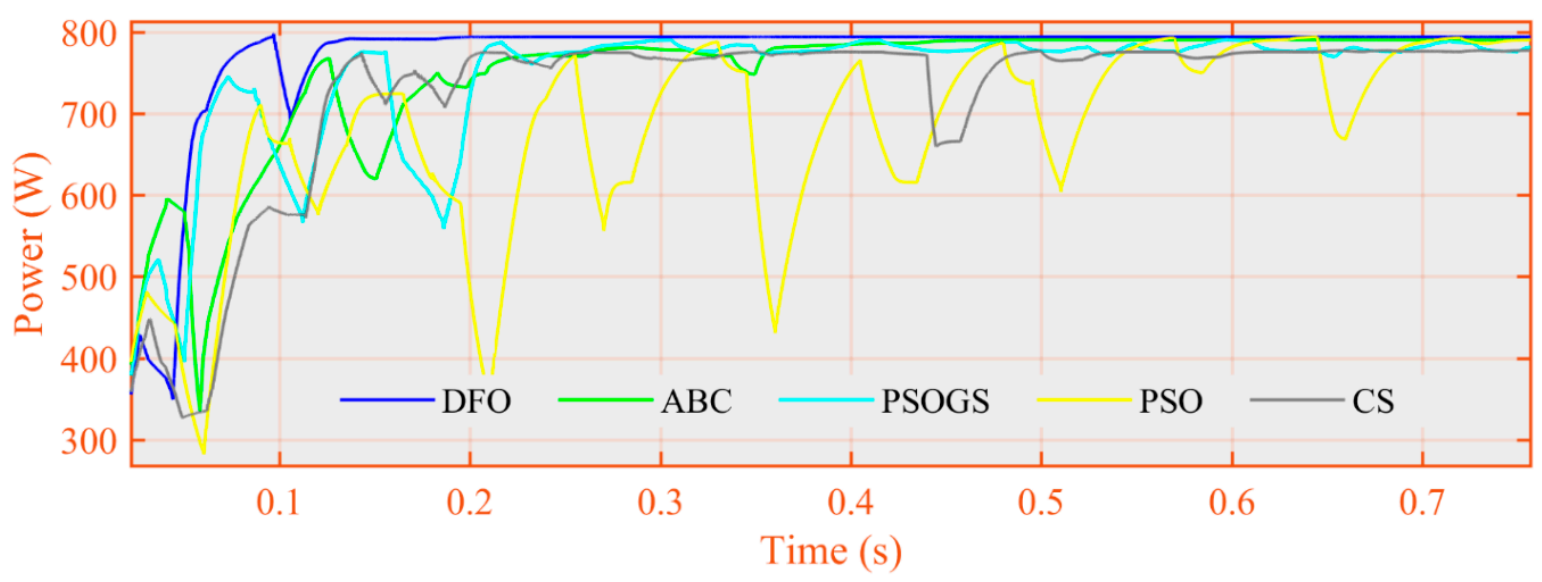

Figure 47. Case 2 PS1 power zoom comparison.

The tracking time of DFO, ABC, PSOGS, PSO and CS is $0.18 \mathrm{~s}, 0.35 \mathrm{~s}, 0.32 \mathrm{~s}, 0.68 \mathrm{~s}$ and $0.35 \mathrm{~s}$, respectively, and settling time is $0.21 \mathrm{~s}, 0.45 \mathrm{~s}, 0.49 \mathrm{~s}, 0.70 \mathrm{~s}$ and $0.45 \mathrm{~s}$, respectively. In tracking GM, DFO settles at GM within $470 \mathrm{~ms}$ achieving 19\% faster tracking to the second-best. Faster tracking shows the robustness, and, due to faster settling time, undesired oscillations are successfully removed. The tracking time of $\mathrm{P} \& \mathrm{O}$ is neglected because it gets stuck at LM1 and can't locate GM. Case 2 again indicates superior performance of DFO followed by ABC and PSOGS, although PSO achieves $99.4 \%$ and random oscillations are still observed in voltage and current. CS also shows a similar behavior that 
is undesired in normal working conditions. DFO achieves $1-5 \%$ better power convergence efficiency with a reduction of ripples $<1$ watt. The output is stable, and current and voltage have zero oscillations as shown in Figures 48 and 49. In Figure 46, the duty cycle updating correlating to each iteration indicates that $\mathrm{DFO}, \mathrm{ABC}$, and PSOGS can detect and converge at GM in lesser iterations.

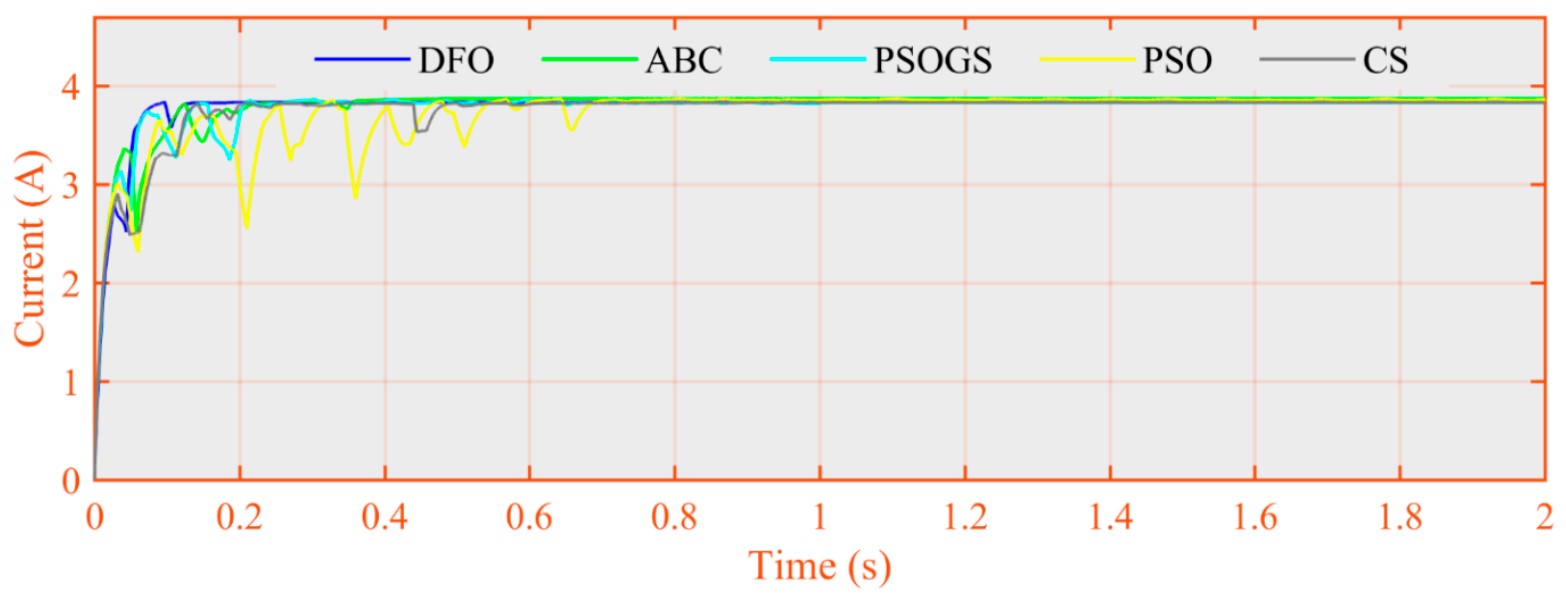

Figure 48. Case 2 current comparison.

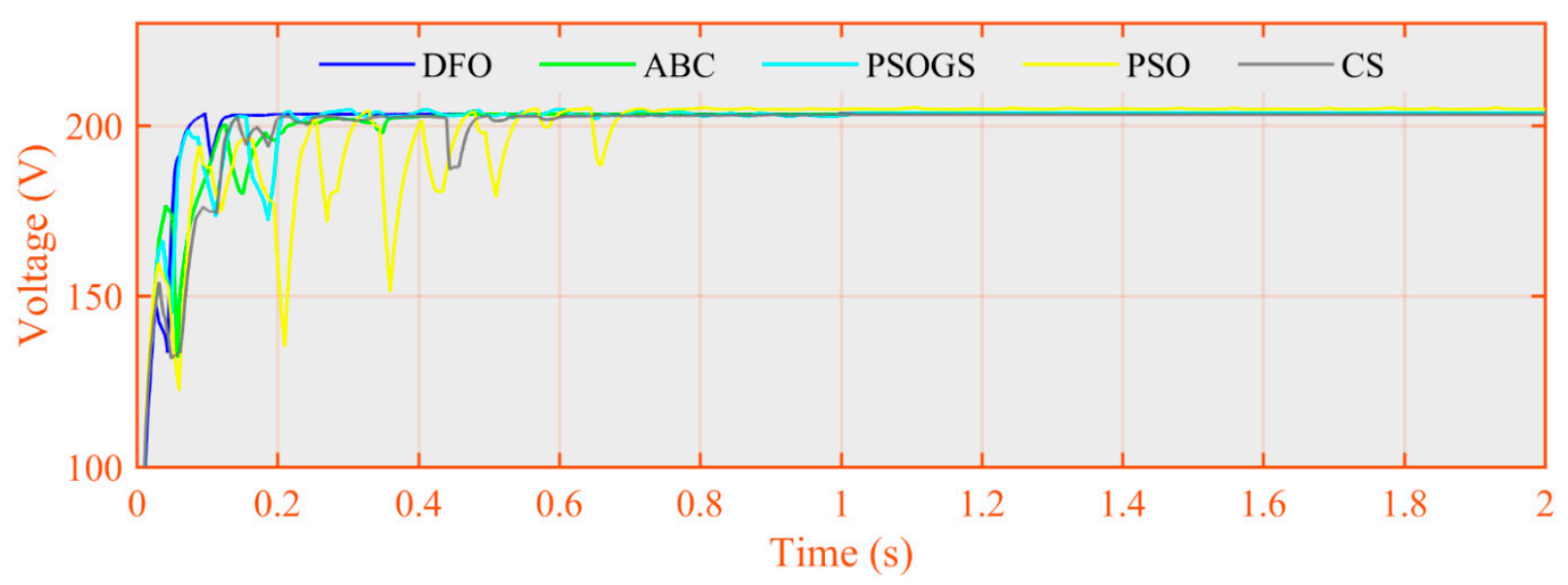

Figure 49. Case 2 voltage comparison.

\subsection{Case 3 Partial Shading}

Case 3 presents another partial shading condition. In this case, the GMPP is at 450 watts. The comparison is made in Figure 50 for the duty cycle. The duty cycle is further elaborated in Figure 51 with zoom in steady-state to show the oscillations and undesired disturbance in control action of implemented techniques. Certain MPPT techniques imply the random selection of searching particles to break the LM trap. This technique is useful but has a drawback. Random oscillations are produced when the casually selected particle is abandoned due to its weak fitness value. Oscillations are produced when the duty cycle obtained by random swarm particles with weak fitness value is abandoned immediately. The CS and PSO exhibit roughest random behavior. Since both techniques make use of randomly selected step size increments in duty cycle, the result can be seen in the form of undesired fluctuations. To enhance the performance of PSO, the gravitational search algorithm is utilized in PSOGS. This technique improvises and significantly minimizes the undesired oscillations and fluctuations in the control signal. The ABC makes use of information provided by onlooker bees, and new solutions do not opt unless a better solution is obtained. This mechanism helps to minimize oscillations. The DFO performs in a similar manner where all the particles are placed closely and follow the particle. With the selection of a candidate, the solution to provide output is not made unless 
a much better solution is produced. In case a new best solution is searched, the new best solution is designated as the global best solution and the rest of the swarm is organized around it simultaneously. This mechanism doesn't allow the selection of random solutions. As shown in results, oscillations are minimized successfully. The minimized oscillations diminish power dissipation and increase efficiency. As seen in the results, CS locates GM within $0.3092 \mathrm{~s}$ as compared to PSO $0.4009 \mathrm{~s}$, being $91 \mathrm{~ms}$ faster. However, careful examination shows that the PSO extracts $439.2 \mathrm{w}$ of power as compared to $430 \mathrm{w}$ by CS. PSOGS further improvises the oscillation reduction and on average produces $1.7556 \%$ more power as compared to PSO. It is concluded that oscillations reduce power harvesting significantly. Therefore, modifications are devised to minimize oscillations in steady state at GMPP.

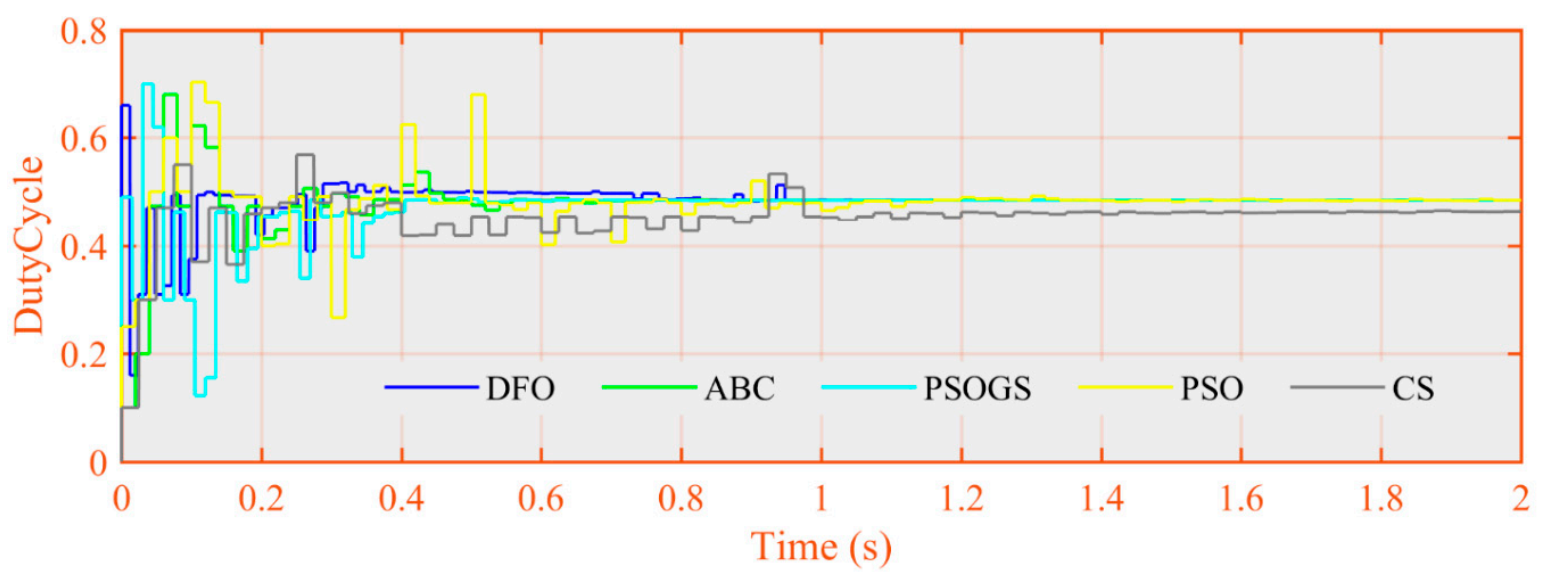

Figure 50. Case 3 duty cycle comparison.

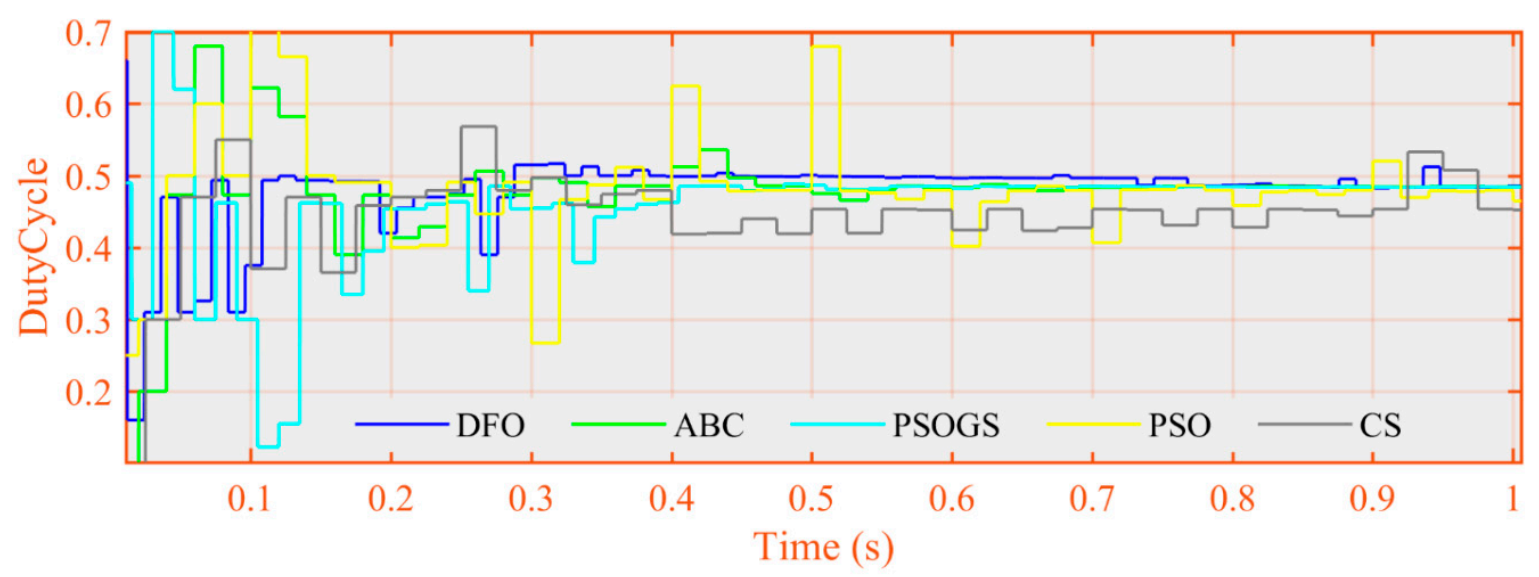

Figure 51. Case 3 zoom duty cycle comparison.

In Figures 52 and 53, the power obtained by DFO, ABC, PSOGS, PSO, and CS is compared for case 3. The efficiency and power are calculated against GMPP located at $450 \mathrm{w}$. The DFO, ABC, PSOGS, PSO, and CS obtain $438.7 \mathrm{w}, 448.8 \mathrm{w}, 447.1 \mathrm{w}, 439.2 \mathrm{w}$, and $430 \mathrm{w}$, respectively, with ABC being the most efficient technique. ABC has the highest efficiency of $99.73 \%$ followed by PSOGS $99.35 \%$, PSO $97.6 \%$, DFO $97.4 \%$, and CS has the least efficiency of $95.56 \%$. Robustness of a technique is exhibited by fast-tracking of GM and efficient settling time at GM. In Figures 52, 54 and 55, a comparison is made to analyze the robustness of studied techniques. Experimental simulations show that it takes DFO, ABC, PSOGS, PSO, and CS on average $0.2635 \mathrm{~s}, 0.3398 \mathrm{~s}, 0.3316 \mathrm{~s}, 0.4009 \mathrm{~s}$, and $0.3092 \mathrm{~s}$, and their settling time is $0.435 \mathrm{~s}, 0.5682 \mathrm{~s}, 0.4549 \mathrm{~s}, 0.8178 \mathrm{~s}$, and $0.849 \mathrm{~s}$, respectively. The current in Figure 54 and voltages in Figure 55 are compared. Results indicate that the stable voltage and current is produced by proposed DFO and PSOGS. On the other hand, the P\&O, PSO, and CS generate random oscillations. 


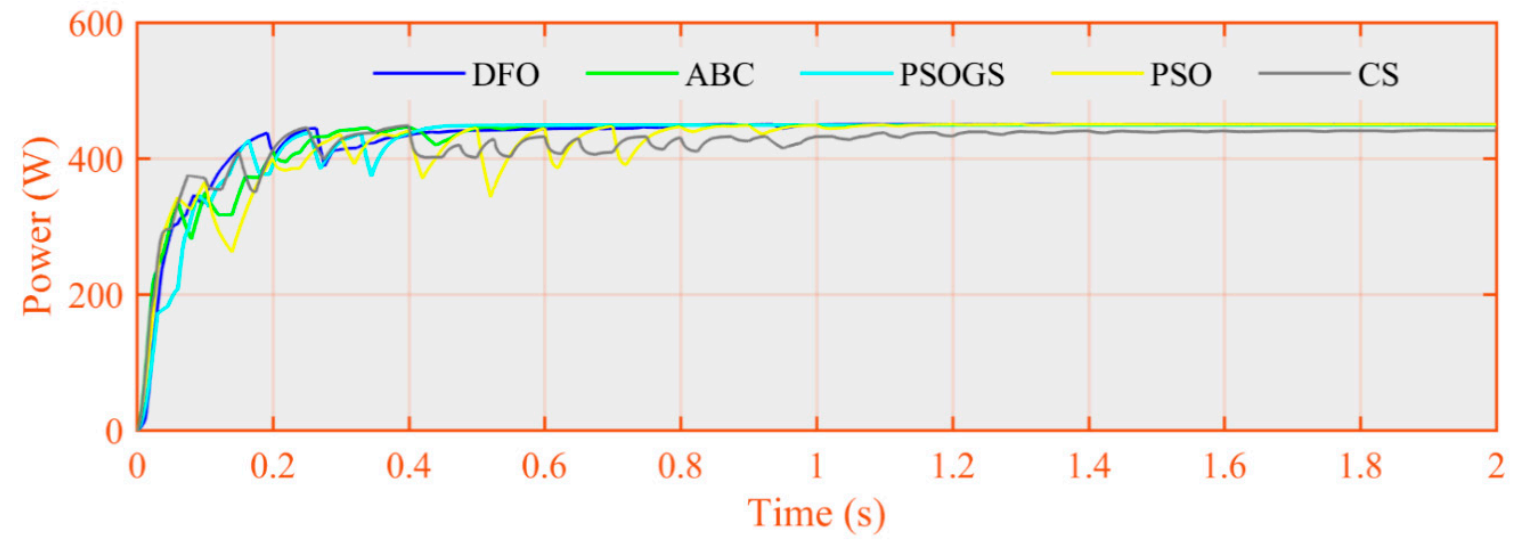

Figure 52. Case 3 power comparison.

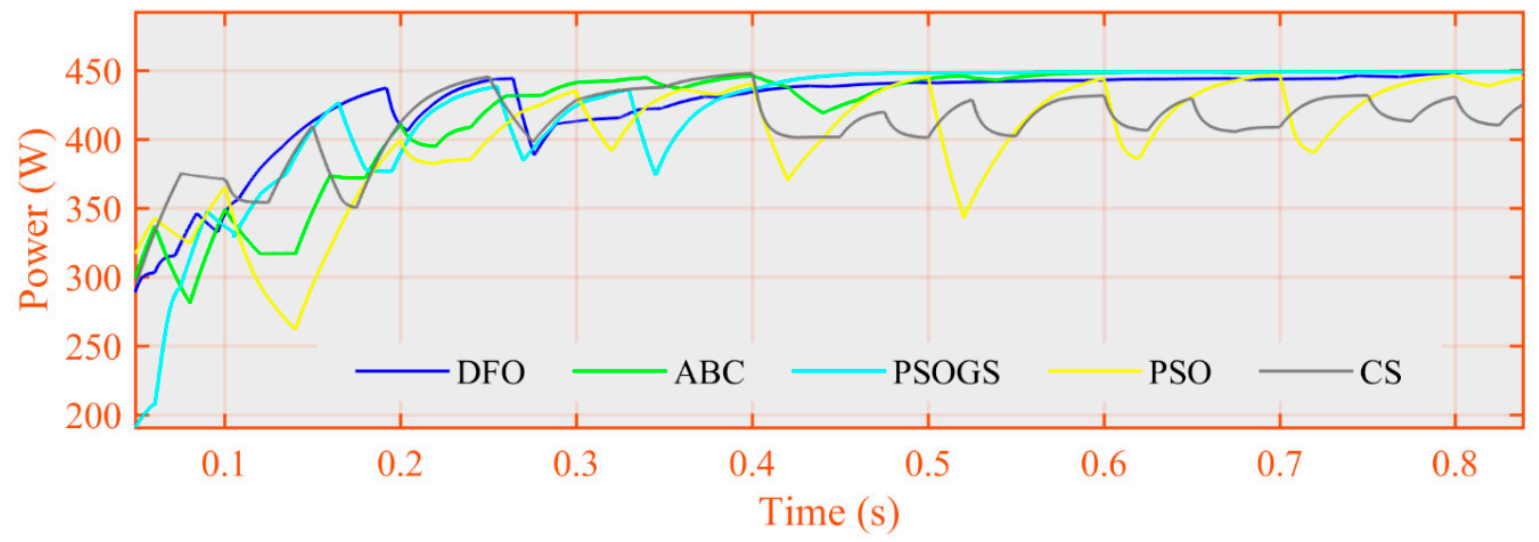

Figure 53. Case 3 zoom power comparison.

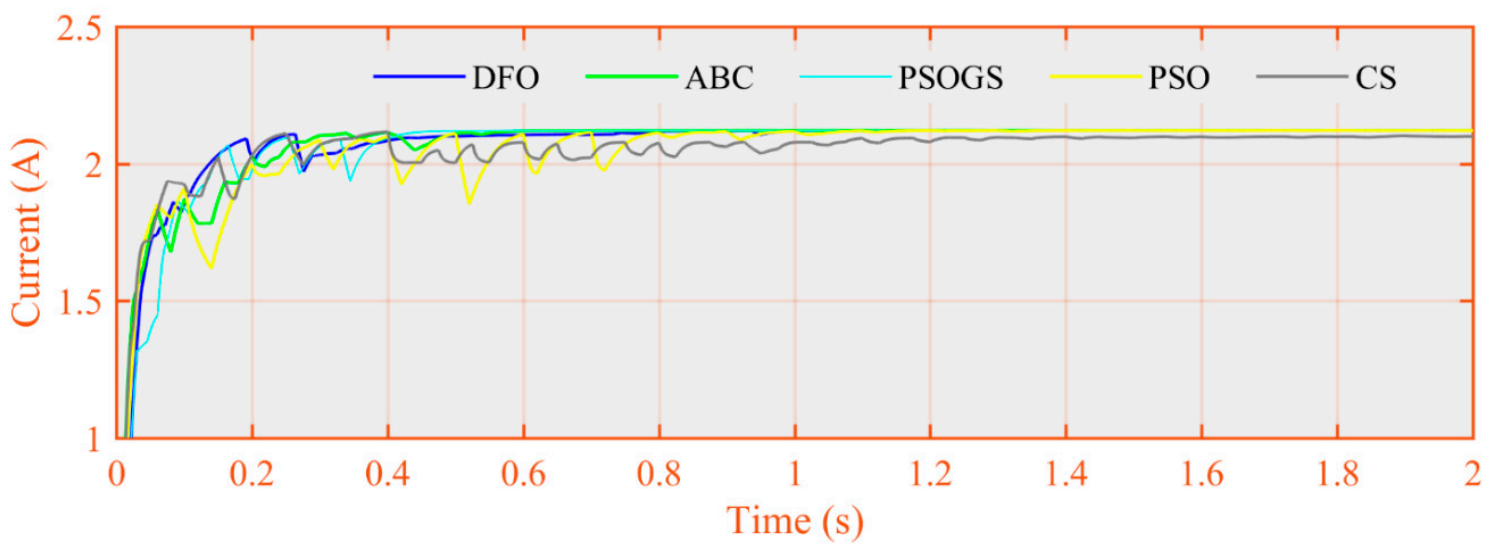

Figure 54. Case 3 current comparison. 


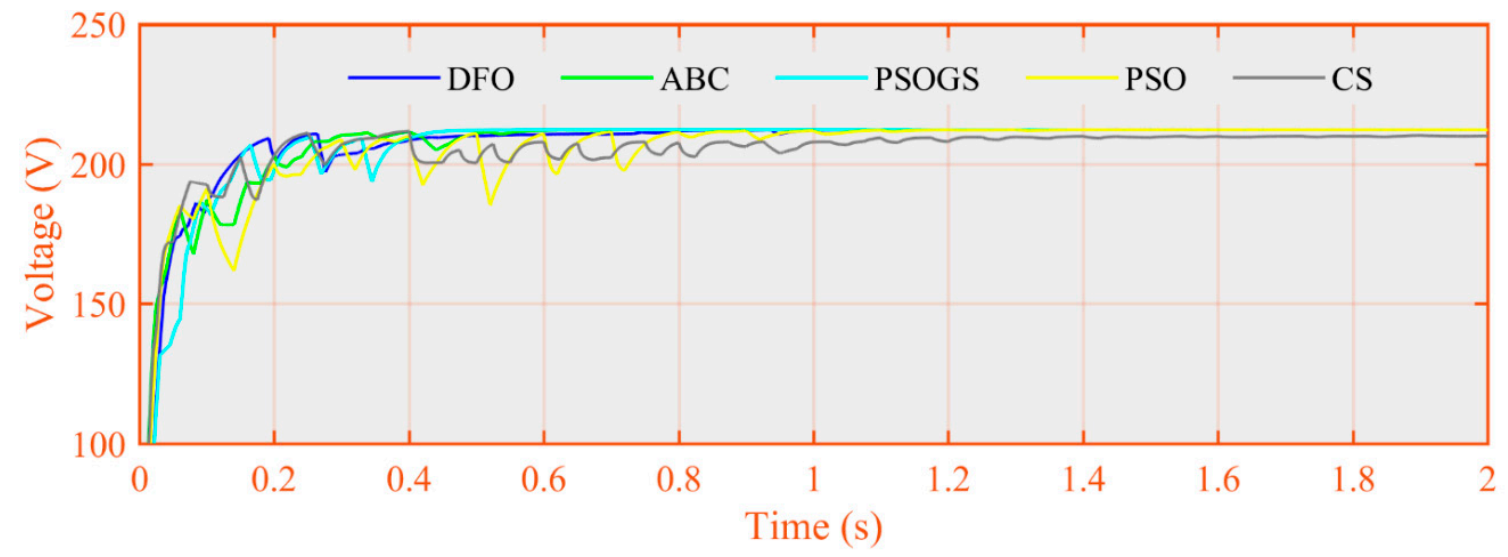

Figure 55. Case 3 voltage comparison.

\subsection{Case 4 Complex Partial Shading (CPS)}

Case 4 deals with CPS condition. The test pattern for this case is given in Table 7 . In this case, $12 \mathrm{PV}$ arrays are connected in series. Corresponding $\mathrm{P}-\mathrm{V}$ and $\mathrm{I}-\mathrm{V}$ curves for this case are presented in Figure 56. Performance comparison is made among well-known DFO, P\&O, ABC, PSOGS, PSO, and CS techniques. All techniques are optimized for better performance. The results of comparative power are given by Figure 57. The control action in PV MPPT is provided by the duty cycle of the boost converter and is given by Figure 58. In Figures 59 and 60, zoom figures of the power and duty cycle are given for closer examination in an iterative manner. A comparison is made to study the behavior of implemented techniques that incorporated their algorithmic natural behavior as per mathematical model.

Table 7. Irradiance levels for Case 4.

\begin{tabular}{ccccc}
\hline Case & \multicolumn{3}{c}{ Irradiance $\mathbf{S}_{\mathbf{i}}\left(\frac{\mathbf{k W}}{\mathbf{m}^{2}}\right)$} & $P_{\text {max }}$ \\
\hline \multirow{4}{*}{ Case 4 4} & PV11: 0.4 & PV12: 0.5 & PV13: 1.0 & \\
& PV21: 0.2 & PV22: 0.4 & PV23: 0.8 & $P_{\max }=1078 \mathrm{~W}$ \\
& PV31: 0.6 & PV32: 0.2 & PV33: 0.7 & \\
& PV41: 0.3 & PV42: 0.3 & PV43: 1.0 & \\
\hline
\end{tabular}

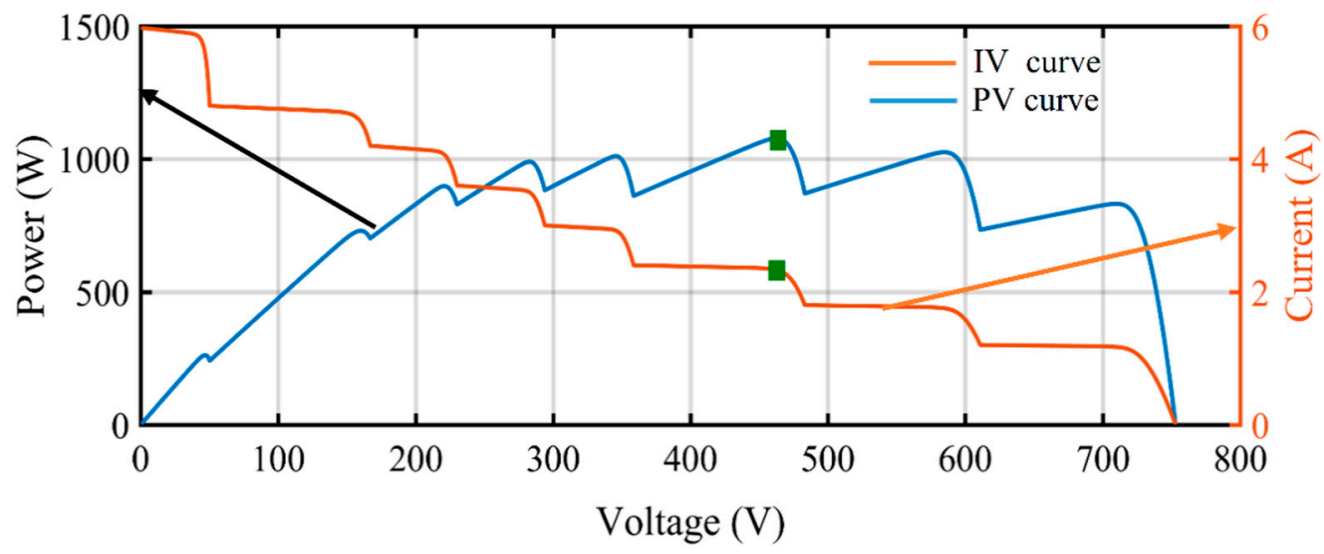

Figure 56. PV and IV curves for Case 4 (CPS). 


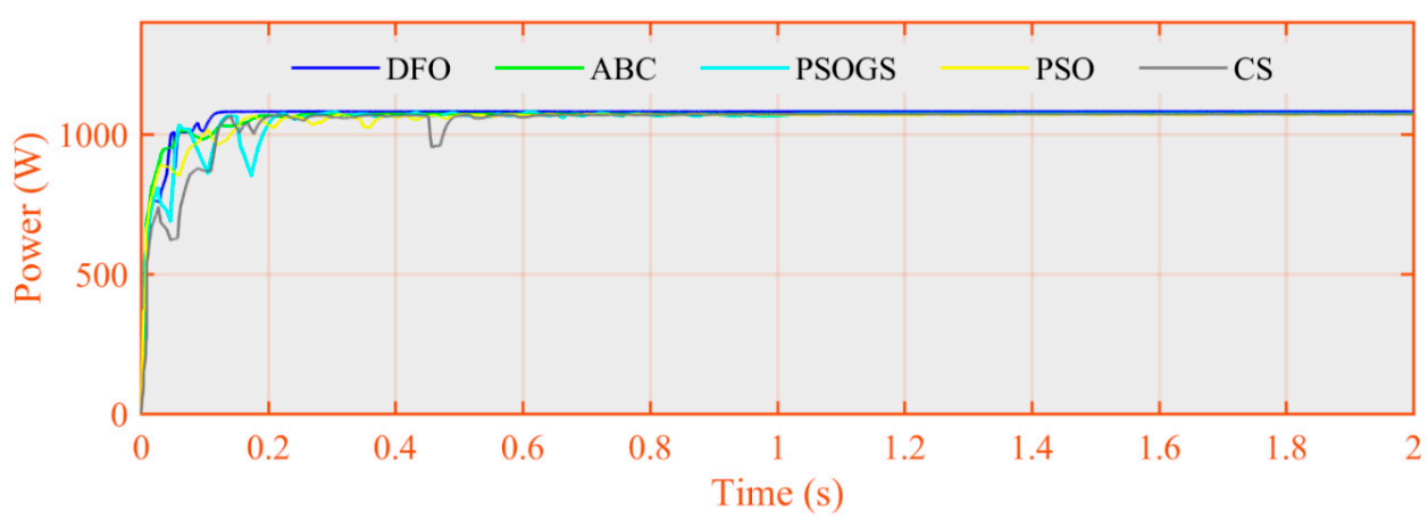

Figure 57. Case 4 power comparison.

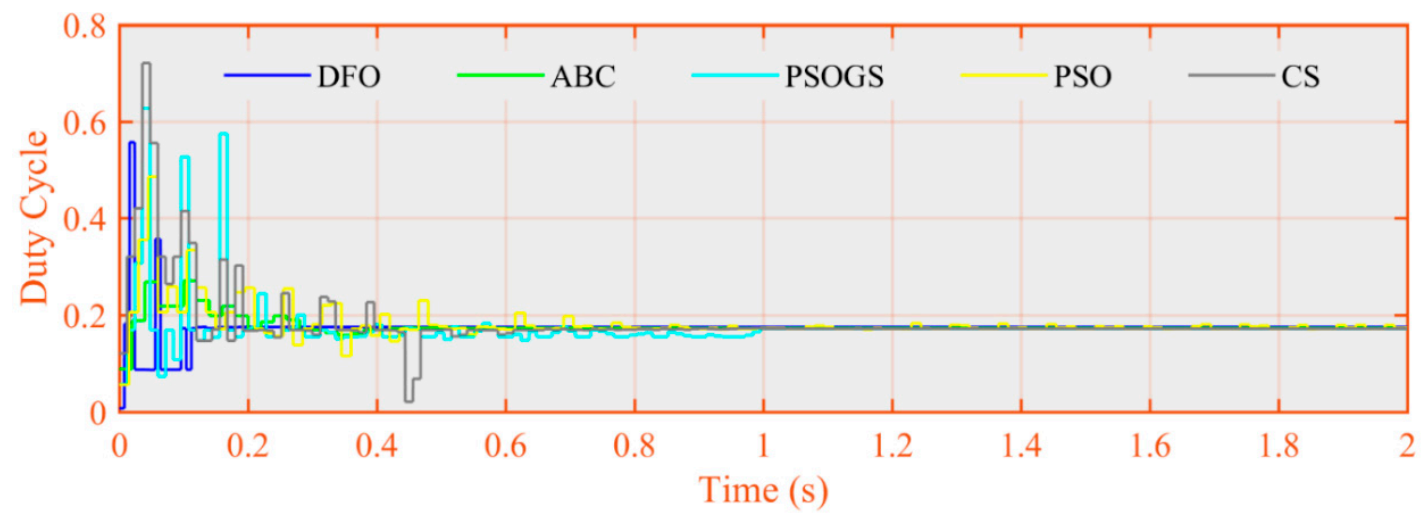

Figure 58. Case 4 duty cycle comparison.

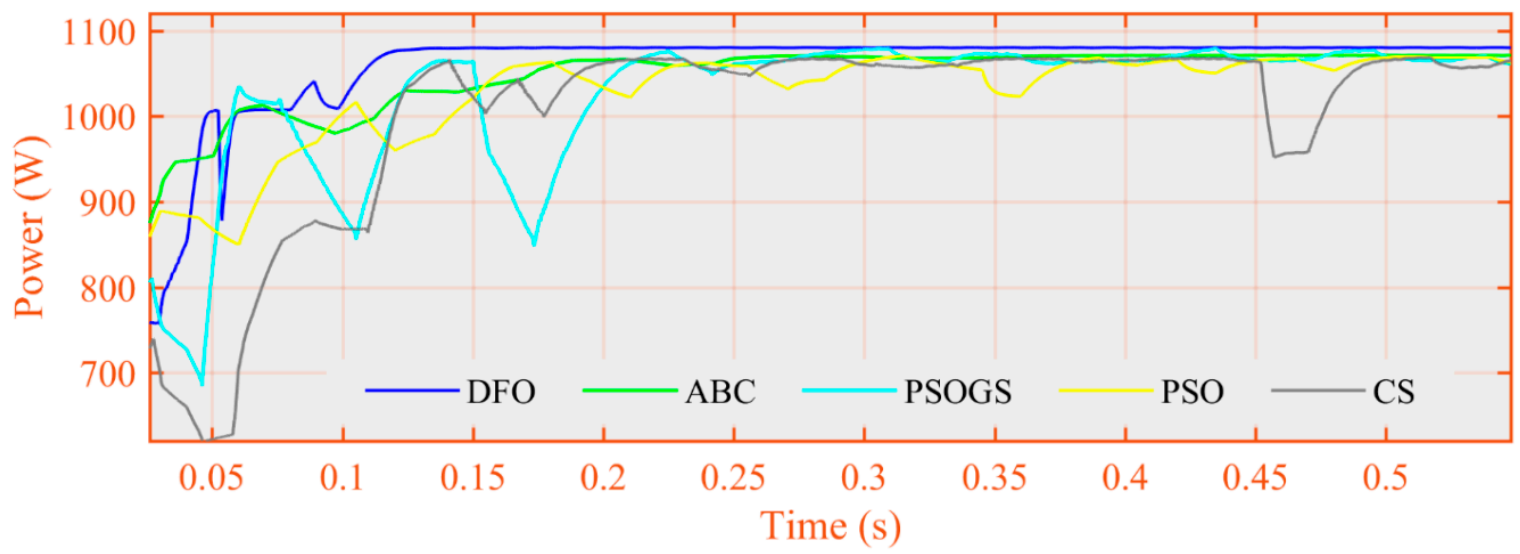

Figure 59. Case 4 power zoom comparison.

The maximum power achieved by DFO, ABC, PSOGS, PSO, and CS is 1074, 1066,1070,1068, and $1067 \mathrm{w}$, respectively. P\&O has achieved lowest $67.79 \%$, DFO $99.98 \%$, ABC $99.07 \%$, PSOGS $99.44 \%$, PSO $99.256 \%$, and CS $99.163 \%$. Figures 59 and 60 depict that the implemented techniques can successfully track GMPP in a different number of iterations. The oscillations are minimum for DFO. The current and voltage comparison corresponding to Case 4 are given by Figures 61 and 62, respectively. Stable output power and steady current are advantageous behaviors. However, the technique which lags in settling time suffers the most in the transient loss. It affects the overall performance and significantly reduces harvested power. 


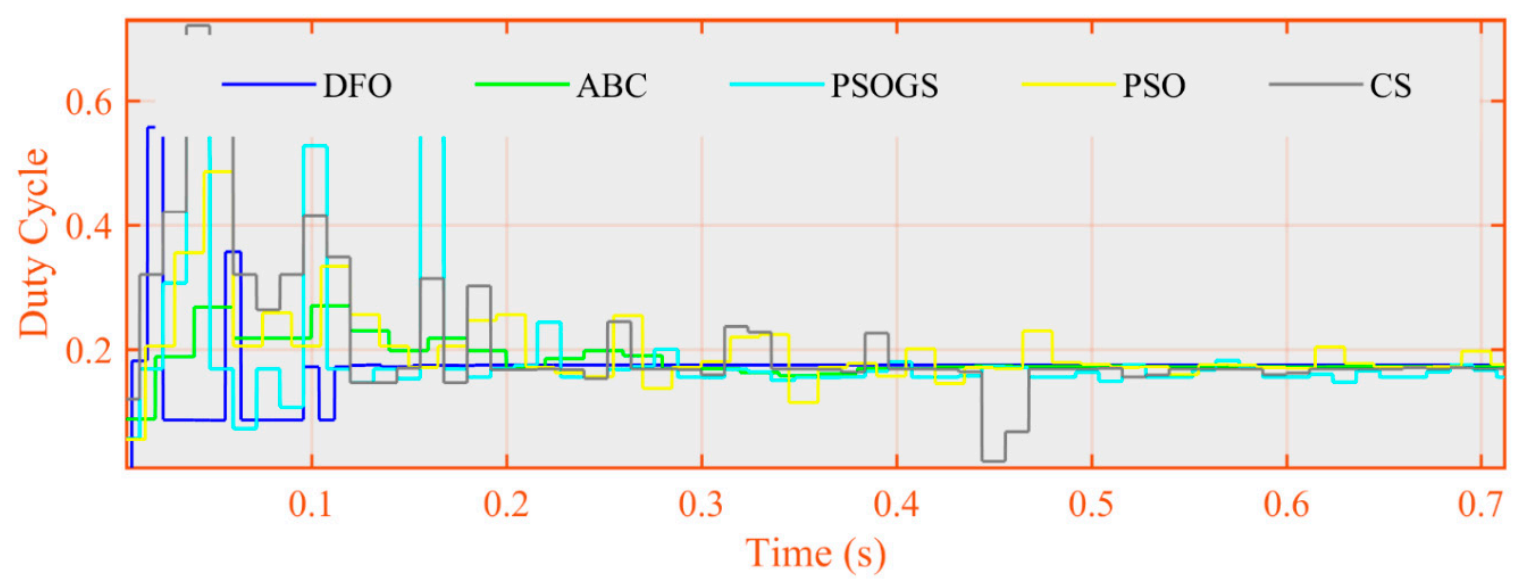

Figure 60. Case 4 zoom duty cycle comparison.

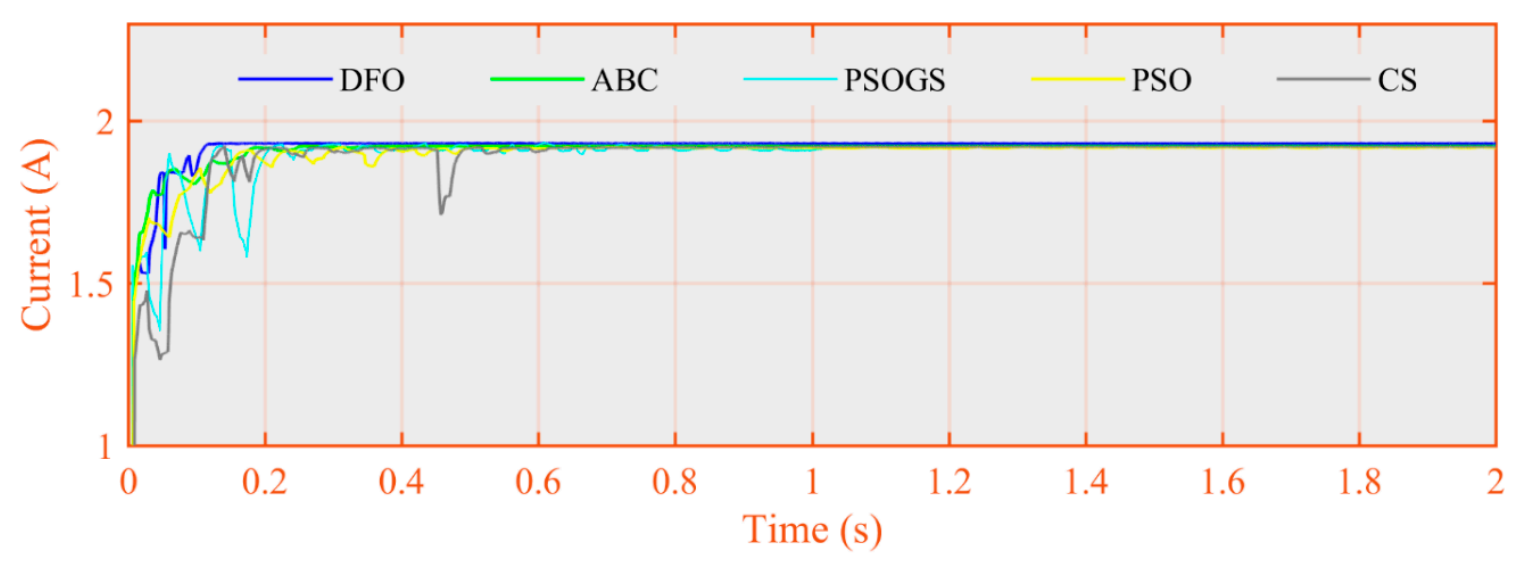

Figure 61. Case 4 current comparison.

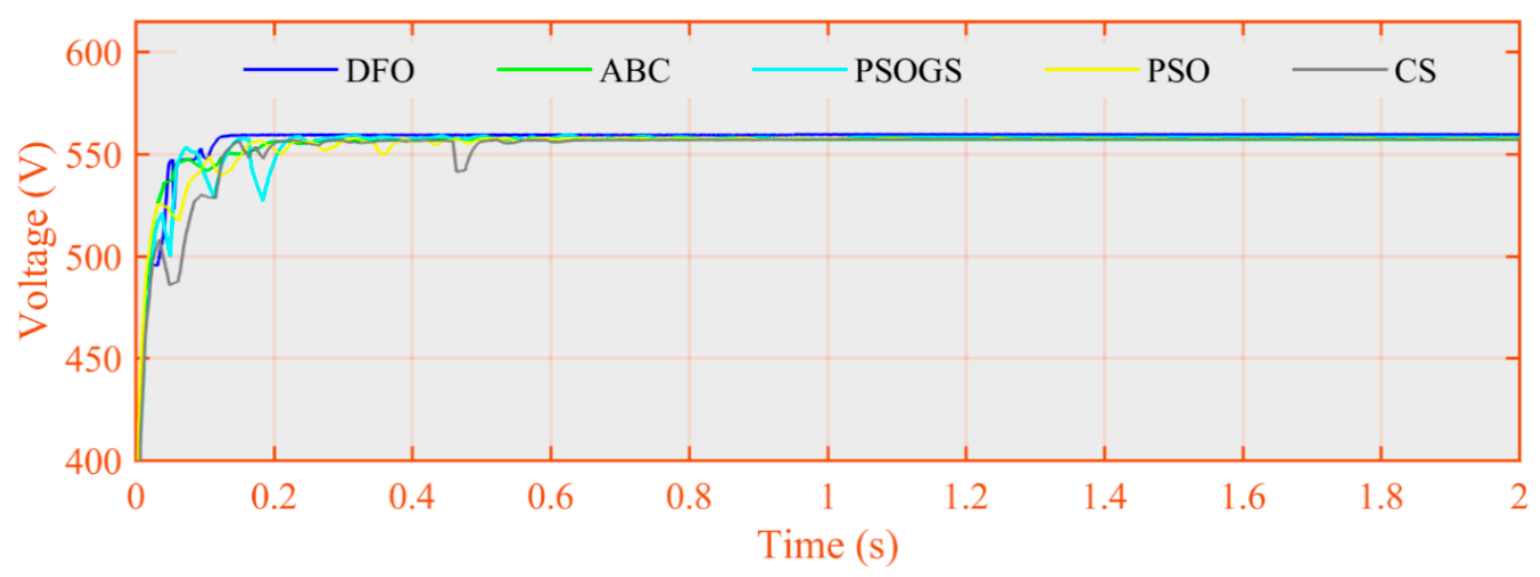

Figure 62. Case 4 voltage comparison.

Figure 63 illustrate that the time taken by DFO, ABC, PSOGS, PSO, and CS to track GM is $0.17 \mathrm{~s}$, $0.25 \mathrm{~s}, 0.31 \mathrm{~s}, 0.42 \mathrm{~s}$, and $0.40 \mathrm{~s}$, respectively. The settling time of each technique is $0.20 \mathrm{~s}, 0.31 \mathrm{~s}, 0.40 \mathrm{~s}$, $0.50 \mathrm{~s}$, and $0.51 \mathrm{~s}$, respectively. As illustrated in comparative results, $\mathrm{ABC}$ has a minimum settling time following DFO. It settles within $0.3 \mathrm{~s}$ and is on average $56 \mathrm{~ms}-300 \mathrm{~ms}$ faster under CPS conditions. CS, PSO, and PSOGS take over $600 \mathrm{~ms}$ each to settle at searched Maxima. The overall performance sequence in Case 4 is DFO $>$ ABC $>$ PSOGS $>$ CS $>$ PSO $>$ P\&O. 


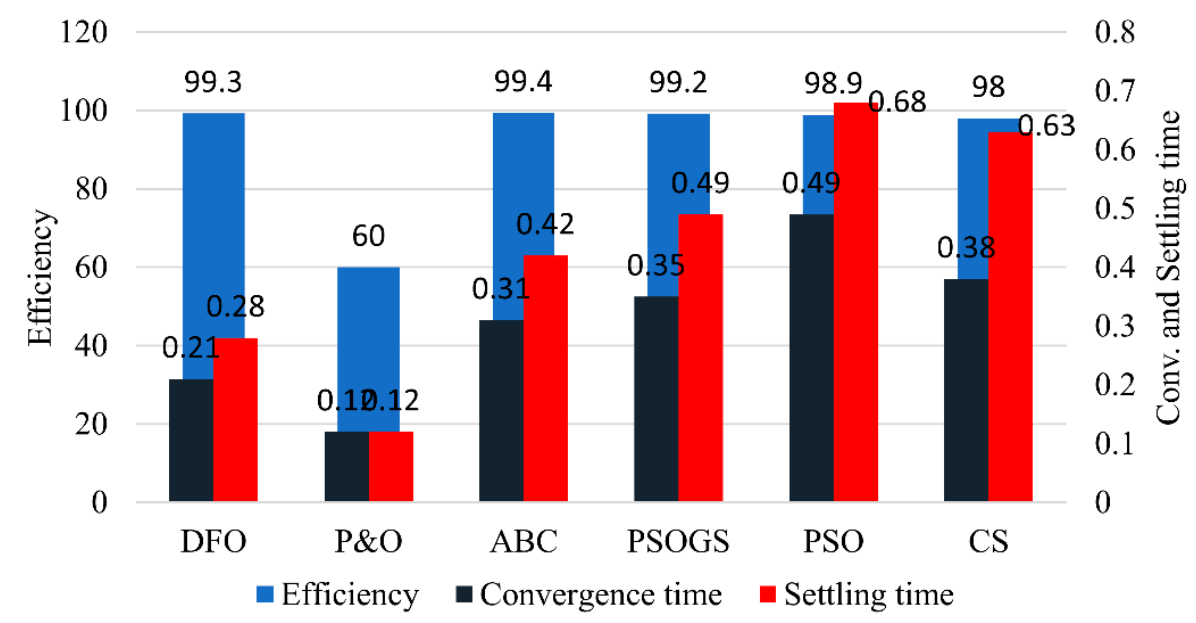

Figure 63. Average efficiency, convergence time and settling time of MPPT techniques.

\subsection{General Conclusions of Results}

The overall efficiency of all MPPT controllers under various test cases is performed, and MPPT controllers are simulated for comparative study. Based on the results, a general comparison is given in Table 8. It shows that bio-inspired techniques are highly adaptive, robust, and redundant in performance. $\mathrm{P} \& \mathrm{O}$ is converging fast in simple irradiance but doesn't converge in any PS and CPS cases. Its efficiency is lower as compared to ABC, PSO, DFO, PSO-GS, and CS in Case 1. Case 2 and Case 3 deal with PS. It is observed that the PSOGS, ABC, and DFO track the MPP with the highest efficiency, and output is oscillation free. PSO takes the longest duration of time to settle at GM; however, the PSOGS has minimized the loss in transient state improvising the PSO mechanism. Steady-state power loss is also minimized, hence energy provided by PSOGS is also higher. The CS, ABC, PSO, PSOGS, and P\&O convergence time is also comparable to a lot of other techniques presented in the literature. Case 4 shows again that these techniques handle CPS effectively. PSO performance is compromised because of particles' random initialization even after converging to GMPP. The ABC and CS show oscillations in both transient and steady-state due to which power is dissipated continuously. Tracking performance is reduced due to Levy flight and random values embedded in CS, and PSO. The DFO algorithm has been included in the comparative analysis because of highly effective characteristics. Coherence, enemy avoidance, and mutual interaction of closely spaced swarm particles help to reduce oscillations. Its results are observed in optimized performance. Results in Case 4 show $100 \%$ efficiency in GM location. The ABC having effective convergence to GMMP within $120 \mathrm{~ms}-320 \mathrm{~ms}$ indicates that this algorithm is highly robust.

Depending upon these results, it is safe to draw the following conclusions:

1. Traditional analytical gradient-based techniques are quick to track MPP in static irradiance and temperature. However, oscillations around GM and LM trap are major drawbacks.

2. Swarm-based techniques implying random variables, distribution functions or stochastic behavior for updating the candidate solutions can find GM successfully. However, due to randomness rooted in solution optimization, they have lower settling time and random oscillations are observed. Examples of such techniques are PSO and CS.

3. The techniques that involve multiple relations within swarm particles such as DFO and $A B C$ show better performance and are able to perform effectively under all weather conditions.

4. A larger number of swarm particles yield better final results; however, it takes a toll on computational resources and time. The practical implementation may become more expensive due to the utilization of costly hardware.

5. It is seen that medium-sized swarm population with multiple effective correlations within swarm particles proves to be more effective for MPPT of PV system under all circumstances. 
Table 8. Power, tracking and efficiency tabular comparison of existing techniques.

\begin{tabular}{|c|c|c|c|c|c|c|c|c|}
\hline Tech. & $\begin{array}{l}\text { Irradiance } \\
\text { Pattern }\end{array}$ & $\begin{array}{l}\text { Converge } \\
\text { Time (s) }\end{array}$ & $\begin{array}{l}\text { Settling Time } \\
\text { GMMP (s) }\end{array}$ & $\begin{array}{c}\text { MPP } \\
\text { Located }\end{array}$ & $\begin{array}{l}\text { Power (W) } \\
\text { at MPP }\end{array}$ & $\begin{array}{l}\text { Power (W) } \\
\text { Tracked }\end{array}$ & Energy & $\begin{array}{l}\text { Eff. } \\
(\%)\end{array}$ \\
\hline \multirow{4}{*}{ DFO } & Case 1 & 0.24 & 0.28 & Yes & 1260 & 1259.5 & $2.517 \times 10^{3}$ & 99.96 \\
\hline & Case 2 PS & 0.19 & 0.21 & Yes & 795 & 793.5 & $1.584 \times 10^{3}$ & 99.68 \\
\hline & Case 3 PS & 0.26 & 0.43 & Yes & 450 & 438.7 & 876.6 & 97.41 \\
\hline & Case 4 CPS & 0.17 & 0.20 & Yes & 1080 & 1074 & $2.156 \times 10^{3}$ & 99.98 \\
\hline \multirow{4}{*}{$\mathrm{P} \& \mathrm{O}$} & Case 1 & 0.12 & 0.12 & Yes & 1260 & 1237 & $2.46 \times 10^{3}$ & 98.17 \\
\hline & Case 2 PS & LM & LM & No & 795 & 396.4 & 791.6 & 49.79 \\
\hline & Case 3 PS & LM & LM & No & 450 & 304 & 609.3 & 67.70 \\
\hline & Case 4 CPS & $\mathrm{LM}$ & LM & No & 1080 & 264 & 520.0 & 24.40 \\
\hline \multirow{4}{*}{$\mathrm{ABC}$} & Case 1 & 0.33 & 0.38 & Yes & 1260 & 1259 & $2.512 \times 10^{3}$ & 99.92 \\
\hline & Case 2 PS & 0.35 & 0.45 & Yes & 795 & 789.4 & $1.576 \times 10^{3}$ & 99.17 \\
\hline & Case 3 PS & 0.33 & 0.56 & Yes & 450 & 448.8 & 895 & 99.73 \\
\hline & Case 4 CPS & 0.25 & 0.31 & Yes & 1080 & 1066 & $2.10 \times 10^{3}$ & 99.07 \\
\hline \multirow{4}{*}{ PSOGS } & Case 1 & 0.45 & 0.62 & Yes & 1260 & 1259 & $2.512 \times 10^{3}$ & 99.92 \\
\hline & Case 2 PS & 0.32 & 0.49 & Yes & 795 & 783.8 & $1.565 \times 10^{3}$ & 98.46 \\
\hline & Case 3 PS & 0.33 & 0.45 & Yes & 450 & 447.1 & 891.5 & 99.35 \\
\hline & Case 4 CPS & 0.31 & 0.40 & Yes & 1080 & 1070 & $2.14 \times 10^{3}$ & 99.44 \\
\hline \multirow{4}{*}{ PSO } & Case 1 & 0.47 & 0.70 & Yes & 1260 & 1257 & $2.500 \times 10^{3}$ & 99.76 \\
\hline & Case 2 PS & 0.68 & 0.70 & Yes & 795 & 791.5 & $1.570 \times 10^{3}$ & 99.43 \\
\hline & Case 3 PS & 0.41 & 0.81 & Yes & 450 & 439.2 & 876.5 & 97.60 \\
\hline & Case 4 CPS & 0.42 & 0.50 & Yes & 1080 & 1068 & $2.13 \times 10^{3}$ & 99.25 \\
\hline \multirow{4}{*}{ CS } & Case 1 & 0.46 & 0.69 & Yes & 1260 & 1258 & $2.511 \times 10^{3}$ & 99.84 \\
\hline & Case 2 PS & 0.35 & 0.45 & Yes & 795 & 778.6 & $1.55 \times 10^{3}$ & 97.81 \\
\hline & Case 3 PS & 0.30 & 0.84 & Yes & 450 & 430 & 859.5 & 95.56 \\
\hline & Case 4 CPS & 0.40 & 0.51 & Yes & 1080 & 1067 & $2.13 \times 10^{3}$ & 99.25 \\
\hline
\end{tabular}

\section{Conclusions}

In this work, a comprehensive review of MPPT methods is presented and categorized as conventional, soft computing, and optimization algorithms-based methods. This work presented developed techniques for MPPT to help readers understand and select suitable techniques for their specific problems. The cost effective and efficient extraction of maximum power from photovoltaic arrays depends on the MPPT control strategy. Various MPPT technologies are reviewed, and the block diagram, schematic diagram, working principle, algorithm, and their advantages and disadvantages are described. This paper summarizes the input, output, and hidden parameters of MPPT under the condition of uniform, rapid change and partial shadow. The conclusion of this paper is that most of the traditional MPPT algorithms perform MPP operation on photovoltaic arrays under uniform weather conditions, but they cannot get real MPP under fast changing and partial shading conditions. The intelligent and advanced algorithm drives the photovoltaic array to reach the real maximum power point under the condition of partial shadow and rapid change, but the algorithm is complex and difficult to be realized with embedded technology. This paper also provides evaluation criteria of various MPPT algorithms, which can help MPPT developers choose a convenient technology for any desired photovoltaic system. The potential application areas of the review document are also illustrated in tabular form, which refers to the load (resistance, inductance, battery and grid) of the MPPT. Here are some noteworthy suggestions, and performance of different techniques are presented. It is very difficult to say which technique is best as one has to consider various factors and parameters while selecting a technique such as application, convergence speed, accuracy, efficiency, system reliability, and cost and performance of available hardware.

Author Contributions: All authors contributed equally to this work.

Funding: This research received no external funding.

Conflicts of Interest: There is no conflict of interest. 


\section{References}

1. Villalva, M.G.; Gazoli, J.R.; Ruppert, E.F. Modeling and Circuit-Based Simulation of Photovoltaic Arrays. Braz. J. Power Electron. 2009, 14, 35-45.

2. KC200GT High Efficiency Multicrystal Photovoltaic Module n.d. Available online: https://www.kyocerasolar. com/dealers/product-center/archives/spec-sheets/KC200GT.pdf (accessed on 29 November 2019).

3. Renu, V.; Scholar, M.T. Optimal Control of Selective Harmonic Elimination in a Grid-Connected Single-Phase PV Inverter. In Proceedings of the 2014 International Conference on Advances in Green Energy (ICAGE), Thiruvananthapuram, India, 17-18 December 2014; pp. 265-271.

4. Zhang, L.; Hurley, W.G.; Wölfle, W.H. A new approach to achieve maximum power point tracking for PV system with a variable inductor. IEEE Trans. Power Electron. 2011, 26, 1031-1037. [CrossRef]

5. Ko, S.; Chao, R. Photovoltaic dynamic MPPT on a moving vehicle. Sol. Energy 2012, 86, 1750-1760. [CrossRef]

6. Chiu, C.-S.; Fuzzy, T.-S. Maximum Power Point Tracking Control of Solar Power Generation Systems. IEEE Trans. Energy Convers. 2010, 25, 1123-1132. [CrossRef]

7. Veerachary, M. Fourth-order buck converter for maximum power point tracking applications. IEEE Trans. Aerosp. Electron. Syst. 2011, 47, 896-911. [CrossRef]

8. Peter, P.K.; Agarwal, V. On the input resistance of a reconfigurable switched capacitor DC-DC converter-based maximum power point tracker of a photovoltaic source. IEEE Trans. Power Electron. 2012, 27, 4880-4893. [CrossRef]

9. Zhao, D.; Hari, V.S.S.P.K.; Narayanan, G.; Ayyanar, R. Space-vector-based hybrid pulsewidth modulation techniques for reduced harmonic distortion and switching loss. IEEE Trans. Power Electron. 2010, 25, 760-774. [CrossRef]

10. Koran, A.; Labella, T.; Lai, J. High Efficiency Photovoltaic Source Simulator with Fast Response Time for Solar Power Conditioning. IEEE Trans. Power Electron. 2014, 29, 1285-1297. [CrossRef]

11. Elgendy, M.A.; Zahawi, B.; Atkinson, D.J. Assessment of perturb and observe MPPT algorithm implementation techniques for PV pumping applications. IEEE Trans. Sustain. Energy 2012, 3, 21-33. [CrossRef]

12. Pernía, A.M.; Arias, J.; Prieto, M.J.; Martínez, J.Á. A modular strategy for isolated photovoltaic systems based on microcontroller. Renew. Energy 2009, 34, 1825-1832. [CrossRef]

13. Dragicevic, T.; Vasquez, J.C.; Skrlec, D. Supervisory Control of an Adaptive-Droop Regulated DC Microgrid With Battery Management Capability. IEEE Trans. Power Electron. 2014, 29, 695-706. [CrossRef]

14. Ahmed, N.A.; Miyatake, M.; Al-Othman, A.K. Power fluctuations suppression of stand-alone hybrid generation combining solar photovoltaic/wind turbine and fuel cell systems. Energy Convers. Manag. 2008, 49, 2711-2719. [CrossRef]

15. Kuo, C.L.; Lin, C.H.; Yau, H.T.; Chen, J.L. Using self-synchronization error dynamics formulation based controller for maximum photovoltaic power tracking in micro-grid systems. IEEE J. Emerg. Sel. Top. Circuits Syst. 2013, 3, 459-467. [CrossRef]

16. Agorreta, J.L.; Reinaldos, L.; González, R.; Borrega, M.; Balda, J.; Marroyo, L. Fuzzy switching technique applied to PWM boost converter operating in mixed conduction mode for PV systems. IEEE Trans. Ind. Electron. 2009, 56, 4363-4373. [CrossRef]

17. Veerachary, M.; Senjyu, T.; Uezato, K. Voltage-based maximum power point tracking control of PV system. IEEE Trans. Aerosp. Electron. Syst. 2002, 38. [CrossRef]

18. Wang, Z.; Li, H. An integrated three-port bidirectional DC-DC converter for PV application on a DC distribution system. IEEE Trans. Power Electron. 2013, 28, 4612-4624. [CrossRef]

19. Jiang, S.; Cao, D.; Li, Y.; Peng, F.Z. Grid-connected boost-half-bridge photovoltaic microinverter system using repetitive current control and maximum power point tracking. IEEE Trans. Power Electron. 2012, 27, 4711-4722. [CrossRef]

20. Alam, M.K.; Khan, F.; Imtiaz, A.M. Optimization of subcell interconnection for multijunction solar cells using switching power converters. IEEE Trans. Sustain. Energy 2013, 4, 340-349. [CrossRef]

21. Enne, R.; Nikolíc, M.; Zimmermann, H. Dynamic integrated MPP tracker in $0.35 \mu \mathrm{m}$ CMOS. IEEE Trans. Power Electron. 2013, 28, 2886-2894. [CrossRef]

22. Choi, W.Y.; Lee, C.G. Photovoltaic panel integrated power conditioning system using a high efficiency step-up DC-DC converter. Renew. Energy 2012, 41, 227-234. [CrossRef] 
23. Enrique, J.M.; Durán, E.; Sidrach-de-Cardona, M.; Andújar, J.M. Theoretical assessment of the maximum power point tracking efficiency of photovoltaic facilities with different converter topologies. Sol. Energy 2007, 81, 31-38. [CrossRef]

24. Urayai, C.; Amaratunga, G.A.J. Electronic load interface for improving PV dual-converter system operational margin. IET Renew. Power Gener. 2013, 7, 10-17. [CrossRef]

25. Wu, T.F.; Kuo, C.L.; Sun, K.H.; Chen, Y.K.; Chang, Y.R.; Lee, Y.D. Integration and operation of a single-phase bidirectional inverter with two buck/boost MPPTs for DC-distribution applications. IEEE Trans. Power Electron. 2013, 28, 5098-5106. [CrossRef]

26. Huusari, J.; Suntio, T. Origin of cross-coupling effects in distributed DC-DC converters in photovoltaic applications. IEEE Trans. Power Electron. 2013, 28, 4625-4635. [CrossRef]

27. Agamy, M.S.; Harfman-Todorovic, M.; Elasser, A.; Chi, S.; Steigerwald, R.L.; Sabate, J.A.; McCann, A.J.; Zhang, L.; Mueller, F.J. An Efficient Partial Power Processing DC/DC Converter for Distributed PV Architectures. IEEE Trans. Power Electron. 2014, 29, 674-686. [CrossRef]

28. Kassem, A.M. MPPT control design and performance improvements of a PV generator powered DC motor-pump system based on artificial neural networks. Int. J. Electr. Power Energy Syst. 2012, 43, 90-98. [CrossRef]

29. Agamy, M.S.; Chi, S.; Elasser, A.; Harfman-Todorovic, M.; Jiang, V.; Mueller, F.; Tao, F. A High Power Density DC-DC Converter for distributed PV architecture. IEEE J. Photovoltaics 2012, 3, 791-798. [CrossRef]

30. Safari, A.; Mekhilef, S. Simulation and hardware implementation of incremental conductance MPPT with direct control method using cuk converter. IEEE Trans. Ind. Electron. 2011, 58, 1154-1561. [CrossRef]

31. Knight, J.; Shirsavar, S.; Holderbaum, W. An improved reliability cuk based solar inverter with sliding mode control. IEEE Trans. Power Electron. 2006, 21, 1107-1115. [CrossRef]

32. Haseeb, M.; Jamil, M.; Faisal, M.F.F. Analysis of Three-Phase Two-Level PWM Inverter with LCL Filter using Classical Controllers for Renewable Energy Sources. In Proceedings of the International Conference on Energy and Sustainability, NED University Of Engineering And Technology, Karachi, Pakistan, 27 April 2013; pp. 63-67.

33. Rajesh, R.; Carolin Mabel, M. A comprehensive review of photovoltaic systems. Renew. Sustain. Energy Rev. 2015, 51, 231-248. [CrossRef]

34. Tse, K.K.; Ho, M.T.; Chung, H.S.H.; Hui, S.Y. A novel maximum power point tracker for PV panels using switching frequency modulation. IEEE Trans. Power Electron. 2002, 17, 980-989. [CrossRef]

35. Veerachary, M. Power tracking for nonlinear PV sources with coupled inductor SEPIC converter. IEEE Trans. Aerosp. Electron. Syst. 2005, 41, 1019-1029. [CrossRef]

36. Mamarelis, E.; Petrone, G.; Spagnuolo, G. Design of a sliding-mode-controlled SEPIC for PV MPPT applications. IEEE Trans. Ind. Electron. 2014, 61, 3387-3398. [CrossRef]

37. Chiang, S.J.; Shieh, H.J.; Chen, M.C. Modeling and control of PV charger system with SEPIC converter. IEEE Trans. Ind. Electron. 2009, 56, 4344-4353. [CrossRef]

38. Zhao, Y.; de Palma, J.; Mosesian, J.; Lyons, R.; Lehman, B. Line-Line Fault Analysis and Protection Challenges in Solar Photovoltaic Arrays. IEEE Trans. Ind. Electron. 2013, 60, 3784-3795. [CrossRef]

39. Seo, G.S.; Lee, K.C.; Cho, B.H. A new DC anti-islanding technique of electrolytic capacitor-less photovoltaic interface in DC distribution systems. IEEE Trans. Power Electron. 2013, 28, 1632-1641. [CrossRef]

40. Kim, Y.H.; Ji, Y.H.; Kim, J.G.; Jung, Y.C.; Won, C.Y. A new control strategy for improving weighted efficiency in photovoltaic AC module-type interleaved flyback inverters. IEEE Trans. Power Electron. 2013, 28, 2688-2699. [CrossRef]

41. Gao, M.; Chen, M.; Zhang, C.; Qian, Z.; Member, S. Analysis and Implementation of an Improved Flyback Inverter for Photovoltaic AC Module Applications. IEEE Trans. Power Electron. 2014, 29, 3428-3444. [CrossRef]

42. Sukesh, N.; Pahlevaninezhad, M.; Jain, P.K. Analysis and implementation of a single-stage flyback PV microinverter with soft switching. IEEE Trans. Ind. Electron. 2014, 61, 1819-1833. [CrossRef]

43. Edwin, F.F.; Xiao, W.; Khadkikar, V. Dynamic modeling and control of interleaved flyback module-integrated converter for PV power applications. IEEE Trans. Ind. Electron. 2014, 61, 1377-1388. [CrossRef]

44. Hsieh, G.; Member, S.; Hsieh, H.; Tsai, C.; Wang, C. Photovoltaic Power-Increment-Aided With Two-Phased Tracking. IEEE Trans. Power Electron. 2013, 28, 2895-2911. [CrossRef] 
45. Lee, J.H.; Park, J.H.; Jeon, J.H. Series-connected forward-flyback converter for high step-up power conversion. IEEE Trans. Power Electron. 2011, 26, 3629-3641. [CrossRef]

46. Thang, T.V.; Thao, N.M.; Jang, J.H.; Park, J.H. Analysis and design of grid-connected photovoltaic systems with multiple-integrated converters and a pseudo-dc-link inverter. IEEE Trans. Ind. Electron. 2014, 61, 3377-3386. [CrossRef]

47. Aleenejad, M.; Ahmadi, R.; Moamaei, P. Selective Harmonic Elimination for Cascaded Multicell Multilevel Power Converters with Higher Number of H-bridge Modules. In Proceedings of the 2014 Power and Energy Conference at Illinois (PECI), Champaign, IL, USA, 28 February-1 March 2014; pp. 3-7.

48. Panda, A.K.; Patnaik, S.S. Analysis of cascaded multilevel inverters for active harmonic filtering in distribution networks. Int. J. Electr. Power Energy Syst. 2015, 66, 216-226. [CrossRef]

49. Moeed Amjad, A.; Salam, Z. A review of soft computing methods for harmonics elimination PWM for inverters in renewable energy conversion systems. Renew. Sustain. Energy Rev. 2014, 33, 141-153. [CrossRef]

50. Rita, A.; Fazio, D.; Russo, M. Photovoltaic generator modelling to improve numerical robustness of EMT simulation. Electr. Power Syst. Res. 2012, 83, 136-143. [CrossRef]

51. Singh, G.K. Solar power generation by PV (photovoltaic) technology: A review. Energy 2013, 53, 1-13. [CrossRef]

52. Kouro, S.; Malinowski, M.; Gopakumar, K.; Pou, J.; Franquelo, L.G.; Wu, B.; Rodriguez, J.; Pérez, M.A.; Leon, J.I. Recent Advances and Industrial Applications of Multilevel Converters. IEEE Trans. Ind. Electron. 2010, 57, 2553-2580. [CrossRef]

53. Rodríguez, J.; Member, S.; Bernet, S.; Wu, B.; Member, S.; Pontt, J.O.; Kouro, S. Multilevel Voltage-Source-Converter Topologies for Industrial Medium-Voltage Drives. IEEE Trans. Ind. Electron. 2007, 54, 2930-2945. [CrossRef]

54. Tai, B.; Gao, C.; Liu, X.; Lv, J. A Voltage Balancing Controller with Fuzzy Logic Strategy for Neutral Point Clamped Multilevel Converter. In Proceedings of the 2014 17th International Conference on Electrical Machines and Systems (ICEMS), Hangzhou, China, 22-25 October 2014; pp. 2490-2494.

55. Amini, J. An Effortless Space-Vector-Based Modulation for N -level Flying Capacitor Multilevel Inverter With. IEEE Trans. Power Electron. 2014, 29, 6188-6195. [CrossRef]

56. Babaei, E.; Laali, S.; Member, S.; Bayat, Z. A Single-Phase Cascaded Multilevel Inverter Based on a New Basic Unit With Reduced Number of Power Switches. IEEE Trans. Ind. Electron. 2015, 62, 922-929. [CrossRef]

57. Reddy, M.; Gowrimanohar, T. Comparison of five level and seven level cascaded multilevel inverter based dstacom for compensation of harmonics and reactive power using instantaneous real-power theory. In Proceedings of the 2012 International Conference on Emerging Trends in Electrical Engineering and Energy Management (ICETEEEM), Chennai, India, 13-15 December 2012; pp. 355-360. [CrossRef]

58. Murtaza, A.; Chiaberge, M.; Giuseppe, M.; De Boero, D. A duty cycle optimization based hybrid maximum power point tracking technique for photovoltaic systems. Int. J. Electr. Power Energy Syst. 2014, 59, 141-154. [CrossRef]

59. Murtaza, A.; Chiaberge, M.; Spertino, F.; Boero, D.; De Giuseppe, M. A maximum power point tracking technique based on bypass diode mechanism for PV arrays under partial shading. Energy Build. 2014, 73, 13-25. [CrossRef]

60. Femia, N.; Giovanni, P.; Massimo, V. Power Electronics and Control Techniuqes for Maximum Energy Harvesting in Photvotltaic System; CRC Press; Taylor \& Francis Group: Boca Raton, FL, USA, 2012.

61. Alajmi, B.N.; Ahmed, K.H.; Finney, S.J.; Williams, B.W. Fuzzy-logic-control approach of a modified hill-climbing method for maximum power point in microgrid standalone photovoltaic system. IEEE Trans. Power Electron. 2011, 26, 1022-1030. [CrossRef]

62. Radjai, T.; Rahmani, L.; Mekhilef, S.; Gaubert, J.P. Implementation of a modified incremental conductance MPPT algorithm with direct control based on a fuzzy duty cycle change estimator using dSPACE. Sol. Energy 2014, 110, 325-337. [CrossRef]

63. Murtaza, A.F.; Sher, H.A.; Chiaberge, M.; Boero, D.; De Giuseppe, M.; Addoweesh, K.E. Optimization of the Perturb and Observe Maximum Power Point Tracker for a Distributed Photovoltaic System. In Proceedings of the International Multi Topic Conference (INMIC), Lahore, Pakistan, 19-20 December 2013; pp. 77-82. [CrossRef]

64. Shivashankar, S.; Mekhilef, S.; Mokhlis, H.; Karimi, M. Mitigating methods of power fluctuation of photovoltaic (PV) sources-A review. Renew. Sustain. Energy Rev. 2016, 59, 1170-1184. [CrossRef] 
65. Jusoh, A.; Baamodi, H.; Mekhilef, S. Active damping network in DC distributed power system driven by photovoltaic system. Sol. Energy 2013, 87, 254-267. [CrossRef]

66. Murtaza, A.F.; Sher, H.A.; Chiaberge, M.; Boero, D.; Giuseppe, M.D.; Addoweesh, K.E. A novel hybrid MPPT technique for solar PV applications using perturb \& observe and Fractional Open Circuit Voltage techniques. In Proceedings of the 15th International Conference MECHATRONIKA, Prague, Czech Republic, 5-7 December 2012; pp. 1-8.

67. Sher, H.A.; Murtaza, A.F.; Addoweesh, K.E.; Chiaberge, M. A two stage Hybrid Maximum Power Point Tracking Technique for Photovoltaic Applications. In Proceedings of the 2014 IEEE PES General Meeting | Conference \& Exposition, National Harbor, MD, USA, 27-31 July 2014; pp. 1-5.

68. Lian, K.L.; Jhang, J.H.; Tian, I.S. A Maximum Power Point Tracking Method Based on Perturb-and-Observe Combined With Particle Swarm Optimization. IEEE J. Photovolt. 2014, 4, 626-633. [CrossRef]

69. Kamarzaman, N.A.; Tan, C.W. A comprehensive review of maximum power point tracking algorithms for photovoltaic systems. Renew. Sustain. Energy Rev. 2014, 37, 585-598. [CrossRef]

70. Krishna, K.S.; Kumar, K.S. A review on hybrid renewable energy systems. Renew. Sustain. Energy Rev. 2015, 52, 907-916. [CrossRef]

71. Bounechba, H.; Bouzid, A.; Snani, H.; Lashab, A. Electrical Power and Energy Systems Real time simulation of MPPT algorithms for PV energy system. Int. J. Electr. Power Energy Syst. 2016, 83, 67-78. [CrossRef]

72. Javed, M.Y.; Ling, Q.; Gulzar, M.M.; Hussain, S.T.; Arif, A. A hybrid technique to harvest maximum power from PV system for Partial Shading Problem. In Proceedings of the 2016 International Conference on Emerging Technologies (ICET), Islamabad, Pakistan, 18-19 October 2016; pp. 1-5. [CrossRef]

73. Huang, Y.P.; Hsu, S.Y. A performance evaluation model of a high concentration photovoltaic module with a fractional open circuit voltage-based maximum power point tracking algorithm. Comput. Electr. Eng. 2016, 51,331-342. [CrossRef]

74. Murtaza, A.F.; Sher, H.A.; Chiaberge, M.; Boero, D.; De Giuseppe, M.; Addoweesh, K.E. Comparative analysis of maximum power point tracking techniques for PV applications. In Proceedings of the IEEE International Multi Topic Conference (INMIC), Lahore, Pakistan, 19-20 December 2013; pp. 83-88. [CrossRef]

75. Houssamo, I.; Locment, F.; Sechilariu, M. Experimental analysis of impact of MPPT methods on energy efficiency for photovoltaic power systems. Int. J. Electr. Power Energy Syst. 2013, 46, 98-107. [CrossRef]

76. Gonzalez, D.; Andrés, C.; Paja, R.; Giral, R. Maximum power point tracking of photovoltaic systems based on the sliding mode control of the module admittance. Electr. Power Syst. Res. 2016, 136, 125-134. [CrossRef]

77. Ahmed, J.; Salam, Z. A Maximum Power Point Tracking (MPPT) for PV system using Cuckoo Search with partial shading capability. Appl. Energy 2014, 119, 118-130. [CrossRef]

78. Yang, B.; Zhong, L.; Zhang, X.; Shu, H.; Yu, T.; Li, H.; Jiang, L.; Sun, L. Novel bio-inspired memetic salp swarm algorithm and application to MPPT for PV systems considering partial shading condition. J. Clean. Prod. 2019, 215, 1203-1222. [CrossRef]

79. Patel, H.; Agarwal, V. MATLAB-based modeling to study the effects of partial shading on PV array characteristics. IEEE Trans. Energy Convers. 2008, 23, 302-310. [CrossRef]

80. Shi, J.; Zhang, W.; Zhang, Y.; Xue, F.; Yang, T. MPPT for PV systems based on a dormant PSO algorithm. Electr. Power Syst. Res. 2015, 123, 100-107. [CrossRef]

81. Conditions, P.; Koutroulis, E.; Blaabjerg, F. A New Technique for Tracking the Global Maximum Power Point of PV Arrays Operating Under. IEEE J. Photovolt. 2012, 2, 184-190.

82. Spertino, F.; Ahmad, J.; Ciocia, A.; Di Leo, P.; Murtaza, A.F.; Chiaberge, M. Capacitor charging method for I-V curve tracer and MPPT in photovoltaic systems. Sol. Energy 2015, 119, 461-473. [CrossRef]

83. Ishaque, K.; Salam, Z. A review of maximum power point tracking techniques of PV system for uniform insolation and partial shading condition. Renew. Sustain. Energy Rev. 2013, 19, 475-488. [CrossRef]

84. Salam, Z.; Ahmed, J.; Merugu, B.S. The application of soft computing methods for MPPT of PV system: A technological and status review. Appl. Energy 2013, 107, 135-148. [CrossRef]

85. Veerachary, M.; Yadaiah, N. ANN based peak power tracking for PV supplied DC motors. Sol. Energy 2000, 69, 343-350. [CrossRef]

86. Amrouche, B.; Belhamel, M.; Guessoum, A. Artificial intelligence based P \& O MPPT method for photovoltaic systems. Rev. Energ. Renouvelables ICRESD 07 Tlemcen 2007, 11-16. 
87. Punitha, K.; Devaraj, D.; Sakthivel, S. Artificial neural network based modified incremental conductance algorithm for maximum power point tracking in photovoltaic system under partial shading conditions. Energy 2013, 62, 330-340. [CrossRef]

88. Xu, J.; Shen, A.; Yang, C.; Rao, W.; Yang, X. ANN based on IncCond algorithm for MPP tracker. In Proceedings of the 2011 Sixth International Conference on Bio-Inspired Computing: Theories and Applications, Penang, Malaysia, 27-29 September 2011; pp. 129-134. [CrossRef]

89. Alabedin, A.Z.; El-Saadany, E.F.; Salama, M.M.A. Maximum power point tracking for Photovoltaic systems using fuzzy logic and artificial neural networks. In Proceedings of the 2011 IEEE Power and Energy Society General Meeting, Detroit, MI, USA, 24-28 July 2011; pp. 1-9. [CrossRef]

90. Ramaprabha, R.; Gothandaraman, V.; Kanimozhi, K.; Divya, R.; Mathur, B.L. Maximum power point tracking using GA-optimized artificial neural network for Solar PV system. In Proceedings of the 2011 1st International Conference on Electrical Energy Systems, Newport Beach, CA, USA, 3-5 January 2011; pp. 264-268. [CrossRef]

91. Jie, L.; Ziran, C. Research on the MPPT algorithms of photovoltaic system based on PV neural network. In Proceedings of the 2011 Chinese Control and Decision Conference (CCDC), Mianyang, China, 23-25 May 2011; pp. 1851-1854. [CrossRef]

92. Islam, M.A.; Kabir, M.A. Neural network based maximum power point tracking of photovoltaic arrays. In Proceedings of the TENCON 2011-2011 IEEE Region 10 Conference, Bali, Indonesia, 21-24 November 2011; pp. 79-82. [CrossRef]

93. Hunt, J. Evolutionary case based design. In UK Workshop on Case-Based Reasoning; Springer: Berlin/Heidelberg, Germany, 1995; pp. 17-31. [CrossRef]

94. Singiresu, S.R. Engineering Optimization, 4th ed.; John Wiley \& Sons, Inc.: Hoboken, NJ, USA, 2009.

95. Kwang, Y.; Lee, M.A.E.-S. Modern Heuristic Optimization Techniques; Wiley Interscience: Hoboken, NJ, USA, 2007.

96. Ahmed, J.; Salam, Z. A critical evaluation on maximum power point tracking methods for partial shading in PV systems. Renew. Sustain. Energy Rev. 2015, 47, 933-953. [CrossRef]

97. Konstantopoulos, C.; Koutroulis, E. Global Maximum Power Point Tracking of Flexible Photovoltaic Modules. IEEE Trans. Power Electr. 2014, 29, 2817-2828. [CrossRef]

98. Akkaya, R.; Kulaksız, A.A.; Aydoğdu, Ö. DSP implementation of a PV system with GA-MLP-NN based MPPT controller supplying BLDC motor drive. Energy Convers. Manag. 2007, 48, 210-218. [CrossRef]

99. Messai, A.; Mellit, A.; Guessoum, A.; Kalogirou, S.A. Maximum power point tracking using a GA optimized fuzzy logic controller and its FPGA implementation. Sol. Energy 2011, 85, 265-277. [CrossRef]

100. Daraban, S.; Petreus, D.; Morel, C. A novel MPPT (maximum power point tracking) algorithm based on a modi fi ed genetic algorithm specialized on tracking the global maximum power point in photovoltaic systems affected by partial shading. Energy 2014, 74, 374-388. [CrossRef]

101. Miyatake, M.; Veerachary, M.; Toriumi, F.; Fujii, N.; Ko, H. Maximum power point tracking of multiple photovoltaic arrays: A PSO approach. IEEE Trans. Aerosp. Electron. Syst. 2011, 47, 367-380. [CrossRef]

102. Ishaque, K.; Salam, Z.; Shamsudin, A.; Amjad, M. A direct control based maximum power point tracking method for photovoltaic system under partial shading conditions using particle swarm optimization algorithm. Appl. Energy 2012, 99, 414-422. [CrossRef]

103. Omar, A.; Hasanien, H.M.; Elgendy, M.A.; Badr, M.A. Identification of the photovoltaic model parameters using the crow search algorithm. J. Eng. 2017, 1570-1575. [CrossRef]

104. Li, L.L.; Lin, G.Q.; Tseng, M.L.; Tan, K.; Lim, M.K. A maximum power point tracking method for PV system with improved gravitational search algorithm. Appl. Soft. Comput. 2018, 65, 333-348. [CrossRef]

105. Sundareswaran, K.; Simon, S.P.; Nayak, P.S.R. Gravitational search algorithm combined with P \& O method for MPPT in PV systems. In Proceedings of the 2016 IEEE Annual India Conference (INDICON), Bangalore, India, 16-18 December 2016.

106. Kumar, N.; Hussain, I.; Singh, B.; Panigrahi, B.K. Single Sensor-Based MPPT of Partially Shaded PV System for Battery Charging by Using Cauchy and Gaussian Sine Cosine Optimization. IEEE Trans. Energy Convers. 2017, 32, 983-992. [CrossRef]

107. Kumar, N.; Hussain, I.; Singh, B.; Panigrahi, B.K. Single sensor based MPPT for partially shaded solar photovoltaic by using human psychology optimisation algorithm. IET Gener. Transm. Distrib. 2017, 11, 2562-2574. [CrossRef] 
108. Kumar, N.; Hussain, I.; Singh, B.; Panigrahi, B.K. Rapid MPPT for Uniformly and Partial Shaded PV System by Using JayaDE Algorithm in Highly fluctuating atmospheric conditions. IEEE Trans. Ind. Inform. 2017, 13, 2406-2416. [CrossRef]

109. Prasanth Ram, J.; Rajasekar, N. A new global maximum power point tracking technique for solar photovoltaic (PV) system under partial shading conditions (PSC). Energy 2017, 118, 512-525. [CrossRef]

110. Rajasekaran, M.; Vaithlingam, A.C. Maximum power point tracking for PV array based on ant colony optimization under uniform and non-uniform irradiance. Int. J. Intellect. Adv. Res. Eng. Comput. 2017, 5.

111. Sundareswaran, K.; Vigneshkumar, V.; Sankar, P.; Simon, S.P.; Nayak, P.S.R.; Palani, S. Development of an Improved P \& O Algorithm Assisted Through a Colony of Foraging Ants for MPPT in PV System. IEEE Trans. Ind. Inform. 2016, 12, 187-200. [CrossRef]

112. Nie, X.; Nie, H. MPPT Control Strategy of PV Based on Improved Shuffled Frog Leaping Algorithm under Complex Environments. J. Control Sci. Eng. 2017, 2017, 1-11. [CrossRef]

113. Sridhar, R.; Jeevananthan, S.; Dash, S.S.; Vishnuram, P. A new maximum power tracking in PV system during partially shaded conditions based on shuffled frog leap algorithm. J. Exp. Theor. Artif. Intell. 2017, 29, 481-493. [CrossRef]

114. Jin, Y.; Hou, W.; Li, G.; Chen, X. A glowworm swarm optimization-based maximum power point tracking for photovoltaic/thermal systems under non-uniform solar irradiation and temperature distribution. Energies 2017, 10, 541. [CrossRef]

115. Mosa, M.; Shadmand, M.B.; Balog, R.S.; Rub, H.A. Efficient maximum power point tracking using model predictive control for photovoltaic systems under dynamic weather condition. IET Renew. Power Gener. 2017, 11, 1401-1409. [CrossRef]

116. Cherukuri, S.K.; Rayapudi, S.R. A Novel Global MPP Tracking of Photovoltaic System based on Whale Optimization Algorithm. Int. J. Renew. Energy Dev. 2016, 5, 225. [CrossRef]

117. Kumar, N.; Hussain, I.; Singh, B. MPPT in Dynamic Condition of Partially Shaded PV System by Using WODE Technique. IEEE Trans. Sustain. Energy 2017, 8, 1204-1214. [CrossRef]

118. Mohanty, S.; Subudhi, B.; Member, S.; Ray, P.K. A New MPPT Design Using Grey Wolf Optimization Technique for Photovoltaic System Under Partial Shading Conditions. IEEE Trans. Sustain. Energy 2015, 7, 181-188. [CrossRef]

119. Kaced, K.; Larbes, C.; Ramzan, N.; Bounabi, M.; Elabadine Dahmane, Z. Bat algorithm based maximum power point tracking for photovoltaic system under partial shading conditions. Sol. Energy 2017, 158, 490-503. [CrossRef]

120. Seyedmahmoudian, M.; Soon, T.K.; Jamei, E.; Thirunavukkarasu, G.S.; Horan, B.; Mekhilef, S.; Stojcevski, A. Maximum power point tracking for photovoltaic systems under partial shading conditions using bat algorithm. Sustainability 2018, 10, 1347. [CrossRef]

121. Prakash, S.; Rajathy, R. Implementation of Symbiotic Organism Search algorithm for Extracting Maximum Power from the PV system under Partially Shaded Condition. Int. J. Control Theory Appl. 2015, 8, 1871-1880.

122. Shareef, H.; Mutlag, A.H.; Mohamed, A. Random Forest-Based Approach for Maximum Power Point Tracking of Photovoltaic Systems Operating under Actual Environmental Conditions. Comput. Intell. Neurosci. 2017, 2017. [CrossRef] [PubMed]

123. Soufyane Benyoucef, A.; Chouder, A.; Kara, K.; Silvestre, S. Artificial bee colony based algorithm for maximum power point tracking (MPPT) for PV systems operating under partial shaded conditions. Appl. Soft. Comput. 2015, 32, 38-48. [CrossRef]

124. Jasmine, A.S.; Gnanasaravanan, A.; Danielsathyaraj, J.; Banumathi, R. A Simulated Annealing MPPT Approach for Partially Shaded PV System. J. ICON Integr. Concepts 2018, 3, 16-24.

125. Feroz, A.; Ling, Q.; Javed, M.Y.; Mansoor, M. Novel MPPT techniques for photovoltaic systems under uniform irradiance and Partial shading. Sol. Energy 2019, 184, 628-648. [CrossRef]

126. Mirjalili, S. Dragonfly algorithm: A new meta-heuristic optimization technique for solving single-objective, discrete, and multi-objective problems. Neural Comput. Appl. 2016, 27, 1053-1073. [CrossRef]

127. Nasikkar, P.S.; Bhos, C.D. Cuckoo Search Based Approach Towards Maximum Power Point Tracking for Solar Photovoltaic System Under Partial Shading. J. Comput. Theor. Nanosci. 2019, 16, 3338-3345. [CrossRef]

128. Abo-Elyousr, F.K.; Abdelshafy, A.M.; Abdelaziz, A.Y. MPPT-Based Particle Swarm and Cuckoo Search Algorithms for PV Systems. In Modern Maximum Power Point Tracking Techniques for Photovoltaic Energy Systems; Springer: Cham, Switzerland, 2020; pp. 379-400. [CrossRef] 
129. Mohamed, M.A.; Diab, A.A.Z.; Rezk, H. Partial shading mitigation of PV systems via different meta-heuristic techniques. Renew. Energy 2019, 130, 1159-1175. [CrossRef]

130. Herrera, J.; Ibeas, A.; Sen MDe Rivera, E.; Pel, J. Generalized Pattern Search Methods for control of stable, unstable and integrating systems with unknown delay under step input. Math. Comput. Simul. 2015, 115, 37-48. [CrossRef]

131. Javed, M.Y.; Murtaza, A.F.; Ling, Q.; Qamar, S.; Gulzar, M.M. A novel MPPT design using generalized pattern search for partial shading. Energy Build. 2016, 133, 59-69. [CrossRef]

132. Daraban, S.; Petreus, D.; Morel, C. A novel global MPPT based on genetic algorithms for photovoltaic systems under the influence of partial shading. In Proceedings of the IECON 2013-39th Annual Conference of the IEEE Industrial Electronics Society, Vienna, Austria, 10-13 November 2013; pp. 1490-1495. [CrossRef]

133. Prasanth Ram, J.; Rajasekar, N. A Novel Flower Pollination Based Global Maximum Power Point Method for Solar Maximum Power Point Tracking. IEEE Trans. Power Electron. 2017, 32, 8486-8499. [CrossRef]

134. Lyden, S.; Member, S.; Member, S. A Simulated Annealing Global Maximum Power Point Tracking Approach for PV Modules under Partial Shading Conditions. IEEE Trans. Power Electron. 2015, 8993, 1-11. [CrossRef]

135. Dash, S.S.; Arun Bhaskar, M.; Panigrahi, B.K.; Das, S. Fireworks Algorithm-Based Maximum Power Point Tracking for Uniform Irradiation as Well as Under Partial Shading Condition. Adv. Intell. Syst. Comput. 2016, 394. [CrossRef]

136. Pilakkat, D.; Kanthalakshmi, S. An improved P\&O algorithm integrated with artificial bee colony for photovoltaic systems under partial shading conditions. Sol. Energy 2019, 178, 37-47. [CrossRef]

137. Zhang, J.; Ding, K.; Mei, R.; Cai, Y. Global maximum power point tracking method based on sorting particle swarm optimizer. Int. J. Green Energy 2018, 15, 821-836. [CrossRef]

(C) 2019 by the authors. Licensee MDPI, Basel, Switzerland. This article is an open access article distributed under the terms and conditions of the Creative Commons Attribution (CC BY) license (http://creativecommons.org/licenses/by/4.0/). 